University of Louisville

ThinkIR: The University of Louisville's Institutional Repository

$12-2016$

\title{
The influence of student, neighborhood, and school factors on college readiness : an examination of factors combined as a result of implementing a race- and socioeconomically-based student assignment plan.
}

Gregory Paul Herberger

University of Louisville

Follow this and additional works at: https://ir.library.louisville.edu/etd

Part of the Educational Assessment, Evaluation, and Research Commons, and the Educational Leadership Commons

\section{Recommended Citation}

Herberger, Gregory Paul, "The influence of student, neighborhood, and school factors on college readiness : an examination of factors combined as a result of implementing a race- and socioeconomically-based student assignment plan." (2016). Electronic Theses and Dissertations. Paper 2611.

https://doi.org/10.18297/etd/2611

This Doctoral Dissertation is brought to you for free and open access by ThinkIR: The University of Louisville's Institutional Repository. It has been accepted for inclusion in Electronic Theses and Dissertations by an authorized administrator of ThinkIR: The University of Louisville's Institutional Repository. This title appears here courtesy of the author, who has retained all other copyrights. For more information, please contact thinkir@louisville.edu. 
THE INFLUENCE OF STUDENT, NEIGHBORHOOD, AND SCHOOL FACTORS ON COLLEGE READINESS: AN EXAMINATION OF FACTORS COMBINED AS A RESULT OF IMPLEMENTING A RACE- AND SOCIOECONOMIC-BASED STUDENT ASSIGNMENT PLAN

By

Gregory Paul Herberger

B.A., Bellarmine University, 2003

M.A.T., University of Louisville, 2006

Ed.S., University of Louisville, 2011

\begin{abstract}
A Dissertation
Submitted to the Faculty of the

College of Education and Human Development of the University of Louisville in Partial Fulfillment of the Requirements

for the Degree of

Doctor of Philosophy

in Educational Leadership and Organizational Development
\end{abstract}

Educational Leadership, Evaluation, and Organizational Development University of Louisville

Louisville, Kentucky

December 2016 

THE INFLUENCE OF STUDENT, NEIGHBORHOOD, AND SCHOOL FACTORS ON COLLEGE READINESS: AN EXAMINATION OF FACTORS COMBINED AS A RESULT OF IMPLEMENTING A RACE- AND SOCIOECONOMIC-BASED STUDENT ASSIGNMENT PLAN

\section{By}

Gregory Paul Herberger

B.A., Bellarmine University, 2003

M.A.T., University of Louisville, 2006

Ed.S., University of Louisville, 2011

\section{A Dissertation Approved on}

November 16, 2016

by the following Dissertation Committee:

\begin{tabular}{c}
\hline $\begin{array}{c}\text { Dissertation Director } \\
\text { Jason C. Immekus }\end{array}$ \\
\hline W. Kyle Ingle \\
\hline Bradley Carpenter \\
Marco Munoz
\end{tabular}




\section{DEDICATION}

\section{To my wife}

\section{Missy}

for your love and friendship that amazes me, for your endless work as a mother that motivates me, and for your commitment as a teacher that inspires me.

\section{To my children}

\section{Carter, Annaleigh, and Emma}

for always making me laugh, for allowing me the time to complete this journey, and for filling our family with love and joy.

\section{To my father and mother}

$$
\text { Denny and Michelle }
$$

for always loving and supporting me, for your endless guidance and motivation during the struggles of my education, and for instilling in me the ethic of working hard and helping others.

To Colton Raymond Herberger. 


\section{ACKNOWLEDGMENTS}

My doctoral journey and successes in education have been possible because of the individuals who have influenced and challenged me to improve the education of for youth. My sincerest appreciation to Dr. Jason C. Immekus. Your guidance, your high standards for my work and research, and your patience in answering my countless questions were critical to my success. Thank you sharing your expertise and for supporting me and my educational aspirations. Thank you to Dr. Bradley Carpenter for your support over these past 4 years. I am grateful for the amount of time you spent guiding me as I meandered through vast amounts of research interests. Our coffee shop meetings, lengthy text messages, and e-mails kept me sane and motivated. Mostly, your belief in my ability to overcome the intruder complex kept me going when I struggled. To Dr. Kyle Ingle, our long talks about our practitioner experiences always provided me with the real-world perspective I often required. I truly appreciate the time you gave me, your approachability, and your support. Lastly, thank you to Dr. Marco Muñoz. Your backing of my research interests allowed me to make this journey, and your passion for improving public education inspires me. Thank you for your unwavering guidance and support.

This dissertation would not have been possible without the participation of Jefferson County Public Schools. Thank you for your openness and your never-ending pursuit for improving the education of our students. 
A special acknowledgement belongs to Ms. Lana Kaelin. Your wisdom, leadership, and personal trust have forever shaped me as an educator. The countless hours we have spent discussing school leadership and student success have been invaluable. My continued growth as a teacher and educational leader is because of you. I will always be professionally and personally indebted to you.

Finally, thank you to my incredible family. To my parents, Denny and Michelle, these words do not begin to describe the love and admiration I have for you. You taught me the value of hard work and the importance of family, and you never gave up on my education. I celebrate while knowing that you are the reason for my accomplishments. To my brother and sister, Dan and Beth, my successes are better when shared with you. Thank you and your families for always supporting me. To Rich and Judy Schulten, thank you for accepting me as part of your family. Not only do I have you to thank for my incredible wife, but I am also grateful for your endless love, support, and guidance. Most importantly, thank you to my wife, Missy, and to our children, Carter, Annaleigh, and Emma. The support and sacrifice you have given has been my motivation through this journey. Missy, your love and dedication for me and our children is the mortar that bonds our family. I love you! 


\begin{abstract}
THE INFLUENCE OF STUDENT, NEIGHBORHOOD, AND SCHOOL FACTORS ON COLLEGE READINESS: AN EXAMINATION OF FACTORS COMBINED AS A RESULT OF IMPLEMENTING A RACE- AND SOCIOECONOMIC-BASED STUDENT ASSIGNMENT PLAN
\end{abstract}

\author{
Gregory Paul Herberger
}

November 16, 2016

In 2006, Meredith v. Jefferson County Board of Education determined race-based student assignment plans violated the 14th Amendment. Through the assistance of Orfield and Frankenberg (2011), Jefferson County Public Schools (JCPS) reconfigured the district's race-based student assignment and implemented a race- and socioeconomicbased student assignment plan. The purpose of this study was to examine students' backgrounds and school composition factors within a race- and socioeconomic-based assignment plan to determine the extent the factors are related to college readiness. Based on data obtained from 3,018 Grade 11 students, hierarchical linear multiple regression was used to examine the utility of student background, school factors, and neighborhood factors to predict ACT scores. The predictors were found to explain $72.4 \%, 64.4 \%$, and $57.4 \%$ of variance in ACT English, Mathematics, and Reading scores, respectively. Implications to policy, practice, and research are discussed. 


\section{TABLE OF CONTENTS}

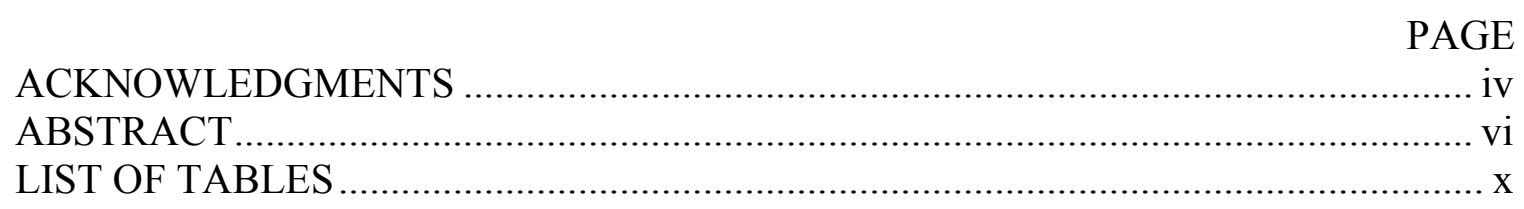

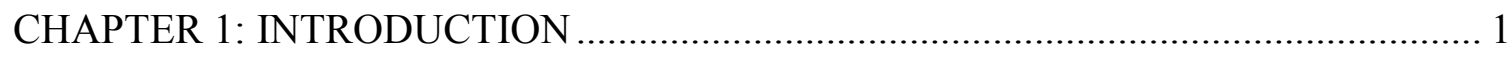

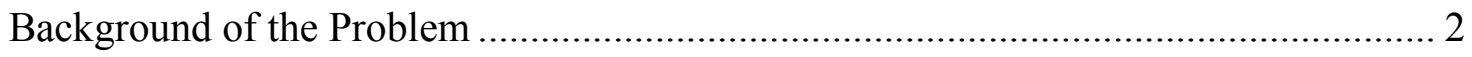

A Background on the Student Assignment Planning ........................................... 8

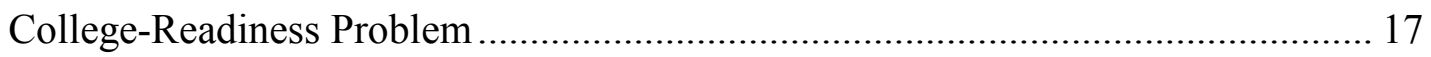

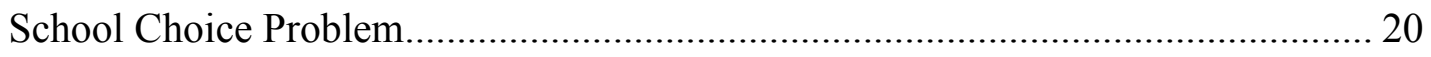

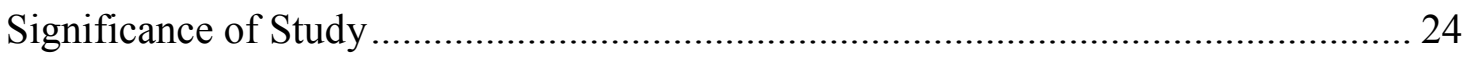

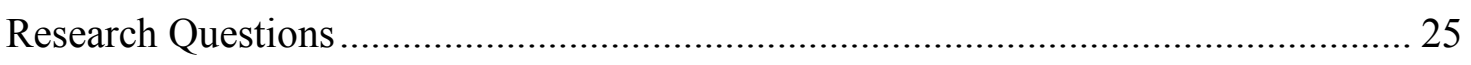

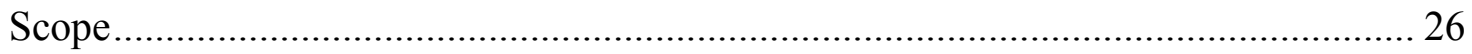

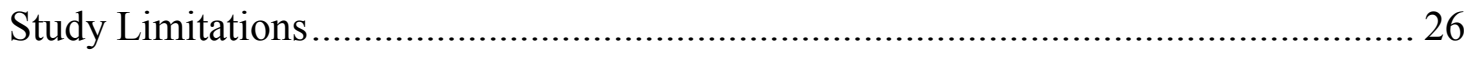

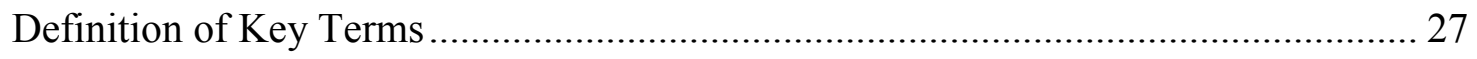

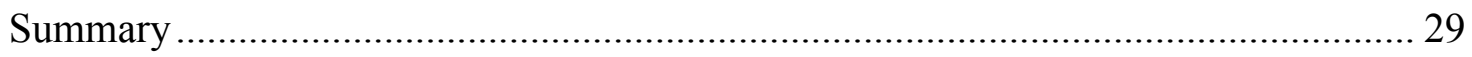

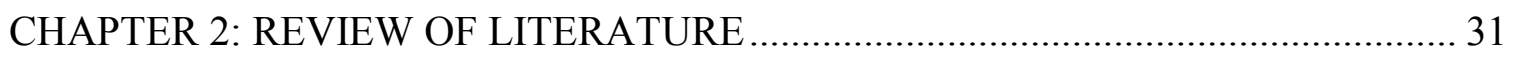

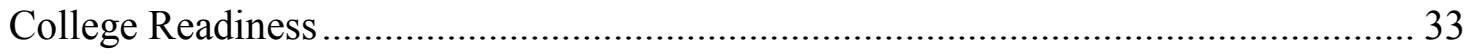

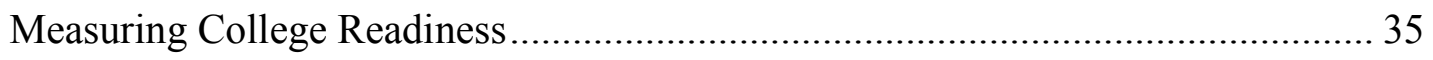

Summary of College-Readiness Literature .................................................... 43

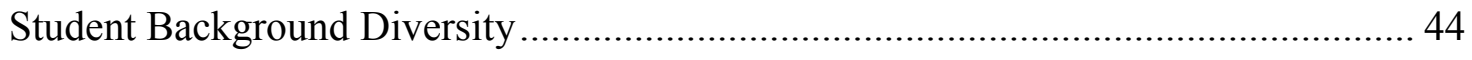

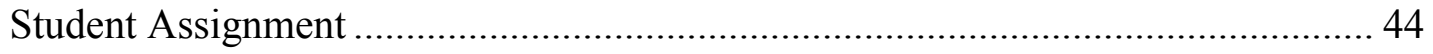




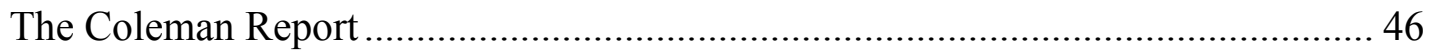

Family Education, Race, and Socioeconomic Status................................................ 48

Neighborhood Education, Race, and Socioeconomic Status ……………............... 52

Summary of Student-Background Literature ............................................................ 57

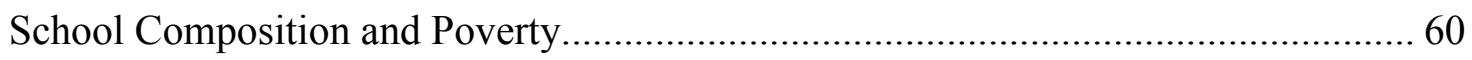

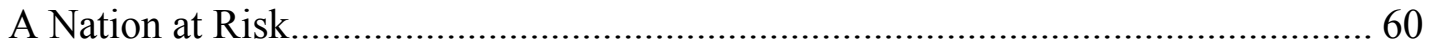

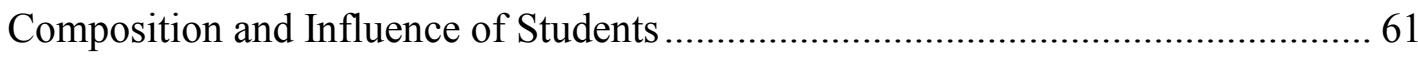

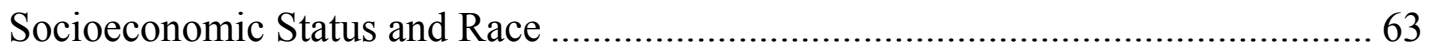

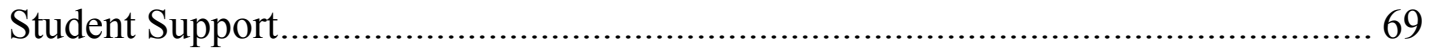

Summary of School Composition and Poverty Literature ……................................ 72

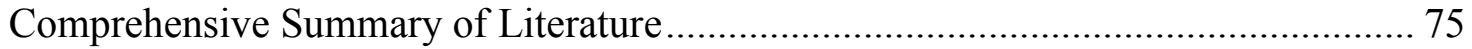

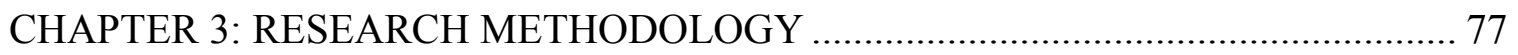

Research Question and Variables .......................................................................... 77

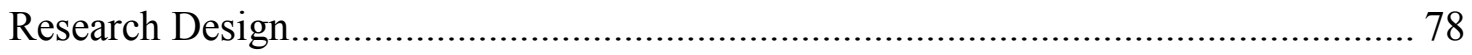

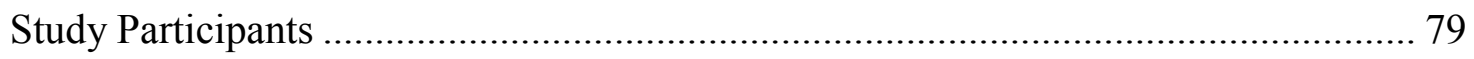

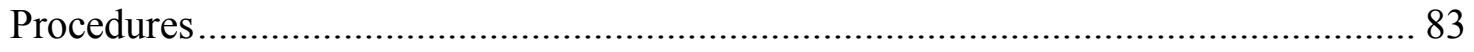

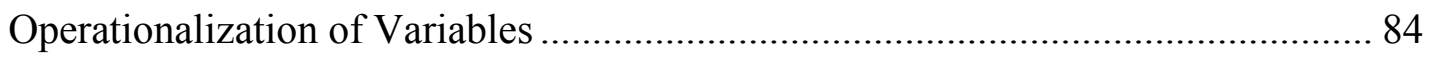

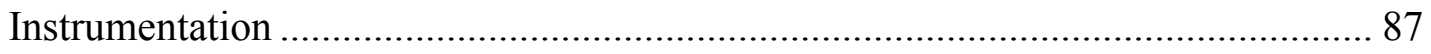

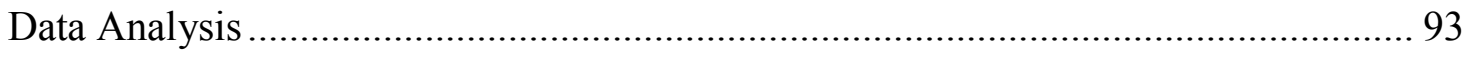

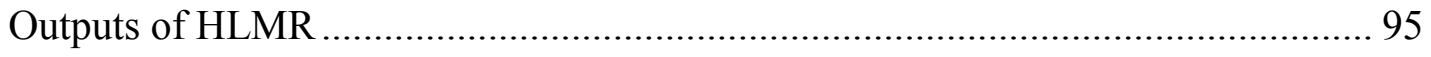

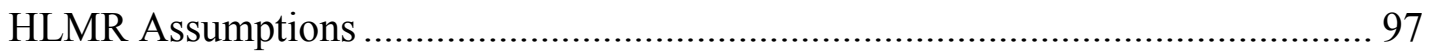

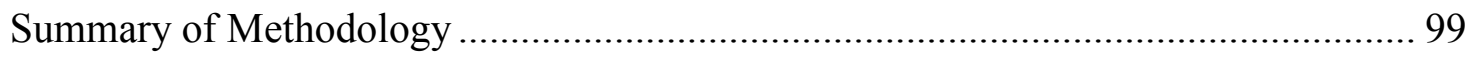

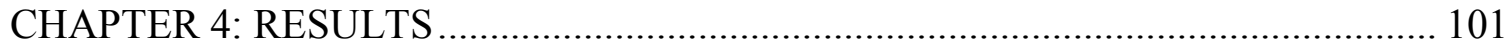




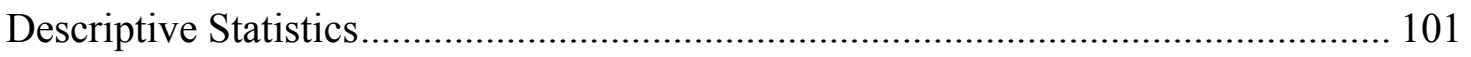

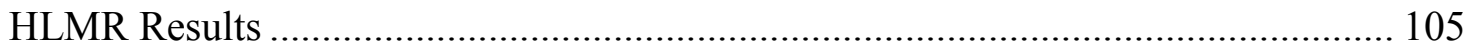

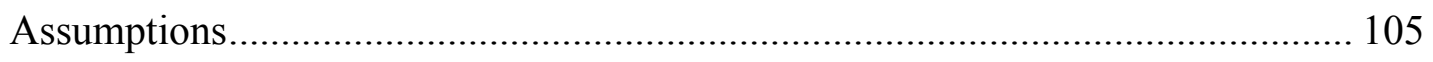

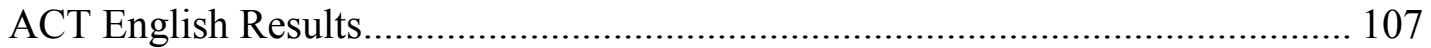

ACT Mathematics Results ......................................................................... 110

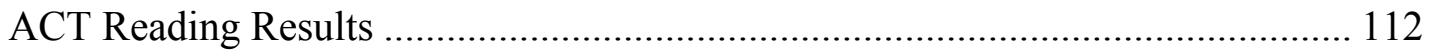

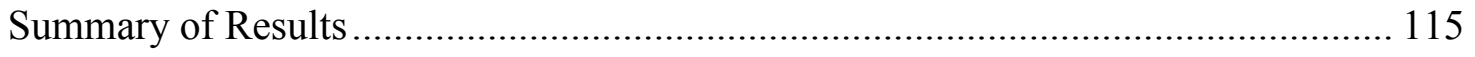

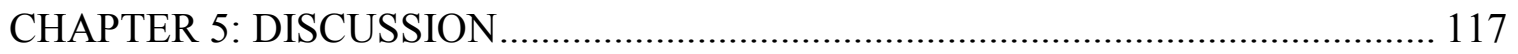

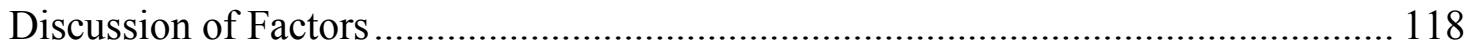

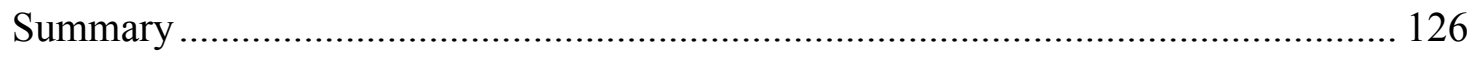

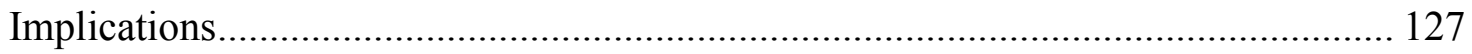

Limitations and Future Research ............................................................... 131

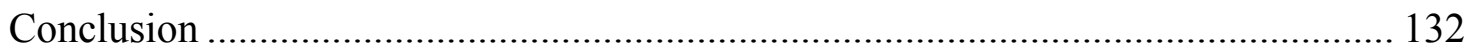

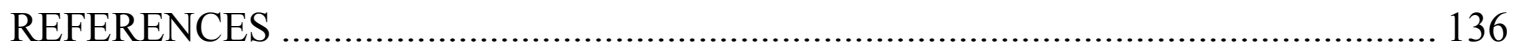

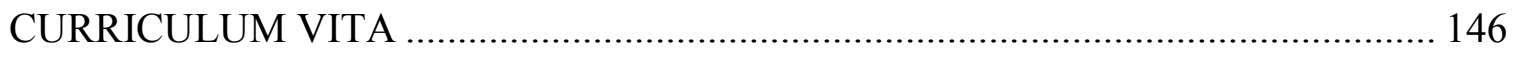




\section{LIST OF TABLES}

$\begin{array}{ll}\text { TABLE } & \text { PAGE }\end{array}$

1. Student Race, Poverty, and Parent Education........................................................ 4

2. School Composition and National Assessment of Educational Progress (NAEP)

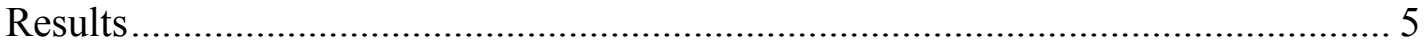

3. Kentucky NAEP 2015 Mathematics and Reading Results ................................... 6

4. Jefferson County Public Schools NAEP Mathematics and Reading Results ............ 7

5. Jefferson County Public Schools Student Assignment Diversity Categories........... 15

6. Parent Education Attainment Weight .................................................................... 15

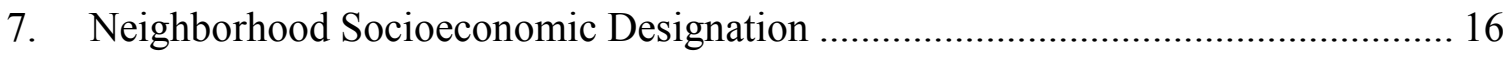

8. Kentucky College Readiness 2012-2015: Percentage of Students Scoring at the College-Ready Level .................................................................................. 19

9. Jefferson County Public Schools Composite College-Readiness Rates 2012-2015: Percentage of 11th-Grade Students Scoring at the College-Ready Level on the

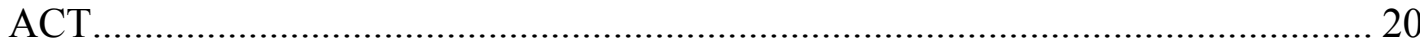

10. 2015 Jefferson County Public Schools Comprehensive School Demographics and ACT Performance

11. National ACT Results 2001-2010 by Student Group......................................... 42

12. National ACT Results $2001-2010$ by Subject Area and Gender............................ 42

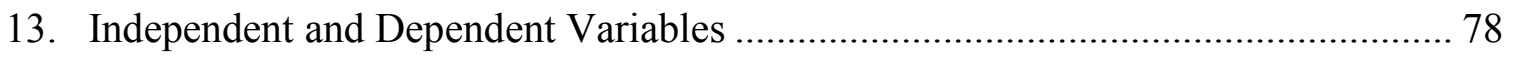

14. Percentage of Student Demographics Represented by Neighborhood Diversity Index 81

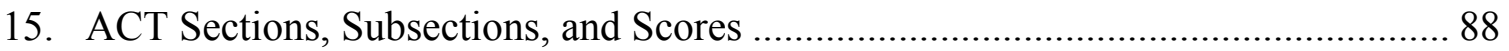

16. ACT Score Reliability and Standard Error of Measurement (SEM) 2011-12 _........ 90

17. Descriptive Statistics of ACT PLAN Scores Across Neighborhoods, 2013-14 „.... 102 
18. Descriptive Statistics of ACT Scores Across Neighborhoods, 2014-15............... 103

19. Hierarchical Linear Multiple Regression Predicting ACT English Scores ........... 108

20. Hierarchical Linear Multiple Regression Predicting ACT Mathematics Scores .... 111

21. Hierarchical Linear Multiple Regression Predicting ACT Reading Scores .......... 114 


\section{CHAPTER 1}

\section{INTRODUCTION}

The effects of students' backgrounds and school composition are key factors in student assignment plans utilized to both develop schools that are racially and socioeconomically diverse as well as promote student achievement (Borman et al., 2004; Diem \& Frankenberg, 2013; Frankenberg, 2013; Frankenberg, Lee, \& Orfield, 2003; Kahlenberg, 2006, 2012; Orfield \& Frankenberg, 2011; Orfield, Frankenberg, \& Garces, 2008; Potter, Quick, \& Davies, 2016; Reardon, Yun, \& Kurlaender, 2006; Tefera, Frankenberg, Siegel-Hawley, \& Chirichigno, 2011). School districts use student assignment to direct students to their appropriate grade-level schools that serve the area in which the students' parents or guardians reside (Frankenberg, 2013; McDermott, Frankenberg, \& Diem, 2014; Tefera et al., 2011). Although assignment plans can be constructed without accounting for student achievement, the Equality of Educational Opportunity (Coleman et al., 1966) report revealed that student backgrounds largely explain student achievement and are responsible for an achievement gap between White and African American students. Coleman et al. (1966) also attributed student achievement to aspects of school composition, but exposed an unfortunate reality that student backgrounds destabilize the effects of schools.

The more recent research of Konstantopoulos and Borman (2011) reinforced the findings of Coleman et al. regarding the influence of students' backgrounds but also exposed significant between-school effects on student achievement when factoring in 
students' backgrounds and school composition. Female, ethnic-minority, and lowincome students were found to be significantly influenced by school racial and socioeconomic composition (Konstantopoulos \& Borman, 2011). Thus, the findings suggest that school districts seeking integrated student assignment while also promoting student achievement should account for students' backgrounds and school composition (Coleman et al., 1966; Kahlenberg, 2006, 2012; Konstantopoulos \& Borman, 2011; Orfield \& Frankenberg, 2011; Orfield et al., 2008; Potter et al., 2016; Reardon et al., 2006). The purpose of this study was to examine students' backgrounds and school composition factors within a race- and socioeconomic-based assignment plan to determine the extent the factors are related to college readiness.

\section{Background of the Problem}

The seminal research of Coleman et al. (1966) and subsequent research conducted by Konstantopoulos and Borman (2011) identified noticeable differences in student learning outcomes between majority-minority and low-minority schools. Specifically, compared to low-minority schools, majority-minority schools had more students from high-poverty and low-education families, larger class sizes, fewer instructional resources, possessed inadequate access to science and language arts laboratories, and limited informal learning opportunities (Coleman et al., 1966; Konstantopoulos \& Borman, 2011). Conversely, White students were found to attend schools with higher academic expectations, were staffed with more highly qualified teachers, and had stronger academic support from parents at home (Coleman et al., 1966; Konstantopoulos \& Borman, 2011). The findings indicated that ethnic-minority students benefited from being moved into schools with students from families with strong academic support and 
required highly qualified teacher support (Coleman et al., 1966; Konstantopoulos \& Borman, 2011). Thus, the conclusions indicated that diversity in school population influences student achievement (Coleman et al., 1966; Konstantopoulos \& Borman, 2011).

Rumberger and Palardy (2005) also examined the impact of student background and school composition on student achievement by focusing on mathematics, science, reading, and social science achievement-based data. The examination of data obtained on 14,000 students across 913 secondary schools, revealed that $40-80 \%$ of the variance in academic achievement was accounted for by student background characteristicsspecifically, student race, socioeconomic status, and family structure-with the largest differences found in mathematics scores. Likewise, $20-60 \%$ of the variability in academic achievement was a result of between-school differences (Rumberger \& Palardy, 2005). Thus, the between-school differences indicated that student achievement was influenced by schools even when considering student backgrounds (Rumberger \& Palardy, 2005). Students attending high-socioeconomic schools outperformed their lowsocioeconomic peers who attended low-socioeconomic schools, and the socioeconomic composition of the school was a stronger influence than the racial composition (Rumberger \& Palardy, 2005). Finally, high-socioeconomic schools were found to have more instructional resources and personnel supports for improving instruction, imposed high expectations for student engagement and performance, and contained more effective teachers (Rumberger \& Palardy, 2005).

Similarly, the National Center for Education Statistics (NCES, 2015c) reported that African American students were more likely to attend schools with higher ethnic- 
minority enrollment than White students. Located mostly in the southern region and urban areas of the United States, African American students attend schools comprised of populations that are almost 50\% African American, whereas White students attend schools with populations approximately 9\% African American (NCES, 2015c). As displayed in Table 1, higher levels of student poverty measured by eligibility for the National School Lunch Program (NSLP) and lower levels of parent education were more prevalent in schools with higher African American student populations (NCES, 2015c).

Table 1

Student Race, Poverty, and Parent Education

\begin{tabular}{|c|c|c|c|c|}
\hline \multirow{2}{*}{$\begin{array}{l}\% \text { African } \\
\text { American student } \\
\text { population }\end{array}$} & \multicolumn{2}{|c|}{$\%$ NSLP eligible } & \multicolumn{2}{|c|}{$\begin{array}{l}\% \text { with parent education beyond } \\
\text { high school }\end{array}$} \\
\hline & White & African American & White & African American \\
\hline $0-20$ & 28 & 60 & 79 & 76 \\
\hline $20-40$ & $35^{*}$ & $72 *$ & $75^{*}$ & $72 *$ \\
\hline $40-60$ & $42 *$ & $75 *$ & $72 *$ & $71 *$ \\
\hline $60-100$ & $53 *$ & $83 *$ & $66^{*}$ & $71 *$ \\
\hline
\end{tabular}

Note. NSLP = National School Lunch Program. Source: School Composition and the Black-White Achievement Gap (NCES 2015-018), by the National Center for Education Statistics, 2015c, Washington, DC: Author.

*Differences from 0-20\% African American population reported as significant $(p<.05)$.

Taking into account the percentage of African American student enrollment and student socioeconomic status, the NCES (2015a) utilized a regression analysis to examine their relationship to African American-White student achievement on the National Assessment and Educational Progress (NAEP) Grade 8 mathematics exam. Table 2 displays the percentage of African American student enrollment, the results of NAEP mathematics testing, and the NAEP results when controlling for student socioeconomic status (NCES, 2015a). The data revealed that as the percentage of African American 
student population increased in a school, African American and White students' NAEP mathematics performance decreased. Additionally, White students regularly outperformed African American students by 26 points, which created an African American-White achievement gap that remained consistent across population categories (NCES, 2015a). However, the achievement gap was reduced to an average of 20 points when controlling for student socioeconomic status (NCES, 2015a). The results on the NAEP mathematics exam were similar when accounting for gender, except for African American males, who performed significantly lower in the $60-100 \%$ population category (NCES, 2015a). The NAEP mathematics data indicate that student socioeconomic status and school composition are related to student achievement (NCES, 2015a).

Table 2

School Composition and National Assessment of Educational Progress (NAEP) Results

\begin{tabular}{lccccc}
\hline \multirow{2}{*}{$\begin{array}{l}\text { \% African } \\
\text { American student } \\
\text { population }\end{array}$} & \multicolumn{2}{c}{ NAEP math score } & & \multicolumn{2}{c}{$\begin{array}{c}\text { NAEP math score, controlled by } \\
\text { socioeconomic status }\end{array}$} \\
\cline { 2 - 3 } \cline { 5 - 6 } \cline { 5 - 6 } & White & African American & & White & African American \\
\hline $0-20$ & 293 & 268 & & 292 & 274 \\
$40-40$ & $290^{*}$ & $264^{*}$ & & 291 & 272 \\
$60-100$ & $290^{*}$ & $264^{*}$ & & 292 & 272 \\
\hline
\end{tabular}

Note. Student socioeconomic status included parent level of education and National School Lunch Program eligibility. Source: The Nation's Report Card: 2015 Mathematics State Snapshot Report: Kentucky, Grade 8, Public Schools, by the National Center for Education Statistics, 2015a, retrieved from http://nces.ed.gov/nationsreportcard/subject /publications/stt2015/pdf/2016009KY8.pdf

*Differences from 0-20\% African American population reported as significant $(p<.05)$.

African American-White and socioeconomic status achievement gap scores on NAEP testing for students in the Commonwealth of Kentucky are similar to those produced nationally. Although African American-White school composition data were 
not available, Table 3 displays the average NAEP mathematics and reading scores for Kentucky students in 2015 (NCES, 2015a, 2015b). Consistent with the national results, Kentucky Grade 8 students produced an African American-White achievement gap of 24 points in mathematics and reading. Similarly, the gap between NSLP eligible and nonNSLP eligible student score was 23 and 20 points for mathematics and reading (NCES, 2015a, 2015b), respectively.

Table 3

Kentucky NAEP 2015 Mathematics and Reading Results

\begin{tabular}{|c|c|c|c|c|c|c|}
\hline \multirow[b]{2}{*}{$\begin{array}{l}\text { Student } \\
\text { group }\end{array}$} & \multicolumn{3}{|c|}{ Mathematics } & \multicolumn{3}{|c|}{ Reading } \\
\hline & Score & $\begin{array}{c}\% \text { at or } \\
\text { above Basic }\end{array}$ & $\begin{array}{c}\% \text { at or above } \\
\text { Proficient }\end{array}$ & Score & $\begin{array}{c}\% \text { at or } \\
\text { above Basic }\end{array}$ & $\begin{array}{c}\% \text { at or above } \\
\text { Proficient }\end{array}$ \\
\hline $\begin{array}{l}\text { African } \\
\text { American }\end{array}$ & 257 & 43 & 12 & 247 & 56 & 15 \\
\hline White & 281 & 71 & 30 & 271 & 81 & 39 \\
\hline $\begin{array}{l}\text { NSLP } \\
\text { eligible }\end{array}$ & 268 & 57 & 17 & 259 & 70 & 26 \\
\hline $\begin{array}{l}\text { Not NSLP } \\
\text { eligible }\end{array}$ & 291 & 82 & 41 & 279 & 88 & 49 \\
\hline
\end{tabular}

Note. NSLP = National School Lunch Program. Sources: The Nation's Report Card: 2015 Mathematics State Snapshot Report: Kentucky, Grade 8, Public Schools, by the National Center for Education Statistics, 2015a; The Nation's Report Card: 2015 Reading State Snapshot Report: Kentucky, Grade 8, Public Schools, by the National Center for Education Statistics, 2015b, retrieved from http://nces.ed.gov /nationsreportcard.

Comparable to the national results, the NAEP mathematics and reading results indicated that student socioeconomic status and race had an influence on student achievement (NCES, 2015a, 2015b). These findings also suggest that the examination of school populations resulting from a race- and socioeconomic-based student assignment plan may reveal significant influences on college readiness. 
The largest school district in Kentucky, Jefferson County Public Schools (JCPS), participated in NAEP testing for Grades 4 and 8 and received scores in mathematics and reading for 2013 and 2015. Although state results are typically compared to other states, JCPS receives results independent of the state because the district participates as a Trial Urban District Assessment, which compares the JCPS results to 21 other urban school districts. Participation as a Trial Urban District Assessment school district requires the city population to be above 250,000 and the majority of students to be either African American or Latinx, eligible for NSLP, or both (JCPS, 2015b). Table 4 displays the results of NAEP Grade 8 mathematics and reading tests administered in 2013 and 2015 (JCPS, 2015b). The data displayed reveal an achievement gap consistent with Kentucky's results, as the African American-White and White-NSLP achievement gaps are 20 points or more for each test category and year.

Table 4

Jefferson County Public Schools NAEP Mathematics and Reading Results

\begin{tabular}{lcccccccc}
\hline & \multicolumn{3}{c}{2013} & & & 2015 \\
\cline { 2 - 4 } \cline { 7 - 8 } \multicolumn{1}{c}{ Test } & $\begin{array}{c}\text { African } \\
\text { American }\end{array}$ & White & $\begin{array}{c}\text { NSLP } \\
\text { eligible }\end{array}$ & & $\begin{array}{c}\text { African } \\
\text { American }\end{array}$ & White & $\begin{array}{c}\text { NSLP } \\
\text { eligible }\end{array}$ \\
\hline Mathematics & 257 & 285 & 261 & & 252 & 285 & 258 \\
Reading & 243 & 271 & 249 & & 247 & 271 & 251 \\
\hline
\end{tabular}

Note. NAEP $=$ National Assessment of Educational Progress; NSLP $=$ National School Lunch Program. Source: The nation's report card: reading and math 2015 Trial Urban District Assessment (TUDA) Grades 4 and 8, Jefferson County Public Schools, 2015b, retrieved from http://www.jcpsky.net.

The results of NAEP testing at the national, state, and local district levels display an obvious gap in Grade 8 achievement in mathematics and reading. White students consistently have outperformed African American and low-socioeconomic students. Additionally, the national results reveal higher performance in schools with lower ethnic- 
minority populations. The NAEP results coupled with the resegregation of schools during the 1990s have created the need to further understand the influence of student backgrounds and school composition on student achievement (Charles, 2003; Diem \& Frankenberg, 2013; Frankenberg, 2013; Frankenberg et al., 2003; Orfield, 2001; Orfield, Kucsera, Siegel-Hawley, 2012; Orfield, Siegel-Hawley, \& Kucsera, 2014; Tefera et al., 2011). This study reached beyond the Grade 8 achievement results and examined student demographics, school compositions, and their influence on college readiness of 11thgrade students in JCPS. Before examining the effects of students' backgrounds and school composition on college readiness in JCPS, a background of the influences on student assignment plans is provided.

\section{A Background on the Student Assignment Planning}

The development of student assignment plans and the composition of schools are the result of political movements, federal and local legislation, and court opinions (Borman et al., 2004). Beginning July 9, 1868, the Constitution of the United States of America was revised to include the newly ratified 14th Amendment guaranteeing equal protection — or a guarantee of common privileges, rights, and protection—of law for all citizens, including recently freed slaves. Despite the fact that the new Amendment expanded the protection of civil rights for American citizens, several state governments enacted legislation to segregate White and African American citizens. The legal foundation for segregation was the landmark Plessy v. Ferguson (1896) case, which granted segregation of African American citizens so long as facilities and resources were equal to those accessible by White citizens. Even though the Plessy decision focused on segregation on railcars, public school districts used the legal precedent in developing 
student assignment plans that resulted in heavily segregated schools. In 1954, Brown $v$. Board of Education examined the segregation of children in public schools in relation to equal protection under the 14th Amendment. The 9-0 Supreme Court decision overturned Plessy v. Ferguson and determined that segregation created an environment of inferiority and unequal protection in accordance with the 14th Amendment.

After the Brown v. Board of Education (1954) decision, school districts in the United States were ordered to implement student assignment plans concentrated on the desegregation of student populations. This Court order was often satisfied through the use of race-based assignment plans intended on establishing thresholds for the percentage of White and ethnic-minority students for schools within a school district. JCPS was among the school districts ordered to implement a desegregation student assignment plan in 1975. After 25 years of desegregation efforts, JCPS was released from the Court order per the ruling of Hampton v. Jefferson County Board of Education (2000). Simply, due to the fidelity in which schools were desegregated from 1975 to 2000, the Court order eliminated the desegregation requirement.

Upon release from the Court order for meeting the desegregation requirements, JCPS enacted an assignment plan allowing students to apply for a choice of schools. Notably, this choice included a filter that was used to ensure schools remained integrated and diverse. Student choice enrollment was decided based upon student residence, school enrollment capacity, and race. The use of race as a standard for enrollment resulted in a legal challenge in Meredith v. Jefferson County Board of Education (2006). The petitioner argued that the JCPS student assignment plan created a proportion system for maintaining racial diversity that violated the students' right to equal protection as 
guaranteed by the 14th Amendment. The Meredith case was heard by the Supreme Court in conjunction with Parents Involved in Community Schools v. Seattle School District Number 1 (2007). As in the Meredith case, the Parents Involved in Community Schools case was rooted in a provision of Seattle's student assignment plan, wherein race was used as a tiebreak for determining assignment.

Students who applied for open enrollment in the Seattle School District were subjected to enrollment criteria based on the amount of applications and student race. Schools were not to exceed the racial thresholds matching the district's demographics of $60 \%$ ethnic minority and $40 \%$ White. A suit alleging violation of the Equal Protection Clause of the 14th Amendment was filed after previous courts ruled that the district had a compelling interest in upholding racial diversity. In a 5 to 4 decision, the Supreme Court ruled the racial tiebreaker to be unconstitutional, as it violated the Equal Protection Clause in the 14th Amendment. The use of White and ethnic-minority designations for race did not meet the "narrow tailoring" standard in creating racial diversity as mandated in Grutter v. Bollinger et al. (2003). The holdings of the Meredith and Parents Involved in Community Schools cases resulted in a new student assignment plan for JCPS. In an effort to retain desegregated schools, JCPS implemented a student assignment plan that accounted for race and socioeconomic status of students.

School districts seeking student assignment that promotes diversity have the option of race- or socioeconomic-based student assignment (Diem, 2012; Frankenberg, 2013; Frankenberg et al., 2003; Kahlenberg, 2006, 2012; Orfield, 2001; Orfield \& Frankenberg, 2011; Orfield et al., 2008; Potter et al., 2016; Reardon et al., 2006; Tefera et al., 2011). Proponents of race-based assignment plans consider integrated schools 
beneficial to students and communities by promoting racial understanding, reducing prejudice, and properly preparing students for a diverse workforce (Orfield, 2001; Orfield et al., 2008; Orfield et al., 2012; Orfield et al., 2014; Tefera et al., 2011). Those who support race-based plans seek an education that reaches beyond curriculum by creating a setting where students learn about cultural values along with curriculum (Diem, 2012; Diem \& Frankenberg, 2013; Frankenberg, 2013; Frankenberg et al., 2003; Orfield, 2001; Orfield \& Frankenberg, 2011; Orfield et al., 2008; Orfield et al., 2014; Reardon et al., 2006; Tefera et al., 2011). Specifically, race-based plans establish thresholds for school populations to create diverse student bodies and prevent schools from becoming segregated (Diem, 2012; Diem \& Frankenberg, 2013; Frankenberg, 2013; Frankenberg et al., 2003; McDermott et al., 2014; Orfield, 2001; Orfield \& Frankenberg, 2011; Orfield et al., 2008; Orfield et al., 2012; Orfield et al., 2014; Reardon et al., 2006; Tefera et al., 2011).

School districts in Boston, Massachusetts; Raleigh, North Carolina; and Louisville, Kentucky have used race-based plans to prevent the establishment of ethnicminority or all-White schools resulting from segregated neighborhoods feeding into neighborhood schools (McDermott et al., 2014). Race-based student assignment plans are necessary in establishing and maintaining integrated schools, and plans developed without the consideration of race isolate students and have negative educational and societal implications (Diem, 2012; Diem \& Frankenberg, 2013; Frankenberg, 2013; Frankenberg et al., 2003; McDermott et al., 2014; Orfield, 2001; Orfield \& Frankenberg, 2011; Orfield et al., 2008; Orfield et al., 2012; Orfield et al., 2014; Reardon et al., 2006; Tefera et al., 2011). Opponents of using a race-only filter contend that student poverty is 
a more accurate predictor of student achievement (Kahlenberg, 2006, 2012; Potter et al., 2016; Reardon et al., 2006; Rumberger \& Palardy, 2005).

Similar to race-based plans, socioeconomic-based student assignment establishes diverse school populations based on student socioeconomic status instead of race (Diem, 2012; Kahlenberg, 2006, 2012; Potter et al., 2016; Reardon et al., 2006). Previous and current socioeconomic-based student assignment plans have employed filters to identify low-income students such as parent income, family qualification for government food stamp programs, and student participation in the NSLP (Diem, 2012; Kahlenberg, 2006, 2012; Potter et al., 2016; Reardon et al., 2006). Socioeconomic-based plans are constructed on the ideology that higher economic students excel academically, are college minded, are supported by parents who are actively involved in academics and schools, and have access to more highly qualified teachers (Kahlenberg, 2006, 2012; Potter et al., 2016; Reardon et al., 2006; Rumberger \& Palardy, 2005). Access to higher performing peers helps establish an academic-oriented environment, promotes academic growth among peers, and reduces distractions in classrooms often associated with lowsocioeconomic students (Kahlenberg, 2006, 2012; Potter et al., 2016; Reardon et al., 2006; Rumberger \& Palardy, 2005). Proponents of socioeconomic-based student assignment plans consider socioeconomic integration an effective tool for establishing racial integration, while also promoting student achievement by placing high-poverty students in low-poverty schools where peers and parents promote academic success (Kahlenberg, 2006, 2012; Potter et al., 2016; Reardon et al., 2006; Rumberger \& Palardy, 2005). Thus, socioeconomic-based plans promote racial diversity but are focused more 
on academic achievement associated with higher economics than racial integration (Kahlenberg, 2006, 2012; Potter et al., 2016).

According to Kahlenberg (2006), about 40 school districts use or have used socioeconomic student assignment plans including La Crosse, Wisconsin; Raleigh, North Carolina; and San Francisco, California. Beginning in the 1970s, La Crosse implemented one of the earliest forms of socioeconomic-based student assignment plans, mandating school populations to stay between 15\% and 45\% NSLP eligible (Kahlenberg, 2006). The basis for assigning students by socioeconomic status was to integrate the district's two high schools, which were previously segregated into affluent and less advantaged populations (Kahlenberg, 2006). The plan was overturned 20 years later with the election of new board members (Kahlenberg, 2006).

Just after La Crosse transitioned to race-based student assignment plan in the 1990s, Raleigh transitioned to a socioeconomic-based assignment plan in 2000 (Kahlenberg, 2006). The previous race-based plan requiring schools to contain $15-40 \%$ ethnic-minority populations was changed to a socioeconomic plan that directed populations to be comprised of no more than $40 \%$ of students eligible for NSLP and no more than $25 \%$ below grade level (Kahlenberg, 2006). The changes to the student assignment in Raleigh also occurred after new board members were elected (McDermott et al., 2014). In 2001, San Francisco dropped a race-based assignment plan and implemented a socioeconomic plan that accounted for nonracial factors such as NSLP eligibility, participation in public housing, and mother's education (Kahlenberg, 2006). Opponents of socioeconomic-based plans contend that the filters used to measure poverty are not necessarily accurate of student poverty and fail to align consistently with student 
race (Diem, 2012; Diem \& Frankenberg, 2013; Frankenberg, 2013; Frankenberg et al., 2003; McDermott et al., 2014; Orfield, 2001; Orfield \& Frankenberg, 2011; Orfield et al., 2008; Orfield et al., 2014; Reardon et al., 2006).

Although a debate exists surrounding the effectiveness of race-based versus socioeconomic-based student assignment plans, this study focused on the influence of students' backgrounds and school composition in a district implementing a student assignment plan constructed on student race and socioeconomic status. In compliance with the Meredith decision, JCPS designed and implemented a student assignment plan that took into account the diversity of students and the 540 county neighborhoods. The plan, however, was race based and failed to comply with the Court order of using factors beyond race such as student socioeconomic status. In cooperation with JCPS, Orfield and Frankenberg (2011) recommended a student assignment plan with a neighborhood diversity index, designed to achieve diversity by reaching beyond race by including the neighborhood socioeconomic element.

The diversity index - comprised of parent income, parent education, and the percentage of White students for each neighborhood - acts as a filter by assigning one of three possible socioeconomic diversity designations to each neighborhood in Jefferson County (Orfield \& Frankenberg, 2011). Table 5 displays the categories of the diversity index and the factors used to calculate and assign the diversity indicator for each neighborhood in the JCPS student assignment plan. 
Table 5

Jefferson County Public Schools Student Assignment Diversity Categories

\begin{tabular}{lccc}
\hline & \multicolumn{3}{c}{ Factor } \\
\cline { 2 - 4 } Category & Annual income & Parent education & Race $(\%$ White $)$ \\
\hline 1 & $<\$ 42,000$ & $<3.5$ & $<73$ \\
2 & $\$ 42,000-62,000$ & $3.5-3.7$ & $73-88$ \\
3 & $>\$ 62,000$ & $>3.7$ & $>88$ \\
\hline
\end{tabular}

Note. Parent education based on a weighted score of $3.5=$ some college or associate's degree and $4=$ bachelor's degree.

Table 6 displays the educational weights assigned to the parent education factor of the diversity index (Orfield \& Frankenberg, 2011). Weighted scores were assigned to each education attainment level, placing increased values on higher levels of education (Orfield \& Frankenberg, 2011).

Table 6

Parent Education Attainment Weight

\begin{tabular}{ll}
\hline Weight & \multicolumn{1}{c}{ Education } \\
\hline 1.0 & Finished Grade 8 or less \\
2.0 & Did not finish high school \\
3.0 & Finished high school \\
3.5 & Some college or associate's degree \\
4.0 & Bachelor's degree \\
5.0 & Master's or professional degree \\
6.0 & Doctorate \\
\hline $\begin{array}{l}\text { Note. } \text { Source: Diversity and Educational Gains: } \\
\text { A Plan for a Changing County and its Schools, } \\
\text { by G. Orfield and E. Frankenberg, 2011, retrieved } \\
\text { from the Civil Rights Project: } \\
\text { http://civilrightsproject.ucla.edu. }\end{array}$
\end{tabular}

Orfield and Frankenberg (2011) recommended that JCPS use the following formula to calculate the diversity index for each neighborhood: 
Neighborhood Socioeconomic Designation $=1+.23($ Income Integer $)+$ .33 (Parent Education Integer) +.33 (Race Integer)

When the neighborhood socioeconomic designation formula is utilized, students from a neighborhood with an income less than $\$ 42,000$, an education weight less than 3.5 , and a racial composition of $73-88 \%$ White would receive a neighborhood designation of 2.22 , or: Neighborhood Socioeconomic Designation: $1+.23(1)+.33(1)+.33(2)=2.22$. The weighted averages displayed in Table 7 were calculated for each of Jefferson County's 540 neighborhoods, and an overall category label was assigned to differentiate each neighborhood (Orfield \& Frankenberg, 2011). A weighted average of 2.22 falls within Category 2 in the JCPS student assignment plan.

\section{Table 7}

Neighborhood Socioeconomic Designation

\begin{tabular}{lcc}
\hline & \multicolumn{2}{c}{ Weight Range } \\
\cline { 2 - 3 } Category & Minimum & Maximum \\
\hline 1 & 1.00 & 1.99 \\
2 & 2.00 & 2.99 \\
3 & 3.00 & $>3.00$ \\
\hline
\end{tabular}

By using available neighborhood data from 2009, Orfield and Frankenberg (2011) reported that $30 \%$ of the neighborhoods were rated as Category 1, 46\% were Category 2, and $24 \%$ were Category 3. Orfield and Frankenberg also recommended that JCPS divide the county into 13 clusters to account for school diversity and bus travel time. Each cluster was to be comprised of neighborhoods that would balance school diversity. In 2012, JCPS adopted an altered version of the plan presented by Orfield and Frankenberg by implementing a race- and socioeconomic-based assignment plan, while continuing the 
use of magnet programs, traditional schools, and school choice. Student assignment in JCPS is now based upon the residential diversity index, resulting in a diversity weight of 1.4-2.5 for its 16 comprehensive high schools (JCPS, 2012b).

The composition of schools is influenced beyond the student assignment plan, as JCPS has retained school choice options as well as magnet and traditional programs. Students enrolling in magnet or traditional programs decrease the number of students assigned to the 16 comprehensive high schools included in this study. For example, a school assigned 100 students from Category 3 neighborhoods may only receive 75 of the students if 25 enroll in magnet or traditional programs. A change in student population could result in a school having a larger or smaller population of NSLP-eligible students than what is assigned by JCPS. School choice within the 16 comprehensive schools also impacts student composition, which is discussed more in depth later in this chapter.

\section{College-Readiness Problem}

Preparing students to adapt to a technologically progressing and academically sophisticated society beyond their secondary education requires them to be college or career ready upon completion of the 12th grade (Camara, 2013; Conley, 2007). Although students may not select a pathway leading to college enrollment, the academic expectations for achieving college readiness are holistically linked to career readiness beyond college (Mattern et al., 2014). Remediation in college, required for students who have not achieved college readiness, results in longer completion times for earning degrees and is viewed more as a method for sorting underqualified students who are paying tuition for no credit (Bettinger \& Long, 2004). Students who successfully complete remediation courses show promise toward obtaining a 4-year degree, but the 
more remediation required results in a reduction in graduation rates (Merisotis \& Phipps, 2000). Thus, the purpose of measuring college readiness is to determine if students have a high probability of academic success in entry-level, credit-bearing courses at the college level (Camara, 2013; Conley, 2007).

According to the ACT (2004), the United States has seen a devastating decline in high school graduates meeting the college-readiness benchmarks in algebra, biology, and English. Less than $25 \%$ of the 1.2 million tested students were able to meet the readiness benchmarks in algebra, biology, and English in 2004 (ACT, 2004). Just as alarming is the reduced college-readiness rate among ethnic-minority students when compared to Asian or White students. Native Americans and Latinx students were only half as likely to meet the readiness benchmarks, whereas African American students were even less likely (ACT, 2004). The findings of ACT were supported by Greene and Forster (2003), as their study revealed a graduation rate of $70 \%$ of public high school students in 2001 , with only $32 \%$ achieving the college-ready status. Additionally, ethnic-minority students were found to achieve college readiness at a lesser rate than their White and Asian peers (Greene \& Forster, 2003).

Students who fail to meet one or more benchmarks but gain entrance into college are often required to take and pass remedial, non-credit-bearing courses during their first year of college. Over one third of students from rural and suburban schools and over $50 \%$ of urban high school students enroll in remedial courses in 4-year colleges (Attewell, Lavin, Domina, \& Levey, 2006). The lowest socioeconomic quartile is comprised of $52 \%$ of the remedial student population, with African American students representing over $60 \%$ of the remedial population (Attewell et al., 2006). 
Similar to the national college-readiness rates, Kentucky and JCPS students have produced results showing disparities in student performance in college readiness.

Provided by the Kentucky Department of Education, Table 8 displays ACT collegereadiness rates for 11th-grade students in Kentucky from 2012-2015 (Kentucky Department of Education, 2016). Asian and White students outperformed the state college-readiness rate, whereas African American, Latinx, and NSLP-eligible students performed below the state rate as well as below Asian and White students.

Table 8

Kentucky College Readiness 2012-2015: Percentage of Students Scoring at the CollegeReady Level

\begin{tabular}{lcccccc}
\hline \multicolumn{1}{c}{ ACT exam } & State & White & Asian & African American & Latinx & NSLP eligible \\
\hline 2012 & & & & & & \\
$\quad$ English & 52.2 & 56.1 & 59.2 & 28.3 & 37.6 & 37.7 \\
Mathematics & 38.6 & 41.5 & 62.3 & 18.7 & 30.4 & 24.8 \\
$\quad$ Reading & 41.9 & 45.5 & 48.9 & 19.3 & 29.6 & 29.5 \\
2013 & & & & & & \\
English & 53.1 & 56.6 & 60.6 & 29.5 & 40.9 & 38.8 \\
Mathematics & 39.6 & 42.5 & 62.0 & 18.1 & 29.5 & 25.7 \\
Reading & 44.2 & 47.5 & 52.0 & 21.8 & 32.4 & 31.6 \\
2014 & & & & & & \\
English & 55.9 & 59.7 & 62.7 & 30.6 & 38.7 & 41.5 \\
Mathematics & 43.5 & 46.4 & 62.8 & 22.2 & 32.6 & 29.6 \\
Reading & 47.1 & 50.5 & 55.4 & 23.8 & 34.2 & 34.0 \\
2015 & & & & & & \\
English & 55.3 & 59.1 & 65.4 & 30.2 & 40.4 & 41.3 \\
Mathematics & 38.1 & 41.1 & 62.4 & 16.7 & 26.7 & 24.5 \\
Reading & 47.4 & 50.8 & 57.3 & 24.1 & 36.3 & 34.9 \\
\hline
\end{tabular}

Note. NSLP = National School Lunch Program.

Table 9 displays the composite college-readiness rates for 11th-grade students in JCPS who were administered the ACT from 2012-2015 (JCPS, 2012a, 2013, 2014c, 
2015a). The results for college-readiness rates in JCPS were similar to Kentucky in that Asian and White students also outperformed the district college-readiness rate, whereas African American, Latinx, and NSLP-eligible students performed below the district rate as well as below Asian and White students.

Table 9

Jefferson County Public Schools Composite College-Readiness Rates 2012-2015: Percentage of 11th-Grade Students Scoring at the College-Ready Level on the ACT

\begin{tabular}{ccccccc}
\hline Year & District & White & Asian & African American & Latinx & NSLP eligible \\
\hline 2012 & 44.95 & 58.79 & 63.92 & 24.60 & 35.98 & 27.13 \\
2013 & 50.89 & 61.89 & 63.27 & 32.22 & 49.48 & 35.21 \\
2014 & 58.65 & 70.52 & 70.39 & 39.60 & 52.60 & 44.53 \\
2015 & 59.52 & 71.00 & 67.70 & 41.17 & 53.07 & 46.54 \\
\hline
\end{tabular}

Note. NSLP = National School Lunch Program.

The Kentucky and JCPS results are consistent with national results in that ethnicminority students are outperformed in college readiness by White and Asian students. Although state and district college-readiness rates generally have increased from 2012 through 2015, noticeable differences exist between Asian and White student scores compared to the African American, Latinx, and NSLP-eligible students. This study expanded on the analysis in the variance of college-readiness rates by accounting for student backgrounds, neighborhood diversity, and school composition.

\section{School Choice Problem}

Parents and students seeking educational opportunities related to increased college readiness use intradistrict transfer procedures to attend affluent, non-Title I schools that produce higher results in mathematics and reading compared to their lower performing district counterparts (Lauen, 2007; Phillips, Hausman, \& Larsen, 2012; 
Tefera et al., 2011). Students participating in the NSLP, who are English language learners, or who come from single-parent families are less likely to use intradistrict transfer procedures (Lauen, 2007; Phillips et al., 2012). School choice ultimately results in the de facto development of racially and socioeconomically segregated schools, with low-poverty and low-minority student populations attending the higher performing schools (Lauen, 2007; McDermott et al., 2014; Phillips et al., 2012). Thus, an effective student assignment plan is necessary to prevent socioeconomic and racial segregation (Kahlenberg, 2006; Kahlenberg, 2012; Lauen, 2007; McDermott et al., 2014; Orfield, 2001; Orfield \& Frankenberg, 2011; Orfield et al., 2008; Orfield et al., 2012; Orfield et al., 2014; Phillips et al., 2012; Potter et al., 2016; Reardon et al., 2006; Tefera et al., 2011).

Previous examinations of census trends revealed that the desegregation efforts of the 1960 s resulted in an increase in racially diverse schools throughout the United States with smaller growth existing mostly in the southern states (Charles, 2003; Frankenberg, 2013; Frankenberg et al., 2003; Orfield, 2001; Orfield et al., 2012; Orfield et al., 2014). However, public school districts began trending back to segregated schools in the 1990s as school districts were released from desegregation mandates (Charles, 2003; Frankenberg, 2013; Frankenberg et al., 2003; Orfield, 2001; Orfield et al., 2012; Orfield et al., 2014). School choice plans, magnet programs, and charter schools have allowed parents and students to create schools with limited ethnic-minority or high-poverty populations (Diem, 2012; Diem \& Frankenberg, 2013; Frankenberg, 2013; Frankenberg et al., 2003; Lauen, 2007; Orfield, 2001; Orfield et al., 2012; Orfield et al., 2014; Phillips et al., 2012; Tefera et al., 2011). Moreover, neighborhoods became less segregated in the 
1990s throughout the United States and in school districts where school choice was limited; yet as the neighborhoods desegregated, White families began moving to suburban neighborhoods and school districts (Charles, 2003; Frankenberg, 2013; Frankenberg et al., 2013; Orfield, 2001; Orfield et al., 2012; Orfield et al., 2014; Tefera et al., 2011). The movement in desegregating neighborhoods has been cited as contributing to the development of segregated schools, as White families move to low-minority areas and establish low-minority schools (Charles, 2003; Frankenberg, 2013; Frankenberg et al., 2003; Orfield, 2001; Orfield et al., 2012; Orfield et al., 2014; Tefera et al., 2011).

Students attending JCPS secondary schools have the opportunity to use a school choice procedure to access a variety a schools and programs. The 16 comprehensive secondary schools are separated into three networks, with five schools of study divided among the schools. Students have the option of enrolling in one of the schools of study listed below or they may attend their default home school, which is already assigned a school of study:

- Business and Finance; Information Technology;

- Communications, Electronic and Print Media, Visual and Performing Arts;

- Engineering, Architecture, Construction;

- Human Services (Law/Government Service, Fire, Police, EMS), Education, International Studies, Heavy Equipment Science; or

- Medical Arts and Science, Allied Health, Environmental Science.

Also available to students are districtwide magnet high schools, traditional structure programs, and districtwide magnet programs, but enrollment is only granted by meeting application standards. Students also may attend a school beyond their network or the 
districtwide programs by applying to any of the 16 comprehensive schools through open enrollment. Students who apply through open enrollment are subject to meeting the application standards established by the individual comprehensive schools, and acceptance is determined by the different schools or principals.

During the 2014-15 school year, approximately $20 \%$ of students in the 16 JCPS comprehensive high schools attended the two most affluent, low-minority schools (JCPS, 2014a). This establishment of low-minority and low-poverty schools is consistent with the segregation movement described by Charles (2003) and Frankenberg (2013). The average NSLP-eligible population of the two schools was about $34 \%$, and the average ethnic-minority enrollment was about 38\% (JCPS, 2014a, 2014d). The remaining 14 comprehensive schools were comprised of NSLP-eligible populations ranging from $40.7-81.9 \%$, with ethnic-minority populations ranging from 33.1-75.2\% (JCPS, 2014a, 2014d). The results of the JCPS student assignment and choice plan created vastly different schools with populations being heavily impoverished and high minority.

Table 10 displays the enrollment and college-readiness performance data as measured by the ACT college-readiness exam for the 16 JCPS comprehensive high schools during the 2014-15 school year (JCPS, 2014a, 2014b, 2014d). The ACT exam was developed for 11th- and 12th-grade students to measure knowledge of curriculum through the final years of a secondary education as students apply for college (ACT, 2014). With a focus on English, mathematics, reading, and science curriculum, the exam is scored on a range of $1-36$, and the results help determine a student's likelihood to attain success in entry-level, credit-bearing college courses (ACT, 2014). The 2015 
average composite scores are displayed along with the percentage of students meeting the English, mathematics, and reading benchmarks by school.

Table 10

2015 Jefferson County Public Schools Comprehensive School Demographics and ACT Performance

\begin{tabular}{|c|c|c|c|c|c|c|}
\hline \multirow[b]{2}{*}{ School } & \multicolumn{2}{|c|}{$\%$ of students } & \multirow[b]{2}{*}{$\begin{array}{l}2015 \text { ACT } \\
\text { composite } \\
M \text { score }\end{array}$} & \multicolumn{3}{|c|}{$\%$ students meeting benchmarks } \\
\hline & White & $\begin{array}{c}\text { National School } \\
\text { Lunch Program } \\
\text { eligible }\end{array}$ & & English & Math & Reading \\
\hline Atherton & 66.9 & 40.7 & 21.6 & 76.6 & 40.6 & 55.7 \\
\hline Ballard & 59.2 & 35.2 & 21.9 & 70.4 & 52.6 & 52.0 \\
\hline Doss & 38.2 & 72.5 & 16.1 & 23.7 & 7.6 & 13.1 \\
\hline Eastern & 65.6 & 32.2 & 21.4 & 72.9 & 38.1 & 51.9 \\
\hline Fairdale & 60.4 & 68.9 & 17.3 & 36.7 & 14.8 & 20.5 \\
\hline Fern Creek & 46.4 & 64.7 & 17.7 & 45.6 & 13.7 & 21.1 \\
\hline Iroquois & 28.9 & 81.9 & 15.2 & 20.3 & 5.5 & 7.8 \\
\hline Jeffersontown & 48.9 & 59.7 & 17.9 & 43.0 & 18.4 & 23.3 \\
\hline Moore & 46.5 & 61.4 & 17.5 & 34.8 & 16.0 & 19.8 \\
\hline PRP & 64.6 & 63.0 & 17.8 & 40.9 & 21.6 & 24.9 \\
\hline Seneca & 39.4 & 69.9 & 16.7 & 35.5 & 8.3 & 15.7 \\
\hline Shawnee & 46.4 & 77.8 & 16.0 & 24.4 & 5.9 & 7.6 \\
\hline Southern & 51.0 & 67.6 & 16.6 & 35.6 & 10.0 & 17.1 \\
\hline Valley & 60.1 & 69.2 & 16.1 & 20.1 & 3.6 & 13.7 \\
\hline Waggener & 40.1 & 68.7 & 17.0 & 31.0 & 12.6 & 18.4 \\
\hline Western & 24.8 & 78.5 & 15.7 & 22.7 & 7.8 & 9.7 \\
\hline
\end{tabular}

\section{Significance of Study}

JCPS has developed and implemented a student assignment plan that accounts for racial diversity, socioeconomic status, family background, and neighborhood factors.

The research and data provided thus far has established a foundation for examining the 
relationship those student factors have to college readiness in English Language Arts and mathematics. Examining the influence of school composition resulting from the JCPS student assignment plan was also justified by the literature and data. Results of the analysis are provided separately for each block of factors to clarify their influence on college readiness. The results also reveal how student and school factors together impact college readiness. The findings of this study may be used by JCPS to examine the district's student assignment and school choice plans as they relate to district collegereadiness rates. Specifically, an understanding into the influence of student background and school factors contained within the JCPS student assignment plan may guide student assignment that continues to establish desegregated schools while also promoting growth in student college readiness. The influence of student and school factors may also be applied to individual schools to clarify local college-readiness achievement rates.

Finally, the findings may guide teacher assignment policies and professional development practices to ensure schools are staffed with experienced teachers who are trained to address the noncognitive factors present in students and school populations.

\section{Research Questions}

The following research question was addressed in this study: To what extent do student, neighborhood, and school factors predict college readiness in English Language Arts and mathematics? The independent variables were the following: student race, student gender, neighborhood socioeconomic designation, school composition, student NSLP eligibility, student special education designation, ACT PLAN English score, ACT PLAN Mathematics score, and ACT PLAN Reading score. The dependent variables were the following: ACT English score, ACT Mathematics score, and ACT Reading score. 


\section{Scope}

The focus and data of this study resided in the JCPS district during the 2014-15 school year. Student backgrounds, neighborhood socioeconomic data, and school poverty data were analyzed in accordance to ACT results produced by 11 th-grade students. The results of this study are limited to JCPS and its students, but the methods can be duplicated for future studies in JCPS and other school districts.

\section{Study Limitations}

Several limitations exist within this study. First, this study focused on a singular metropolitan school district, which limits the generality of the findings. Relating the results to other school districts with different student, neighborhood, and school demographics may produce varying results on their influence on college readiness. Additionally, moderating factors such as student support programs offered by schools or districts to support college readiness may not be found in JCPS.

Second, this study examined the influence of student, neighborhood, and school factors on college readiness, but other factors such as the effectiveness of ACT preparation programs used by districts and schools were not included. The review of literature discussed the presence of academic resources in low-poverty and low-minority schools, specific academic programs were note examined. A future examination of the effectiveness of college preparatory resources may produce further insight into overcoming any negative effects of student, neighborhood, or school factors.

Third, this study included data only from 11 th-grade students enrolled in the 16 comprehensive JCPS high schools. Students enrolled in magnet or traditional programs were excluded. The student selection processes used by magnet and traditional programs 
result in student populations that are not reflective of the 16 comprehensive schools, as not all students qualify for enrollment. For example, writing samples, letters of recommendation, and middle school performance scores are required for consideration of enrollment into a magnet program. Students who do not meet the standards for enrollment are not considered. Instead, this study focused on the comprehensive schools for which performance in middle school is not required for enrollment. Thus, the comprehensive schools used in this study were comprised of student populations resulting from student assignment rather than student selection.

Finally, this study utilized the ACT college-readiness assessment as the instrument to measure college readiness. Although JCPS annually administers the exam to 11th-grade students, effort and completion of the exam cannot be mandated or controlled. Students who refuse to complete the exam with genuine effort may produce scores not reflective of their college-readiness status. The a priori estimation of power above .70 was necessary for this study to ensure the appropriate number of participants was included to counter any imprecise results (Stevens 2007, 2009). Despite the limitations present in this study, the findings have utility in understanding the influence of student, neighborhood, and school factors on college readiness.

\section{Definition of Key Terms}

The basic terms used in this study are defined as follows:

1. Student assignment is the practice by school districts of assigning students to their appropriate, grade-level schools. Schools serve geographic areas in which students' parent or guardian reside (McDermott et al., 2014). 
2. College readiness refers to the academic preparation of students providing them the ability to effectively adapt to a technologically progressing and academically sophisticated society beyond their secondary education (Camara, 2013; Conley, 2007). Academic expectations for achieving college readiness are holistically linked to career readiness beyond college (Mattern et al., 2014).

3. Neighborhood socioeconomic designation was conceptualized by Orfield and Frankenberg (2011) as the result of combining the weighted averages for household income, parent education, and percentage non-White for each of Jefferson County's 540 neighborhoods.

4. Student background is a construct of noncognitive factors including gender, race, neighborhood socioeconomic designation, NSLP eligibility, and special education designation.

5. NSLP eligibility refers to the participation in the NSLP as a meal assistance provided by the U.S. Department of Agriculture (USDA, 2016) to students whose family income is within $130-185 \%$ of the national poverty level. Depending upon income, students qualify for free lunch or reduced-price lunch.

6. Special education, according to the Americans With Disabilities Act of 1990, is the act of providing educational accommodations to students by allocating access to aids and services that create an equal opportunity to participate and benefit from public education.

7. School composition refers to the poverty rate of a school. 
8. According to the Elementary and Secondary Education Act of 1965, Title I refers to the designation given to elementary and secondary schools provided financial assistance because of the percentage of students from low-income families. Schools above $40 \%$ enrollment of students from low-income families are granted Title I status in JCPS (JCPS, 2014e).

9. The ACT exam was developed for 11th- and 12th-grade students to measure knowledge of curriculum through the final years of a secondary education as students apply for college (ACT, 2014).

\section{Summary}

The Constitution of the United States and opinions from the Supreme Court have established a framework for providing students a public education free from segregation. School districts such as JCPS have used that framework to design and implement student assignment plans that bring together students from a variety of backgrounds to create unique school populations. JCPS in particular has previously implemented race-based student assignment plans, but student assignment is now determined by student background and neighborhood socioeconomic status (JCPS, 2012b). The change in student assignment was the result of Meredith v. Jefferson County Public Schools (2006) but was guided by Orfield and Frankenberg (2011).

This study used the criteria of the JCPS student assignment plan along with school poverty data to determine their influence on student college readiness. The analysis also considered individual student backgrounds, the neighborhood socioeconomic designation assigned to each student's residence, and the school poverty level for the school attended by each student to discover the level of influence the JCPS 
student assignment plan and school poverty on individual student college readiness. The findings of this study can be used to support the current JCPS student assignment plan or guide changes for the improvement of student achievement on college readiness.

Additionally, district leaders may use the findings to establish school poverty thresholds that promote student college readiness. Chapter 2 provides a synthesized literature review for each of the factors included in this study. Chapter 3 provides a detailed methodology for analyzing the relationship of the factors with college readiness, and Chapters 4 and 5 review the findings and discuss their implications. 


\section{CHAPTER 2}

\section{REVIEW OF LITERATURE}

The purpose of this study was to examine the influence of student and school characteristics on students' college readiness. In particular, it sought to determine the extent to which student and school factors within a race- and socioeconomic-based student assignment plan are related to college readiness. Student assignment plans are often developed as a result of political movements, federal and local legislation, and court opinions (Borman et al., 2004), and school districts such as JCPS have implemented student assignment plans that are a direct result of Supreme Court opinions. Based on Orfield and Frankenberg (2011), JCPS implemented a race- and socioeconomic-based student assignment plan that sought to account for student background and neighborhood socioeconomic factors. Although the plan met the decree of the Supreme Court, it led to the formation of schools with populations that vary racially and socioeconomically. This review of literature details the influence of student- and school-level factors as they independently relate to student achievement in English Language Arts and mathematics. It also lays a foundation for examining how the structures of students' families, neighborhoods, and schools collectively influence college-readiness rates.

Student assignment plans_-influenced by political movements, legislation, or legal opinions - result in schools comprised of students with family backgrounds that have a variety of economic and parent education levels and from neighborhoods that vary in racial and economic diversity (McDermott et al., 2014; Orfield \& Frankenberg, 2011; 
Tefera et al., 2011). Understanding how those factors impact college readiness was the focus of this study. Understanding the degree to which race- and socioeconomic-based student assignment plans, in conjunction with school choice, impacts college readiness provides district leaders the opportunity to guide necessary changes to manage student assignment and improve student college readiness. Accordingly, this review of literature addresses the study's research question and variables. The research question was the following: To what extent do student, neighborhood, and school factors predict college readiness in English Language Arts and mathematics? Independent variables were student race, student gender, neighborhood socioeconomic designation, school composition, student NSLP eligibility, student special education designation, ACT PLAN English score, ACT PLAN Mathematics score, and ACT PLAN Reading score. Dependent variables were ACT English score, ACT Mathematics score, and ACT Reading score.

The studies included in this review to address the research question and variables are predominately quantitative in their analyses. They examined factors associated with student achievement as a result of child development, family and neighborhood influences, and school composition. Including the findings of previous quantitative research is beneficial, as the results create a foundation for the results provided and discussed in later chapters.

The literature review is organized into three major sections. The first section of this review is focused on the dependent variable of college readiness. A definition of college readiness is provided, the ACT instrument and scores are detailed, and literature focused on the use of ACT scores for measuring college readiness is reviewed. Sections 
2 and 3 review literature focused on the independent variables of student backgrounds and school characteristics. Section 2 concentrates on students' diverse backgrounds by reviewing Equality of Educational Opportunity (Coleman et al., 1966), which drew conclusions about diverse students' backgrounds and schools, the effects of student and school poverty, and the impact on educational achievement. Coleman et al. (1966) and additional articles lay the groundwork for the impact of noncognitive influences of families and neighborhoods on student development and academic performance. Finally, Section 3 provides insight into the influence of schools by concentrating on the composition of schools with particular focus on student race and socioeconomic status.

\section{College Readiness}

As students progress through their primary and secondary education, they are exposed to diverse learning experiences designed to empower students to adapt to a technologically progressing and academically sophisticated society (ACT, 2009). Students who complete their secondary education are awarded a diploma, signifying they have achieved a level of mastery of academic knowledge and skills serving as a foundation for continued learning or entry into a career (Conley, 2007, 2008). Measuring those skills and knowledge against standards of performance established for college English, mathematics, reading, and science curricula is the purpose of instituting readiness standards, as they determine the likelihood of student success in college (ACT, 2014). As noted by ACT (2004), the United States has seen a decrease in students graduating prepared to meet college-readiness standards. Thus, the proper preparation of students for the academic rigors of college or career has to be one of the essential roles of secondary schools (Conley, 2007). Moreover, the overarching goal of establishing a 
college-readiness standard is to determine if students have a high probability of academic success in entry-level, credit-bearing courses, which requires an operational definition of academic success at the college level (Camara, 2013; Conley, 2007).

College readiness can be operationally defined in a number of ways to account for both the college- and career-readiness elements (Camara, 2013; Conley, 2007). Determining a student's readiness to successfully transition from a secondary to postsecondary education requires an operational definition or standard that moves beyond eligibility attained through earning a high school diploma (Conley, 2008). According to Conley (2007), college readiness is defined as students entering institutions offering baccalaureate programs without requiring remediation before enrolling in degreerequisite courses. Beyond enrollment in credit-bearing courses, student performance should align with the probability of earning a grade above a standard or benchmark for success (ACT, 2014; Allen \& Sconing, 2005; Camara, 2013). Successful performance in those courses indicates that students possess the cognitive ability for intellectual openness and inquisitiveness, analysis and reasoning, and problem solving with accuracy (Conley, 2007, 2008). College-ready students use these cognitive abilities to master the academic skills of research and writing to learn essential core content knowledge in English, mathematics, science, and social studies (Conley, 2007; Conley, 2008; Roderick, Nagaoka, \& Coca, 2009). These characteristics of college readiness transcend a simple formulaic definition as they expound on what students should be able accomplish when college ready.

Once students advance beyond their postsecondary education, their cognitive abilities and skills obtained should translate to their ability to successfully adapt to the 
demands of their career (ACT, 2009; Conley 2012). Although major educational legislation like the No Child Left Behind Act (2002) and the American Recovery and Reinvestment Act of 2009 focused on students being college or career ready, the academic expectations for achieving college readiness are holistically linked to career readiness beyond college (Mattern et al., 2014). Thus, the focus of this research was restricted to the academic performance expectations for students entering college, with the understanding that success in college is linked to career readiness.

\section{Measuring College Readiness}

Developed at the beginning of the 20th century, standardized college admissions exams - namely the ACT and SAT exams - were established to reduce the variety and inconsistencies of college entrance exams and served to provide a measure for the probability for college success of an applicant (Zwick, 2007). The SAT was originally developed as a measure of logic and reasoning, whereas the ACT measured student college readiness (Zwick, 2007). However, revisions in early 2014 reshaped the SAT to measure college readiness as well. SAT and ACT have separately established predetermined standards to regulate the level of academic readiness required for students to successfully complete college-level, nonremedial courses (Camara, 2013; Conley, 2007). This study utilized the ACT, as the exam is annually administered to students in JCPS.

The ACT exam is the last of a three-test series, preceded by the ACT Explore and ACT PLAN, which are designed to measure student trajectories for college readiness; however, students are not required to be administered the Explore or PLAN before taking the final college-readiness exam (ACT, 2013a, 2013b). Traditionally, 
eighth-grade students are administered the ACT Explore, and the results are used to guide academic supports for students during their secondary education (ACT, 2013a). The ACT PLAN was developed for 10th-grade students, as it measures knowledge of curriculum obtained in middle and early secondary education (ACT, 2013b). Finally, the ACT exam was developed for 11th- and 12th-grade students to measure knowledge of curriculum through the final years of a secondary education, prior to college application (ACT, 2014). Containing four separate multiple-choice sections, the ACT exam concentrates on English, mathematics, reading, and science curricula, and the results are provided to postsecondary institutions to determine a student's likelihood to attain success in entry-level, credit-bearing courses (ACT, 2014).

The English section of the ACT is comprised of 75 multiple-choice questions focused on the use of writing standards. Students are allotted 45 minutes to read five passages and answer 75 questions. The Mathematics section is comprised of 60 knowledge and application questions that assess curriculum taught through 11th grade. Students are allotted 60 minutes to answer 60 questions and may use a calculator if desired. The Reading section of the ACT contains 40 questions answered in 35 minutes. The reading section focuses on literacy and reasoning derived from answering questions that follow four separate passages. Finally, the Science section contains 40 questions answered in 35 minutes. Based upon knowledge learned in introductory science, students demonstrate their ability to interpret, analyze, and reason through the use of graphs and passages (ACT, 2014). An optional Writing section is administered with the exam, lasting 30 minutes, but does not influence the multiple-choice scores. 
The composite score produced by the ACT exam ranges from 1-36 and is obtained by averaging the scale scores (also 1-36) for the English, Mathematics, Reading, and Science sections (ACT, 2014). Aside from the composite and section scale scores, seven subscores ranging from 1-18 are provided by the English (two scores), Mathematics (three scores), and Reading (two scores) sections. Scores are reported as percentages in regards to performing below, at, or above the national and college-bound sample, and students receive a percentage score normed from the previous 3 years of ACT scores produced by students in Grades 10, 11, and 12 (ACT, 2014).

The ACT exam assesses academic preparedness in English, mathematics, science, and reading by measuring skills developed in an ordinary college-preparatory school (Allen \& Sconing, 2005; Zwick, 2007). The questions for each section are derived from content and statistical specifications, ensuring that questions originate from curricula and standards taught prior to the exam (ACT, 2014). Benchmark scores also have been established for each content section, enabling students and colleges to determine academic readiness (ACT, 2014). Accordingly, to be considered a valid measure of college readiness, grades in a postsecondary institution should be tightly aligned with the ACT exam (Camara, 2013; Zwick, 2007).

Allen and Sconing (2005) examined college courses and found the grades of A, $\mathrm{B}, \mathrm{D}$, and $\mathrm{F}$ as the most common grades issued to students. The course grades earned and ACT exam scores were analyzed through the use of a hierarchical logistical regression, and specific ACT scores were determined to provide a college student a .50 probability of earning a B or higher in English composition, college algebra, social science, and biology, which are typical courses for a 1st-year college student (ACT, 
2014; Allen \& Sconing, 2005). Thus, the standard of B or higher was established as the letter grade of college readiness (ACT, 2014; Allen \& Sconing, 2005). Furthermore, the following ACT exam scores were designated as college-ready benchmarks: English Composition, 18; College Algebra, 22; Reading, 22; and Biology, 23 (Allen, 2013; Allen \& Sconing, 2005). Allen (2013) found that $64 \%$ of high school graduating students and $78 \%$ of enrolled 1st-year college students met the English benchmark. Similarly, $44 \%$ of high school graduating students met the mathematics and reading benchmarks, whereas enrolled 1st-year college students reached $56 \%$ and $55 \%$, respectively. Finally, $36 \%$ of high school graduating students and $47 \%$ of enrolled 1 styear college students achieved the science benchmark.

During national ACT testing dates in 1996, ACT administered a survey to students requesting them to indicate the coursework in which they were enrolled or had completed. Students also provided their expected or earned grade for each course, and the survey data revealed that students completed approximately 30 common English, mathematics, natural science, and social studies courses (ACT, 2014). The common course curricula were reviewed, and a regression model measured the association of ACT scores with high school coursework and student grade point averages (GPAs). The results of the analysis revealed that of the 23 courses entered into the regression model, only mathematics, chemistry, and physics courses were found to significantly ( $p$ <.01) explain variance in ACT scores (ACT, 2014). Other courses beyond mathematics, chemistry, and physics were found to be related to ACT performance, but collinearity removed those courses from the model (ACT, 2014). ACT used these findings to recommend that students complete 4 years of high school English and 3 
years of mathematics, natural science, and social studies courses. Students who completed or indicated they would be completing the minimal suggested coursework scored 2-3 scale points higher than students who did not complete the recommended coursework (ACT, 2014). Additionally, ACT (2014) revealed that $25-38 \%$ of variance in ACT scores is explained by high school GPA. Together, high school GPA and coursework explain $30-55 \%$ of the variance in ACT scores (ACT, 2014). The results produced by ACT have been bolstered by other studies focused on the relationship of curriculum and GPA on ACT scores.

Noble, Davenport, Schiel, and Pommerich (1999b) established that the variances in ACT exam scores were mostly explained by coursework completed and student GPA $\left(R^{2}=.29\right.$ to .52$)$. More specifically, completion of high school mathematics and science courses is highly associated to an increase in ACT scores (ACT, 2014; Noble, Davenport, Schiel, \& Pommerich, 1999a, 1999b; Noble \& McNabb, 1989; Schiel, Pommerich, \& Noble, 1996). Each high school mathematics course completed was associated with a 2point gain in ACT mathematics scores, and each additional science course was associated with gains of 1.26-1.58 in science (Noble \& McNabb, 1989). The completion of mathematics and science courses was associated with increased ACT scores even when controlling for the grades earned in those courses (Noble \& McNabb, 1989).

Students who earned higher grades in the recommended coursework also produced higher ACT scores; hence, higher student GPAs are associated with higher ACT scores (ACT, 2014; Noble et al., 1999a, 1999b; Noble \& McNabb, 1989). However, inconsistency in high school grading practices has weakened the GPA's predictive association to 1st-year college student success (Noble \& Sawyer, 2002; 
Sawyer, 1989, 2013). Though high school GPA and ACT scores were significant predictors of 1st-year college student performance, a high school GPA of 2.0-3.0 was a stronger predictor compared to ACT scores (Noble \& Sawyer, 2002; Sawyer, 1989, 2013). When the high school GPA exceeded 3.0, ACT scores served as a stronger predictor of 1st-year college student performance (Noble \& Sawyer, 2002; Sawyer, 1989, 2013). Thus, ACT scores are associated with 1st-year college student performance, the association is strengthened when high school GPA is included, and both should be used when determining college course placement (ACT, 2014; Noble et al., 1999a, 1999b; Noble \& McNabb, 1989; Noble \& Sawyer, 2002; Sawyer, 1989, 2013).

Examining the influence of race and gender provides further clarification of variance on ACT scores and adds to the association between coursework and grades on ACT scores. With data from 2012-13, ACT analyzed scores from students with a GPA of 3.0 or higher, including the influence of completing the recommended collegepreparatory curriculum. Students who completed the minimal recommended core curriculum earned higher ACT scores than students who completed less than the core curriculum, regardless of race or gender (ACT, 2014). Although Asian students possessed the highest average ACT scores and African American students possessed the lowest, the average composite score was higher across all races or ethnicities when students completed the minimal recommended coursework (ACT, 2014). Additionally, male students scored only marginally higher than their female counterparts (ACT, 2014). Noble and McNabb (1989) found that independently examining the influence of race or ethnicity on ACT scores explained $12-20 \%$ of variance between Asian and White students compared to ethnic-minority students. So, before other factors such as 
socioeconomic status and gender are considered, race and ethnicity explain $12-20 \%$ of the difference in ACT scores (Noble \& McNabb, 1989). Additionally, Asian and White students produced higher average composite scores and higher median scale scores than African American students (differences ranging from .36 in reading to .67 in science) when controlling for ACT PLAN scores, completed coursework, gender, and family income (ACT, 2014). The differences in scale scores between majority and minority races or ethnicities ranged from 2.14 in mathematics to 2.81 in reading when examined without control variables (ACT, 2014). Thus, the relationship of race or ethnicity and ACT scores is actually minimal - around $1-2 \%$ - as other variables correlated to race or ethnicity contribute to the increase in score variance (ACT, 2014; Noble et al., 1999a; Noble, Roberts, \& Sawyer, 2006). Table 11 displays national longitudinal ACT scores from 2001-2010, including composite scores and scores by gender and race (NCES, 2010). Table 12 also displays longitudinal ACT data but is separated by test section and gender from 2001-2010 (NCES, 2010).

Analysis of the relationship of gender and ACT scores revealed that males produced higher average results on the ACT, ranging from 0.60 for composite scores to 1.51 in science, when ACT PLAN scores, coursework, family income, and race were controlled (ACT, 2014). Males also achieved higher results than females in ACT Mathematics and Reading, but females performed better on English and produced higher GPAs in college (ACT, 2014; Mau \& Lynn, 2001). When controls were not applied, the range in male over female scores increased similarly to the race and income analyses (ACT, 2014; Mau \& Lynn, 2001). 
Table 11

National ACT Results 2001-2010 by Student Group

\begin{tabular}{ccccccccc}
\hline Year & Composite & Male & Female & White & American & Hispanic & Asian & $\begin{array}{c}\text { Native } \\
\text { American }\end{array}$ \\
\hline 2001 & 21.0 & 21.1 & 20.9 & 21.8 & 16.9 & - & 21.7 & 18.8 \\
2002 & 20.8 & 20.9 & 20.7 & 21.7 & 16.8 & 18.4 & 21.6 & 18.6 \\
2003 & 20.8 & 21.0 & 20.8 & 21.7 & 16.9 & 18.5 & 21.8 & 18.7 \\
2004 & 20.9 & 21.1 & 20.9 & 21.8 & 17.1 & 18.5 & 21.9 & 18.8 \\
2005 & 20.9 & 21.1 & 20.9 & 21.9 & 17.0 & 18.6 & 22.1 & 18.7 \\
2006 & 21.1 & 21.2 & 21.0 & 22.0 & 17.1 & 18.6 & 22.3 & 18.8 \\
2007 & 21.2 & 21.2 & 21.0 & 22.1 & 17.0 & 18.7 & 22.6 & 18.9 \\
2008 & 21.1 & 21.2 & 21.0 & 22.1 & 16.9 & 18.7 & 22.9 & 19.0 \\
2009 & 21.1 & 21.3 & 20.9 & 22.2 & 16.9 & 18.7 & 23.2 & 18.9 \\
2010 & 21.0 & 21.2 & 20.9 & 22.3 & 16.9 & 18.6 & 23.4 & 19.4 \\
\hline
\end{tabular}

Note. Source: ACT High School Profile Report, 1995-2010, by the National Center for

Education Statistics, 2010, Washington, DC: Author.

Table 12

National ACT Results 2001-2010 by Subject Area and Gender

\begin{tabular}{lcccccccccc}
\hline Subject & 2001 & 2002 & 2003 & 2004 & 2005 & 2006 & 2007 & 2008 & 2009 & 2010 \\
\hline English & & & & & & & & & & \\
All & 20.5 & 20.2 & 20.3 & 20.4 & 20.4 & 20.6 & 20.7 & 20.6 & 20.6 & 20.5 \\
Male & 20.0 & 19.7 & 19.8 & 19.9 & 20.0 & 20.1 & 20.2 & 20.1 & 20.2 & 20.1 \\
Female & 20.8 & 20.6 & 20.7 & 20.8 & 20.8 & 21.0 & 21.0 & 21.0 & 20.9 & 20.8 \\
Mathematics & & & & & & & & & & \\
All & 20.7 & 20.6 & 20.6 & 20.6 & 20.7 & 20.8 & 21.0 & 21.0 & 21.0 & 21.0 \\
Male & 21.4 & 21.2 & 21.2 & 21.3 & 21.3 & 21.5 & 21.6 & 21.6 & 21.6 & 21.6 \\
Female & 20.2 & 20.1 & 20.1 & 20.2 & 20.2 & 20.3 & 20.4 & 20.4 & 20.4 & 20.5 \\
Reading & & & & & & & & & & \\
All & 21.3 & 21.1 & 21.2 & 21.3 & 21.3 & 21.4 & 21.5 & 21.4 & 21.4 & 21.3 \\
Male & 21.1 & 20.9 & 21.0 & 21.1 & 21.0 & 21.1 & 21.2 & 21.2 & 21.3 & 21.1 \\
Female & 21.5 & 21.3 & 21.4 & 21.5 & 21.5 & 21.6 & 21.6 & 21.5 & 21.4 & 21.4 \\
Science & & & & & & & & & & \\
All & 21.0 & 20.8 & 20.8 & 20.9 & 20.9 & 20.9 & 21.0 & 20.8 & 20.9 & 20.9 \\
Male & 21.6 & 21.3 & 21.3 & 21.3 & 21.4 & 21.4 & 21.4 & 21.3 & 21.4 & 21.4 \\
Female & 20.6 & 20.4 & 20.4 & 20.5 & 20.5 & 20.5 & 20.5 & 20.4 & 20.4 & 20.5 \\
\hline $\begin{array}{l}\text { Note: Scores reported as averages. Source: ACT High School Profile Report, 1995-2010, } \\
\text { by the National Center for Education Statistics, } 2010, \text { Washington, DC: Author. }\end{array}$
\end{tabular}


Race and gender together explain an additional $2-3 \%$ of variance in ACT scores (ACT, 2014; Noble et al., 1999a). Student background, self-perception, and other noncognitive factors explain an additional $15 \%$ of variance, whereas academic factors clarify almost 60\% (Noble et al., 1999a). Therefore, the strongest influence on ACT scores is high school coursework and GPA (ACT, 2014; Noble et al., 1999a, 1999b; Noble \& McNabb, 1989; Noble et al., 2006; Noble \& Sawyer, 2002; Sawyer, 1989, 2013).

\section{Summary of College-Readiness Literature}

The review of literature on college readiness has presented a multitude of concepts to contextualize the definition and measure of college readiness. This concise review efficiently summarizes the current body of literature.

Measuring academic skills and knowledge against the performance standards for college courses is the purpose of establishing college-readiness standards (ACT, 2014). Entering a baccalaureate program without requiring remediation in core content courses demonstrates that students possess the cognitive foundation in analysis and reasoning to successfully support them for the demands of college and their future careers (Conley, 2007, 2008). Readiness measurement instruments such as the ACT assess student knowledge of curriculum provided through high school and have established benchmarks to determine students' probability in achieving success in 1st-year college courses (ACT, 2014). Students who complete courses recommended by ACT in preparation for college perform better on the ACT exam, and higher performance in those preparation courses results in higher performance on the ACT exam (ACT, 2014). The findings of prior studies revealed that minimal variation exists on the ACT exam 
because of race and gender, and the most influential factor on ACT results is the performance and completion of high school coursework (ACT, 2014; Noble et al., 1999a, 1999b; Noble \& McNabb, 1989; Noble et al., 2006; Noble \& Sawyer, 2002; Sawyer, 1989, 2013). Understanding how diversity in student background influences college readiness was a goal of this study, and therefore the next section of the review focuses on student background factors.

\section{Student Background Diversity}

Student-level factors such as race, gender, family and neighborhood socioeconomic status, parent education, and neighborhood diversity are brought together by student assignment plans to form unique student populations (Orfield \& Frankenberg, 2011; Tefera et al., 2011). The difference in student-level factors and their influence on student achievement is the focus of this section, which begins with a review of diversityoriented student assignment plans, as they are responsible for the composition of student bodies with diverse student-level backgrounds. Student-level factors are also reviewed to create an understanding of how they influence student achievement and create schoollevel influences.

\section{Student Assignment}

The effects of students' backgrounds and school composition are relevant factors in the development of diversity-oriented student assignment plans, as school districts strive for racial or socioeconomic diversity while promoting student achievement (Borman et al., 2004; Diem \& Frankenberg, 2013; Frankenberg, 2013; Frankenberg et al., 2003; Kahlenberg, 2006, 2012; Orfield \& Frankenberg, 2011; Orfield et al., 2008; Potter et al., 2016; Reardon et al., 2006; Tefera et al., 2011). School districts promoting 
diversity through student assignment have the option of race- or socioeconomic-based student assignment (Diem, 2012; Diem \& Frankenberg, 2013; Frankenberg, 2013; Frankenberg et al., 2003; Kahlenberg, 2006, 2012; Orfield, 2001; Orfield \& Frankenberg, 2011; Orfield et al., 2008; Potter et al., 2016; Reardon et al., 2006; Tefera et al., 2011). Race-based student assignment is beneficial to students and communities, as the integration of students promotes racial understanding, reduces prejudice, and prepares students for a diverse workforce (Diem, 2012; Diem \& Frankenberg, 2013; Frankenberg, 2013; Frankenberg et al., 2003; Orfield, 2001; Orfield \& Frankenberg, 2011; Orfield et al., 2008; Orfield et al., 2014; Reardon et al., 2006; Tefera et al., 2011). Developed on student race, race-based plans establish thresholds for school populations to create diverse student bodies and prevent schools from becoming segregated. Race-based student assignment plans are necessary to establishing and maintaining integrated schools, and plans developed without the consideration of race isolate students and have negative educational and societal implications (Diem, 2012; Diem \& Frankenberg, 2013; Frankenberg, 2013; Frankenberg et al., 2003; McDermott et al., 2014; Orfield, 2001; Orfield \& Frankenberg, 2011; Orfield et al., 2008; Orfield et al., 2012; Orfield et al., 2014; Reardon et al., 2006; Tefera et al., 2011).

Similar to race-based plans, socioeconomic-based student assignment integrates school populations, but student socioeconomic status is the diversity measure in place of race (Diem, 2012; Kahlenberg, 2006, 2012; Potter et al., 2016; Reardon et al., 2006). Socioeconomic-based integration is established on the ideology that higher economic students excel academically, are college minded, are supported by parents who provide early educational opportunities and academic resources, and have access to more highly 
qualified teachers. Additionally, access to higher performing peers establishes an academic-oriented environment, promotes academic growth among peers, and reduces distractions in classrooms associated with low-socioeconomic students (Kahlenberg, 2006, 2012; Potter et al., 2016; Reardon et al., 2006; Rumberger \& Palardy, 2005). Socioeconomic-based student assignment considers socioeconomic integration as an effective tool for establishing racial integration, while also promoting student achievement by placing high-poverty students in low-poverty schools where peers and parents promote academic success (Kahlenberg, 2006, Kahlenberg, 2012; Potter et al., 2016; Reardon et al., 2006; Rumberger \& Palardy, 2005). Thus, socioeconomic-based plans promote racial diversity but are focused more on academic achievement associated with higher economic levels than racial integration (Kahlenberg, 2006, 2012; Potter et al., 2016). Integrating schools brings together a variety of student-level factors to form a student population. Beginning with the Equality of Educational Opportunity (Coleman et al., 1966), also known as the Coleman Report, the remaining literature in this section focuses on the impact of student-level factors on student achievement.

\section{The Coleman Report}

Released in 1966, the Equality of Educational Opportunity (Coleman et al., 1966) examined the effects of the segregation of ethnic-minority students by surveying public school administrators, teachers, and students from 4,000 schools. Although additional and more recent studies on student and school backgrounds have been conducted since 1966, Coleman et al.'s (1966) findings serve as the seminal artifact for this study. The data collection process allowed over 600,000 students to provide information on their socioeconomic status, parent education levels, and access to resources such as literature 
and reference materials. The findings of the report provided a bleak educational outlook for ethnic-minority students. Lower family socioeconomic status, lower levels of educational attainment, and limited access to educational resources were just some of the differences when comparing ethnic-minority to White students (Coleman et al., 1966). Upon examination of school-level characteristics, Coleman et al. revealed larger class sizes, fewer resources, inadequate access to science and language laboratories, and sparse academic and extracurricular programs as some of the obstacles facing students in majority-minority schools. Further increasing the educational gap between White and ethnic-minority students was a deficit of highly qualified teachers and higher rates of teacher mobility and turnover in schools with a majority-minority population (Coleman et al., 1966).

Coleman et al. (1966) also exposed an academic achievement gap between ethnicminority and White students that widened from Grade 1 to Grade 12. The achievement gap was partially attributed to school socioeconomic status, which correlated to lower poverty schools outperforming higher poverty schools (Coleman et al., 1966). The achievement gap between White and ethnic-minority students also revealed that White students were less affected by the composition of a school when compared to ethnicminority students; thus, teacher quality was more critical for ethnic-minority students than White students (Coleman et al., 1966). Similarly, the educational and family background of students had a significant effect on student achievement, and the influence was strongest for ethnic-minority students. White students who were strongly supported at home were found to thrive regardless of their classmates' background, whereas ethnic- 
minority students benefited from being moved into schools with students who received strong family and educational support (Coleman et al., 1966).

Finally, Coleman et al. (1966) provided findings supporting the integration of schools. White students were revealed to have higher attendance rates and a dropout rate half that of the ethnic-minority rate, and ethnic-minority students who experienced integrated schools earlier in their education were more stable and outperformed ethnicminority students who entered integrated schools at an older age (Coleman et al., 1966). However, school district assignment plans offered little support for the integration of students at the elementary level, as the plans were designed around segregated neighborhood resides (Coleman et al., 1966). Integrated student assignment plans were reported as prevalent at the secondary level, as middle and high schools were the appropriate age to integrate students (Coleman et al., 1966).

Similar to Coleman et al. (1966), this study examined student-level factors, with a specific focus on family education levels, student race, and socioeconomic status. Orfield and Frankenberg (2011) recommended a student assignment plan for JCPS that reached beyond student race to include parent education levels and socioeconomic status. The recommendation also set diversity designations founded on student-level factors for each neighborhood (Orfield \& Frankenberg, 2011). The next section reviews literature related to the student-level factors found in the Orfield and Frankenberg recommendation and examines their impact on academic performance.

\section{Family Education, Race, and Socioeconomic Status}

Prior to beginning their education, children experience 3-5 years of developmental influences through contact with members of their family and 
neighborhood (Brooks-Gunn, Duncan, Klebanov, \& Sealand, 1993). As children mature, they learn their basic developmental skills through interactions with adults and children in social structures, such as family and neighborhoods, even before reaching the age to attend school (Brooks-Gunn et al., 1993). The home environment, defined by the number of parents and siblings in the household as well as parent education, is influential on the intellectual development in children as young as 3 years old (Brooks-Gunn et al., 1993). Depending on the family and neighborhood, the developmental experiences may vary considerably. Single-parent versus two-parent households, single child versus multiple siblings in a family, and low levels versus higher levels of educational accomplishment of parents provide different foundational experiences in a child's development (BrooksGunn et al., 1993). Hence, unless all students in a student population have the same family composition and parent education attainment levels, then variance in childhood development exists in the student population. Understanding how a variance in childhood development impacts academic achievement is the next course of this literature review.

Beginning with IQ and behavioral development, Brooks-Gunn et al. (1993) revealed that family income and maternal education levels were significantly associated with IQ (adjusted $R^{2}=.32$ ) and behavioral development (adjusted $R^{2}=.08$ ). The culminated findings actually suggested that family income had a stronger influence on IQ and behavioral development than a mother's education (Brooks-Gunn et al., 1993). Furthering the examination of family composition and childhood development, DavisKean (2005) also reviewed the influence of parent education and income on childhood academic achievement. Consistent with Brooks-Gunn et al., parent education and income 
were found to be moderately correlated to academic support and achievement, and higher levels of parental education attainment were associated with increased academic expectations for their children (Davis-Kean, 2005). Unlike Brooks-Gunn et al., DavisKean found a parent's educational level as a stronger predictor of a child's academic support and expectations compared to family income. Family socioeconomic status was moderately correlated to academic achievement in children, but parent education achievement was found to overcome financial strain (Davis-Kean, 2005). Parents who attended college positively influence their children's GPA, mathematics, and reading performance (Brooks-Gunn et al., 1993; Davis-Kean, 2005; Duncan, 1994; Israel, Beaulieu, \& Hartless, 2001). Additionally, parents with higher levels of educational achievement established higher but realistic academic expectations for their children (Brooks-Gunn et al., 1993; Davis-Kean, 2005; Duncan, 1994; Israel et al., 2001).

The effects of parent income and education also varied when accounting for race. Datcher (1982) revealed that White families averaged 11.1 years of education, whereas the average African American family was less, at 9.6 for males and 9.7 years for females. African American families also earned an average income of $\$ 4,000$ lower than White families, and lived in neighborhoods with a lower average income than White families (Datcher, 1982). A more recent study by the National Center for Children in Poverty (NCCP, 2006) also revealed an imbalance between White and ethnic-minority educational and economic attainment. According to the NCCP (2006), approximately 30 million, or $41 \%$, of U.S. children identified with an ethnic-minority group, and the educational attainment of their parents varied greatly when compared to White parents. Specifically, $73 \%$ of White children's parents had attained some college education, 
whereas 51\% of African American and 35\% of Latinx children had parents with some college education (NCCP, 2006). However, the attainment of a college education did not directly correlate to family income, as $18 \%$ of White, $44 \%$ of African American, and $40 \%$ of Latinx children lived in low-income families even when parents possessed some college education (NCCP, 2006). Moreover, $13 \%$ of White, $30 \%$ of African American, and 32\% of Latinx children lived in low-income households where parents possessed some college and were full-time employed (NCCP, 2006). Thus, African American and Latinx children lived in poverty at higher rates than White children even when their parents had some college education.

Duncan (1994) revealed that the influence of family socioeconomic status and parental education attainment was responsible for approximately $25 \%$ of the variance in academic achievement for White males and females and approximately $14 \%$ for African American males and females. The influence of family socioeconomic status on academic achievement was outweighed by parent education, but children born into financially affluent families had access to more educational resources and were raised by parents with higher educational achievement (Dornbusch, Ritter, \& Steinberg, 1991; Duncan, 1994; Israel et al., 2001). It is important to note that although parent education and socioeconomic status were influential to children, African American males were least influenced. Additionally, African American males and females saw a decrease in educational achievement when the mother was employed (Duncan, 1994; Israel et al., 2001). The influence of family socioeconomic status, however, faded as children reached adolescence and was replaced by the influence of neighborhood and school socioeconomic status (Duncan, 1994; Israel et al., 2001). 


\section{Neighborhood Education, Race, and Socioeconomic Status}

Since Coleman et al. (1966) published the effects of neighborhoods on student achievement, multiple studies have focused on neighborhood environment and structures associated with adolescent development and behavior. Through the use of a hierarchical linear regression, Garner and Raudenbush (1991) controlled for family effects and student aptitude to reveal a negative correlation between neighborhood poverty and educational attainment. Before controlling for student backgrounds, almost $20 \%$ of the variance in educational attainment was found between neighborhoods, but that number increased to $34 \%$ when also controlling for student backgrounds and the effects of schools (Garner \& Raudenbush, 1991). An increase of families with low-socioeconomic backgrounds was found to enhance the negative influence of neighborhood poverty (Brooks-Gunn et al., 1993; Garner \& Raudenbush, 1991).

Even before Garner and Raudenbush (1991) conducted their analysis on the effects of neighborhoods, Datcher (1982) used regression models to examine the relationship of parent education, family income, and neighborhood factors to educational attainment. The results of the regression analysis found the average neighborhood income accounted for approximately $25 \%$ of the variance in educational attainment, within- and between-race, for African American and White males (Datcher, 1982). Moreover, the variance in educational attainment between low- and high-poverty neighborhoods increased as the level of neighborhood poverty increased (Datcher, 1982). Those studies as well as others from the same time period confirmed that the presence of affluent neighbors promoted the importance of educational attainment and influenced positive student performance for White males as well as White and African American 
females (Brooks-Gunn et al., 1993; Datcher, 1982; Dornbusch et al., 1991; Duncan, 1994; Garner \& Raudenbush, 1991). Lastly, association with affluent neighbors also expanded the influence of family socioeconomic status and parent education levels (Brooks-Gunn et al., 1993; Datcher, 1982; Dornbusch et al., 1991; Duncan, 1994; Garner \& Raudenbush, 1991).

Since school districts vary in their geographic setting and students are found to reside in rural and urban settings, McLoyd (1998) examined the locations of residences along with the composition of neighborhoods. Family and neighborhood poverty was revealed to be more prevalent in urban and ethnic-minority neighborhoods compared to White suburban neighborhoods, and higher poverty was associated with lower results on intelligence exams and academic achievement (McLoyd, 1998). Although racial integration trends since 1980 have resulted in neighborhoods that are economically and educationally diverse, White families have tended to reside in lower poverty neighborhoods than African American families (Charles, 2003; Diem \& Frankenberg, 2013; Frankenberg, 2013; Frankenberg et al., 2003; Orfield, 2001; Orfield et al., 2012; Orfield et al., 2014; Tefera et al., 2011). Upon examination and analysis of 1970, 1980, and 1990 U.S. census data, Mayer (2002) found that affluent neighbors were beneficial to low-income children, and children raised in high-poverty neighborhoods often lacked educational attainment and resources. Consistent with the prior research of Dornbusch et al. (1991) and McLoyd, Mayer revealed that economic segregation between census tracts increased the disparity in quality education. As neighborhoods became more economically segregated, high-income children gained additional access to high-quality education, while low-income students lost access (Dornbusch et al., 1991; Mayer, 2002; 
McLoyd, 1998). Hence, a growing economic divide between neighborhoods has led to imbalanced access to educational support and resources.

Furthering the results of Mayer (2002) and McLoyd (1998), Squires and Kubrin's (2006) analysis of U.S. Census data from 1990 and 2000 discovered that neighborhood integration of African American families moving into predominately White neighborhoods increased approximately $9 \%$ during the decade. Moreover, neighborhoods in suburban areas were found as traditionally White and had higher incomes when compared to urban neighborhoods (Squires \& Kubrin, 2006).

Neighborhoods also ranked differently in educational and social opportunities because of the wealth and race of residents (Squires \& Kubrin, 2006). The analysis of the imbalance in neighborhood composition revealed affluent environments as more beneficial in the fundamental development of cognitive abilities (Squires \& Kubrin, 2006). Essentially, children raised in neighborhoods with more affluent neighbors exhibited increased opportunities to associate with stable families, were exposed more often to successful business professionals, and had increased access to more advanced educational settings (Brooks-Gunn et al., 1993; Datcher, 1982; Dornbusch et al., 1991; Duncan, 1994; Garner \& Raudenbush, 1991; Mayer, 2002; McLoyd, 1998; Squires \& Kubrin, 2006). African American males were also positively influenced by affluent neighborhoods, but the influence existed most often if the neighbor residents were African American (Duncan, 1994). The absence of affluent role models and limited access to supplemental academic resources were more prevalent in lower income neighborhoods (Brooks-Gunn et al., 1993; Datcher, 1982; Dornbusch et al., 1991; Duncan, 1994; Garner \& Raudenbush, 1991; Mayer, 2002; McLoyd, 1998; Squires \& Kubrin, 2006). Thus, the presence of role 
models positively influenced student achievement, but unfortunately, affluent role models were least found in low-income neighborhoods.

The poverty level of neighborhoods moved beyond providing access to highquality education by also providing structures that influenced student academic behavior (Ainsworth, 2002; Mayer, 2002; Squires \& Kubrin, 2006). Though the socioeconomic status of the family was a strong predictor of student performance on mathematics and reading achievement, the presence of high-income neighborhood residents extended the influence of family, as residents helped provide a stable environment in which students exhibited positive academic behaviors, such as more time spent on homework (Ainsworth, 2002). The poverty level of neighborhoods was associated with parental educational involvement, and increased neighborhood poverty levels mediated parental practices and negatively influenced achievement in mathematics (Catsambis \& Beveridge, 2001). Neighborhood low-socioeconomic status was negatively related to academic and behavior supervision (Catsambis \& Beveridge, 2001). Hence, the presence of stable neighbors provides a network wherein children gain pragmatic knowledge that bolsters educational performance (Ainsworth, 2002; Catsambis \& Beveridge, 2001; Mayer, 2002; Squires \& Kubrin, 2006).

Students from high-socioeconomic neighborhoods have increased rates of high school graduation when attending high-socioeconomic schools (Owens, 2010). Conversely, students from low-socioeconomic neighborhoods have lower rates of high school graduation even when attending high-socioeconomic schools. This suggests that students from low-socioeconomic neighborhoods require support when attending highsocioeconomic schools (Owens, 2010). Finally, high-poverty neighborhoods have lower 
rates of educational attainment, which is further reduced in low-socioeconomic schools (Owens, 2010).

Moving from high-poverty to low-poverty neighborhoods is academically beneficial for adolescent male students when compared to students in high-poverty neighborhoods (Leventhal \& Brooks-Gunn, 2004). Although some student behaviors may minimize the influence of lower poverty neighborhoods on achievement (Sanbonmatsu, Kling, Duncan, \& Brooks-Gunn, 2006), students in low-poverty neighborhoods generally spent more time on homework and attended safer schools (Leventhal \& Brooks-Gunn, 2004; Sanbonmatsu et al., 2006). Male adolescent students who moved from high-poverty to low-poverty neighborhoods were also more likely to be retained in elementary school or placed in special education courses because of increased academic standards in low-poverty schools (Leventhal \& Brooks-Gunn, 2004). Policies concentrated on educational improvement should reach beyond school improvement and address neighborhood and community deprivation (Garner \& Raudenbush, 1991; Leventhal \& Brooks-Gunn, 2004; Sanbonmatsu et al., 2006).

Fruchter, Hester, Mokhtar, and Shahn (2012) continued the education attainment and achievement discussion by examining the impact of neighborhood income and racial composition on student college readiness. Upon examination, students from highminority and high-poverty neighborhoods produced lower rates of college readiness when comparing neighborhoods in New York City (Fruchter et al., 2012). When analyzed separately, high-minority and low-income neighborhoods were independently significant predictors of lower college-readiness rates (Fruchter et al., 2012). Students living in high-minority neighborhoods produced lower levels of academic achievement in 
mathematics and reading, which resulted in higher dropout rates (Fruchter et al., 2012;

Israel et al., 2001). Equally, low-minority and high-income neighborhoods were significant predictors of higher rates of college readiness (Fruchter et al., 2012; Israel et al., 2001).

The literature presented on the influence of family, race, and neighborhood provides a foundation for supporting the claims of Coleman et al. (1966) that family and neighborhood factors impact the performance of students. The magnitude of the influence of student-level factors was examined in Sirin's (2005) meta-analysis that focused on the association of socioeconomic status and academic achievement. The student-level factors of parent education (.30), parent occupation (.28), parent income (.29), NSLP eligibility (.33), and neighborhood characteristics (.25) were found to have a significant influence on student achievement (Sirin, 2005). Moving beyond student-level factors, Sirin also examined the effect size of school-level characteristics; grade level (.28), ethnic-minority status (.24) and school location (.25) served as moderating variables and were also large. The overall results of the analysis revealed a positive association between student- and school-level characteristics that are significant to student achievement. However, since the effect sizes of school-level characteristics are smaller than the student-level characteristics, extended time in the educational environment may be necessary to impact student achievement (Sirin, 2005). Therefore, the final section of the literature review focuses on the influence of school composition and poverty to better understand the influence of schools.

\section{Summary of Student-Background Literature}

The review of literature on students' backgrounds has presented a multitude of 
concepts to contextualize the influence of student development and backgrounds on student achievement. This concise review efficiently summarizes the current body of literature.

Diversity in student background often results because of variation in developmental influences through family and neighborhood experiences when the students are 3-5 years of age (Brooks-Gunn et al., 1993). As children mature, they obtain developmental skills through interaction with adults and children in family and neighborhood structures (Brooks-Gunn et al., 1993). Early research identified parental education attainment and socioeconomic status as two major factors that influence childhood development and student achievement (Brooks-Gunn et al., 1993; Davis-Kean, 2005; Dornbusch et al., 1991; Duncan, 1994; Israel et al., 2001). Specifically, parental education and socioeconomic status were moderately correlated to student academic support and achievement (Brooks-Gunn et al., 1993; Davis-Kean, 2005; Duncan, 1994; Israel et al., 2001) and were found to influence IQ and behavioral development (BrooksGunn et al., 1993). The influence of parental income and education explained approximately $25 \%$ of the variance in academic achievement for White males and females and approximately 14\% for African American males and females (Duncan, 1994). Parental education attainment was associated with increased academic expectations for students (Brooks-Gunn et al., 1993; Davis-Kean, 2005; Duncan, 1994; Israel et al., 2001). Finally, 51\% of African American and 35\% of Latinx children had parents with at least some college, compared to $73 \%$ of White children, and $44 \%$ of African American and $40 \%$ of Latinx children lived in low-income families, compared to $18 \%$ of White children (NCCP, 2006). 
Social structures beyond the family also have an influence on student academic achievement, as a negative correlation exists between neighborhood poverty and educational attainment (Brooks-Gunn et al., 1993; Datcher, 1982; Dornbusch et al., 1991; Duncan, 1994; Garner \& Raudenbush, 1991). An increase of families with lowsocioeconomic backgrounds enhanced the negative influence of neighborhood poverty. The presence of affluent neighbors, however, promoted the importance of educational attainment and influenced positive student performance as affluent neighbors expanded the influence of family socioeconomic status and parent education levels (Brooks-Gunn et al., 1993; Datcher, 1982; Dornbusch et al., 1991; Duncan, 1994; Garner \& Raudenbush, 1991). Children raised in affluent neighborhoods have increased opportunities to associate with stable families, are exposed more often to successful business professionals, and have increased access to more advanced educational settings (Datcher, 1982; McLoyd, 1998; Squires \& Kubrin, 2006).

Low-socioeconomic families and neighborhoods were more prevalent in urban and ethnic-minority neighborhoods (McLoyd, 1998), and neighborhoods in suburban areas were found as traditionally White with higher incomes compared to ethnicminority, urban neighborhoods (McLoyd, 1998; Squires \& Kubrin, 2006). The poverty level of neighborhoods is associated with structures that influence student academic behavior, as the presence of stable neighbors in higher socioeconomic neighborhoods provides a network that bolsters educational performance (Ainsworth, 2002; Catsambis \& Beveridge, 2001; Dornbusch et al., 1991; 2001; Mayer, 2002). Specifically, students in low-poverty neighborhoods spend more time on homework and attend safer schools (Ainsworth, 2002; Leventhal \& Brooks-Gunn, 2004). Additionally, students from low- 
poverty neighborhoods have increased rates of high school graduation when attending high-socioeconomic schools, whereas students from high-poverty neighborhoods have lower rates of high school graduation, even when attending high-socioeconomic schools (Leventhal \& Brooks-Gunn, 2004; Owens, 2010). Finally, students from high-minority and high-poverty neighborhoods produced lower rates of college readiness compared to those of low-minority and low-poverty neighborhoods (Fruchter et al., 2012). When students from a variety of backgrounds are brought together, the influences of their development are combined to form a single student population, and understanding how school composition influences academic performance is the focus of the next section.

\section{School Composition and Poverty}

Regardless of student assignment plan model, school populations are developed by bringing students with a variety of backgrounds together to create a unique student body for each school. This section examines the influence of school composition and school poverty levels on student achievement.

\section{A Nation at Risk}

After the Coleman Report was released in 1966, the findings for the effectiveness of schools, funding of schools, and student assignment plans were analyzed and scrutinized, and in 1983 A Nation at Risk was released by the U.S. Department of Education, further illustrating disparities in public education. Detailing the tribulations of public education, Gardner (1983) revealed the shortfalls in expectations impacting student growth and achievement. These shortfalls existed because of weakened curriculum, lowered expectations for student performance on homework and time spent studying, disorganized teaching of study skills, and unqualified teachers who received 
ineffective training or were recruited from the lower levels of colleges or universities (Gardner, 1983). Though the goal of education is to improve each generation of society, the shortfalls suffered in curriculum, expectations, planning, and teacher quality resulted in an educational experience that established a standard of obtaining the basic minimums of knowledge rather than achieving beyond the standard (Gardner, 1983).

The findings of Coleman et al. (1966) and Gardner (1983) depicted an educational environment suffering from inequities as a result of racial and socioeconomic segregation, wherein students received a substandard education filled with meager academic expectations and bland curricula. Understanding how these noncognitive factors influence academic achievement is essential to developing an effective student assignment or school choice plan. The next section reviews the literature focused on noncognitive influences of academic achievement since Equality of Educational Opportunity and A Nation at Risk.

\section{Composition and Influence of Students}

Over 40 years after Equity of Educational Opportunity was released, Konstantopoulos and Borman (2011) reanalyzed the data for the 12th-grade students original in the 1966 report. The purpose of their analysis and reason for using the same data as Coleman et al. (1966) was to determine if the same conclusions concerning the effect of schools on student achievement would be reached when using multilevel modeling statistical methods.

Konstantopoulos and Borman's (2011) reanalysis was similar to Coleman et al.'s (1966), as the results revealed family socioeconomic status to have a significant impact on mathematics and reading performance. Konstantopoulos and Borman's results also 
supported Coleman et al. by confirming that students who attended higher socioeconomic schools and who had access to more academic resources outperformed their peers in mathematics and reading who attended lower socioeconomic schools with fewer resources. However, when the multilevel modeling analysis was applied to the data, only $24 \%$ of variance in mathematics and only $30 \%$ of the variance in reading achievement was attributed to between-school measures, thus leaving within-school variance at $70 \%$ and higher for mathematics and reading achievement (Konstantopoulos \& Borman, 2011).

When controlling for student-level predictors, Konstantopoulos and Borman (2011) were able to explain $60-80 \%$ of the between-school variance in mathematics, reading, and vocabulary achievement scores. The multilevel analysis found student race and lower socioeconomic status as a negative effect on student performance (Konstantopoulos \& Borman, 2011). Student race explained almost 50\% of the variance in the ethnic-minority versus White achievement scores, which between schools and student socioeconomic status explained approximately $40 \%$ of the variance between schools (Konstantopoulos \& Borman, 2011).

Contrary to Coleman et al. (1966), the variance in mathematics and English achievement results within and between schools suggested that schools had a significant impact on student achievement (Konstantopoulos \& Borman, 2011). Although both analyses attributed variance in student achievement in mathematics and reading to student background factors, an enhanced statistical analysis revealed that schools have an effect on student achievement. Though Coleman et al. minimized the effectiveness of schools in overcoming the influence of student background variables, Konstantopoulos 
and Borman's (2011) findings revealed that school composition, including poverty level and race, and student backgrounds influence student achievement.

\section{Socioeconomic Status and Race}

Prior to the reanalysis by Konstantopoulos and Borman in 2011, analyses of student assignment plans determined race and socioeconomic status to have a significant association with student achievement (Ikpa, 1994). Schools with ethnic-minority enrollment above $90 \%$ were discovered to be negatively associated with student achievement, yet an increase in school-level socioeconomic status was positively associated with student achievement (Ikpa, 1994). Student assignment or school choice plans requiring the integration of students were developed to comply with the holdings in Brown v. Board of Education (1954) and to counteract the negative effects of neighborhood and school segregation (Ikpa, 1994; Orfield, 2001).

Through the analysis of student- and school-level composition data, Caldas and Bankston (1997) revealed that students often exercised their choice to enroll in schools with peers similar racially and socioeconomically. Specifically, schools comprised mostly of ethnic-minority students often attracted the additional enrollment of ethnicminority students. To determine the impact a concentration of ethnic-minority of students had on academic achievement, Bankston and Caldas (1996) analyzed the Louisiana Graduate Exam scores for 10th-grade students. Their findings indicated that student populations comprised mostly of ethnic-minority students had a negative influence on student achievement, as did the rate of participation in the NSLP. However, student race was a stronger predictor. Parent high-socioeconomic status also indicated a 
significant positive effect for student achievement, but this factor had a lesser influence than student race (Bankston \& Caldas, 1996).

Further examining school choice and enrollment, Caldas and Bankston (1997) reviewed influences on enrollment populations. Whereas individual race and the racial composition of a school were strongly correlated (.61), individual student socioeconomic status and school poverty status were also strongly correlated (.48), which indicated that schools with high-poverty students were often excessively comprised of students in poverty (Caldas \& Bankston, 1997). Conversely, low-poverty students disproportionately attended low-poverty schools (Caldas \& Bankston, 1997). When analyzing individual race and poverty level along with school race and poverty level, Caldas and Bankston (1997) found that as the percentage of ethnic-minority population in a school increased, the poverty level of a school increased, with a strong correlation (.73). Upon analysis of Louisiana Graduate Exam scores, individual race and economic status along with a school's percentage of ethnic-minority population and poverty rate were found to have a moderate negative correlation (-.36) on student achievement (Bankston \& Caldas, 1996; Caldas \& Bankston, 1997, 1998). Thus, increases in ethnic-minority populations or poverty populations are common with reduced academic performance (Bankston \& Caldas, 1996; Caldas \& Bankston, 1997, 1998).

Furthering the understanding of the relationship of race and socioeconomic status and student achievement, Caldas and Bankston (1998) analyzed within- and betweenschool variance on the Louisiana Graduate Exam scores of 10th-grade students. Analysis of the achievement gap between ethnic-minority and White students within schools, they found approximately $6 \%$ of variance within schools and $58 \%$ of the variance between 
schools (Caldas \& Bankston, 1998). Including socioeconomic status as a factor increased the between-school variance by $19 \%$, but when student and school socioeconomic status were analyzed separately from race, $47 \%$ of the variance of between-school performance was attributed to socioeconomic status (Caldas \& Bankston, 1998). Hence, student and school socioeconomic status are positively correlated to student achievement (Caldas \& Bankston, 1998). Student and school race accounted for approximately $30 \%$ of the variance between-schools, but socioeconomic status better explained variance in student academic achievement (Caldas \& Bankston, 1998). After 3 years of analysis on student performance on the Louisiana Graduate Exam, student and school minority and socioeconomic levels were found to be significant predictors of student performance (Caldas \& Bankston, 1998). White students from high-socioeconomic families who attended low-poverty and low-minority schools were found to consistently outperform ethnic-minority students from low-socioeconomic families who attended high-poverty and high-minority schools (Bankston \& Caldas, 1996; Caldas \& Bankston, 1997, 1998). Additional investigation into the association of socioeconomic status and student achievement when accounting for student race and the social class found ethnic-minority students consistently scored behind White students in standardized achievement exams (Hedges \& Nowell, 1999). Through the examination and analysis of over 97,000 student scores from 1965-1992, a gap between African American and White student achievement scores was revealed but was found to be tightening at the same rate as the high- and lowsocioeconomic gap in achievement scores (Hedges \& Nowell, 1999). However, a tightening in the achievement gap was more prevalent in the low and middle quadrant of achievement scores and less in the upper quadrant of scores (Hedges \& Nowell, 1999). 
In essence, high-poverty ethnic-minority students were narrowing the distribution of scores, but the distribution had tightened more in the lower quadrant and not to the point of closing the achievement gap with the upper quadrant.

With the understanding that students with comparable socioeconomic backgrounds and race perform similarly in achievement quadrants, Hanushek, Kain, Markman, and Rivkin (2003) examined the ability and influence of student peers at the elementary school level with specific focus on performance in mathematics and reading achievement. When taking into account student race, family socioeconomic status, school race, and school poverty level, the findings revealed a strong and positive association between an individual student's achievement and the achievement of the student's peers (Hanushek et al., 2003). This is not to say that low-performing peers negatively influence student scores, but high-performing peers were more strongly associated with increased student achievement (Hanushek et al., 2003). The analysis revealed that an average increase of .01 standard deviations in peer achievement resulted in an increase of .02 in individual students. The presence of high-poverty peers was found to diminish student achievement growth and have a negative association with student achievement scores, but this association was diminished as the level of student performance increased (Hanushek et al., 2003). Equally, the composition of low- and high-poverty schools has been associated with student achievement, and the ratio of ethnic-minority enrollment also serves as a significant predictor of student performance on standardized mathematic and reading assessments (Borman et al., 2004; Hanushek et al., 2003; Orfield \& Lee, 2005). 
In determining the impact of segregation and the composition of schools at the secondary level, Rumberger and Palardy (2005) used National Education Longitudinal Study data to examine individual- and school-level characteristics on student standardized mathematics, science, reading, and social science exams for over 14,000 students in 913 secondary schools. After conducting the hierarchical multilevel analysis, high-socioeconomic schools were found to have a stronger influence on student achievement than student-level backgrounds (Rumberger \& Palardy, 2005). Examination of peer influences revealed that students who attended high-socioeconomic schools outperformed their low-socioeconomic peers who attended low-socioeconomic schools, and the socioeconomic effect was stronger than the racial effect (Rumberger \& Palardy, 2005). Examining growth in reading, mathematics, science, and history revealed that 40 $80 \%$ of the variability in growth was attributed to student backgrounds, whereas $20-60 \%$ of the variance in growth was credited to the schools (Rumberger \& Palardy, 2005). Additionally, high-socioeconomic schools were found to have more effective supports for improving instruction, enforced high expectations for student engagement and performance, and contained more effective teachers. However, an inflow of lowsocioeconomic students was found to reduce the effects of teacher instruction, high-level expectations, and instructional supports (Rumberger \& Palardy, 2005).

Academic supports for improving student performance also have been analyzed to reveal differences in low- versus high-poverty and ethnic-minority schools. The influence of instruction and school supports was reduced in low-socioeconomic and highminority schools, as students were found to have lower attendance rates, higher dropout rates, and low postsecondary enrollment (Balfanz \& Legters, 2004; Kahlenberg, 2006, 
2012; Potter et al., 2016; Rumberger \& Palardy, 2005). Conversely, Konstantopoulos (2005) revealed that students in high-socioeconomic schools had higher attendance rates, lower secondary dropout rates, and higher postsecondary enrollment rates. High academic expectations and stability were consistent in middle-class and low-poverty schools and were the results of peer influence, parent involvement, and highly qualified teachers (Kahlenberg, 2006, 2012; Konstantopoulos, 2005; Potter et al., 2016; Rumberger \& Palardy, 2005). High-poverty schools have demonstrated success, but only $1 \%$ of high-poverty schools are consistently high performing (Kahlenberg, 2006, 2012). Study of student- and school-level factors on student achievement in mathematics, reading, and science also revealed high-socioeconomic schools to have stronger results in mathematics and reading when compared to low-socioeconomic schools (Konstantopoulos, 2005; Rumberger \& Palardy, 2005). Konstantopoulos's multilevel analysis focused on the variance between high- and low-socioeconomic schools in mathematics, reading, and science revealed an increased variance in the mathematics and reading scores from $10 \%$ in the early 1970 s to approximately $20 \%$ by the early 1990 s.

Continuing the examination of the influence of school composition and poverty while including neighborhood factors, Schwartz's (2010) examination of the effects of neighborhoods and schools on student achievement in elementary school used multilevel modeling to measure to effects of student and school poverty. Specifically, the Maryland State Assessment achievement scores based on high-poverty public housing students who were enrolled in low- or high-poverty schools were examined and analyzed to measure the effect of schools. Low-poverty schools with $20 \%$ or less participation in the NSLP were found most beneficial to high-poverty students. Students who attended schools with 
an NSLP participation of 35\% performed equally to students who attended schools with a participation rate up to $85 \%$ (Schwartz, 2010). When taking neighborhood poverty level and student assignment into consideration, the analysis revealed the highest academic achievement in mathematics and reading was produced by students who lived in lowpoverty neighborhoods and attended low-poverty schools. Additionally, public housing students who resided in high-poverty neighborhoods but attended low-poverty schools outperformed their peers from the same living environment who attended high-poverty schools (Schwartz, 2010). Students who lived in public housing in low-poverty neighborhoods but attended low-poverty schools outperformed their peers from the same living environment who attended high-poverty schools (Schwartz, 2010).

The literature focused on the influence of student-level factors revealed influences of student race and socioeconomic status on academic achievement. Schools comprised of low-minority and low-poverty populations positively influence academic performance, and the positive influence was found to increase with the length of time students spent in low-minority and low-poverty schools (Mickelson, Bottia, \& Lambert, 2013; Schwartz, 2010; Sirin, 2005). Finally, students exposed to low-poverty integrated schools earlier in their academic career experienced a larger positive effect on their academic performance in mathematics and reading (Mickelson et al., 2013; Schwartz, 2010; Sirin, 2005).

\section{Student Support}

In trying to extend the exposure of students to integrated school environments, student assignment plans built upon student race or socioeconomic status blend students from a variety of backgrounds. Angrist and Lang (2004) sought to examine the Boston Metropolitan Council for Educational Opportunity student assignment plan, and 
determined the plan was beneficial to African American students who voluntarily attended suburban schools without negative academic effects to White students. The benefit for African American students, however, was only temporary, as students struggled to meet the high demands of the receiving schools (Angrist \& Lang, 2004). Ethnic-minority students and student from low-socioeconomic backgrounds who were assigned or transferred into schools composed of majority-White or high-socioeconomic backgrounds reported having increased feelings of depression and often required supplemental support from the school (Crosnoe, 2009). Though low-minority and highsocioeconomic schools were found to use highly effective instructional practices and stable teaching staffs, the mathematics and reading achievement of ethnic-minority and high-poverty enrolled in those schools did not match their White and high-socioeconomic peers. However, support from teachers and student extracurricular programs were found to reduce student anxiety and helped prolong student exposure to integrated schools (Crosnoe, 2009).

Understanding the effect of schools on student achievement also requires the examination of the effect of teachers on student achievement. Through the use of multilevel modeling, Konstantopoulos (2005) found teacher effects—such as credentials and instructional methods - to be independent of school characteristics as the withinschool effect was larger than the between-school effect. Teacher effects in mathematics and science performance were influenced more by the students assigned to the teacher as opposed to the school the assigned to the teacher (Konstantopoulos, 2005). However, high-socioeconomic schools were found to have more effective practices and processes for improving instruction and employed more effective teachers who established higher 
expectations for student performance in mathematics, science, reading, and social sciences (Rumberger \& Palardy, 2005). Moreover, when measuring the instructional quality in integrated and segregated schools, the schools that were integrated or segregated were found to have lower instructional quality with less stable teaching staffs, requiring additional funding and training to support teacher improvement (Borman et al., 2004; Orfield \& Lee, 2005).

The examination of the achievement gap between high- and low-poverty schools revealed the effect of teachers in high-poverty schools to be less than teachers in lowpoverty schools (Sass, Hannaway, Xu, Figlio, \& Feng, 2012). When analyzing teacher effectiveness in high- and low-poverty schools separately, the results revealed lowpoverty schools to have a greater number of highly effective teachers, who held more postbaccalaureate degrees and certifications, and a lower teacher mobility rate. However, little variance existed between the most effective teachers in a high-poverty school versus the most effective teachers in low-poverty schools (Clotfelter, Ladd, Vigdor, \& Wheeler, 2007; Sass et al., 2012). The gap in effective instruction in high- versus low-poverty schools was between the least effective teachers who generally possessed less teaching experience than highly effective teachers. The least effective teachers in low-poverty schools were found to be more effective than the least effective teachers in high-poverty schools, and high-poverty schools more often employed inexperienced teachers (Sass et al., 2012).

Similar to the findings of teacher effectiveness, principals in high-poverty schools were found to have graduated from lower grade institutions and scored lower on quality scales than principals from low-poverty schools (Clotfelter et al., 2007). Experienced 
principals with distinguished leadership ratings also attract more effective teachers while reducing teacher mobility and have been positively correlated to higher student achievement (Clotfelter et al., 2007). Schools receiving Title I federal funding require substantial and continuous human and capital support beyond the Title I funds to overcome the magnitude and influence of risk factors associated with high-poverty students in urban areas (Neild \& Balfanz, 2006).

\section{Summary of School Composition and Poverty Literature}

The review of literature on school composition and poverty has presented a multitude of concepts to contextualize the influence of school composition and poverty on student achievement. This concise review summarizes the current body of literature.

Focusing specifically on the findings of Coleman et al. (1966) regarding the effects of school composition and poverty, Konstantopoulos and Borman (2011) confirmed that higher socioeconomic schools positively influenced student performance in mathematics and reading. Specifically, students who attended higher socioeconomic schools outperformed their peers who attended lower socioeconomic schools. The analysis also confirmed that student race and lower socioeconomic status had a negative effect on student performance (Konstantopoulos \& Borman, 2011). However, the variance in mathematics and English achievement results within and between schools suggests that schools have a significant impact on student achievement (Konstantopoulos \& Borman, 2011). Ikpa (1994) also exposed student race and socioeconomic status as having a significant association with student achievement, as schools with ethnicminority enrollment above $90 \%$ were found to be negatively associated with student achievement. Although these findings support Coleman et al. (1966), schools were found 
to have a significant influence on student achievement (Konstantopoulos \& Borman, 2011; Rumberger \& Palardy, 2005).

School choice exercised by parents and students was also associated with school composition and poverty. Students exercised choice options to enroll in schools comprised of similar peers, and populations comprised mostly of ethnic-minority students were found to have a negative effect on student achievement as did the rate of participation in the NSLP (Bankston \& Caldas, 1996; Caldas \& Bankston, 1997). Increases in ethnic-minority populations or poverty populations were also common with reduced academic performance, with school poverty level as the stronger predictor (Bankston \& Caldas, 1996; Caldas \& Bankston, 1997, 1998). Moreover, the ratio of ethnic-minority enrollment significantly predicted performance on standardized mathematic and reading assessments (Borman et al., 2004; Hanushek et al., 2003; Konstantopoulos, 2005; Orfield \& Lee, 2005). A strong and positive association was also found between an individual student's achievement and the achievement of the student's peers (Hanushek et al., 2003). Lastly, high-socioeconomic schools were found to have stronger effects on student achievement than student-level backgrounds (Konstantopoulos, 2005; Rumberger \& Palardy, 2005).

Examining school composition and neighborhood effects, $20 \%$ or less participation in the NSLP was most beneficial to high-poverty students (Schwartz, 2010). Increased rates of NSLP eligibility, between $35 \%$ and $85 \%$, resulted in similar performance across schools in mathematics and reading, and students who lived in lowpoverty neighborhoods and attended low-poverty schools produced the highest results (Schwartz, 2010). Public housing students who resided in high-poverty neighborhoods 
but attended low-poverty schools outperformed their peers from the same living environment but who attended high-poverty schools, and students who lived in public housing in low-poverty neighborhoods but attended low-poverty schools outperformed their peers from the same living environment but who attended high-poverty schools (Schwartz, 2010). Finally, the positive influence associated with school composition was found to increase with the length of time students spent in low-minority and low-poverty schools (Mickelson et al., 2013; Schwartz, 2010; Sirin, 2005).

The examination of school supports revealed that low-minority and highsocioeconomic schools used highly effective instructional practices, but the mathematics and reading achievement of ethnic-minority and high-poverty students enrolled in those schools did not match that of their White and high-socioeconomic peers (Angrist \& Lang, 2004; Crosnoe, 2009). High-socioeconomic schools were also found to have more effective practices and processes for improving instruction and employed more effective teachers who established higher expectations for student performance in mathematics, science, reading, and social sciences (Rumberger \& Palardy, 2005). When analyzing teacher effectiveness in high- and low-poverty schools separately, the results revealed that low-poverty schools had a greater number of highly effective and qualified teachers, but little variance existed between the most effective teachers in a high-poverty school versus the most effective teachers in low-poverty schools (Clotfelter et al., 2007; Sass et al., 2012). Finally, schools receiving Title I federal funding require substantial and continuous human and capital support to overcome the risk factors associated with highpoverty students in urban areas (Neild \& Balfanz, 2006). 


\section{Comprehensive Summary of Literature}

The purpose of this study was to examine the influence of student and school characteristics on students' college readiness, in order to determine the extent to which a race- and socioeconomic-based student assignment plan is related to college readiness. Student background factors have been shown to have a major role in the development and support of students, as the literature demonstrated a strong association of parental educational attainment, family socioeconomic status, and neighborhood socioeconomic status on student achievement. Moreover, the literature revealed a significant influence of schools on student achievement. Specifically, the composition of schools-measured by race and socioeconomic rates_-was associated with student achievement; the rates influenced academic behaviors and student achievement.

In 2001, Kahlenberg and Orfield published articles in which the benefits and shortcomings of socioeconomic- or race-based assignment plans were reviewed (Kahlenberg, 2001; Orfield, 2001). Although Kahlenberg (2001) and Orfield (2001) each argued for the use of either socioeconomic or racial integration, JCPS implemented an assignment plan with aspects of each plan. This study was designed to determine the extent to which a race- and socioeconomic-based student assignment plan is related to college readiness. Further examining the effects of students' backgrounds and school composition on the achievement of college readiness is necessary, as the alignment of college readiness to career readiness demands all students to achieve college readiness before graduating high school (Conley, 2007, 2008).

The reviewed literature addressed the influence of student background and school factors on student achievement. Comprehensively, the findings in the literature clarified 
the variance in achievement resulting from the influences of student background, school, and neighborhood factors. Although the influence of student background and school factors was examined in these prior studies, this study furthers the discussion with the inclusion of a race- and socioeconomic-based student assignment plan to determine its relation to college readiness. The findings of this study contribute knowledge to the influence of race- and socioeconomic-based student assignment plans and may be used by JCPS to examine the district's student assignment and school choice plans as they relate to district college-readiness rates. The influence of student and school factors also may be applied to each school to clarify local college-readiness achievement rates. Moreover, the findings and conclusions may guide school professional development to properly prepare teachers for the noncognitive factors present in students and school populations. Finally, determining the amount of influence resulting from neighborhood factors may benefit Louisville Metro Government and Louisville Metro Housing Authority leaders to help establish maximum neighborhood poverty thresholds.

The following null hypotheses were tested in this study:

$\mathrm{H} 1_{0}$ : There is not a significant influence of student factors on English Language Arts and mathematics achievement.

$\mathrm{H} 2_{0}$ : There is not a significant influence of neighborhood factors on English Language Arts and mathematics achievement.

$\mathrm{H} 3_{0}$ : There is not a significant influence of school factors on English Language Arts and mathematics achievement.

$\mathrm{H} 4_{0}$ : There is not a significant influence of student, neighborhood, and school factors on English Language Arts and mathematics achievement. 


\section{CHAPTER 3}

\section{RESEARCH METHODOLOGY}

The purpose of this study was to examine students' backgrounds and school composition factors within a race- and socioeconomic-based assignment plan to determine the extent the factors are related to college readiness. The findings of the study can be used to support the current JCPS student assignment plan or to guide the use of programs or resources for the improvement of college readiness. This chapter is organized into the following sections: Research Question and Variables, Research Design, Study Participants, Procedures, Data Analysis, and Summary of Methodology.

\section{Research Question and Variables}

The relationship between student background and neighborhood, school composition, and college readiness was addressed by the following research question and variables. The research question was the following: To what extent do student,

neighborhood, and school factors predict college readiness in English Language Arts and mathematics?

The research question was examined through the use of eight independent variables, with ACT English, Mathematics, and Reading serving as the dependent variables. The independent variables were grouped into variable blocks for use in the regression analyses. Table 13 displays the variables of the study, their level of measurement, and the measurement score for each variable. 
Table 13

Independent and Dependent Variables

\begin{tabular}{|c|c|c|c|}
\hline Variable type & Variable & $\begin{array}{c}\text { Level of } \\
\text { measurement }\end{array}$ & $\begin{array}{l}\text { Measurement } \\
\text { indicator }\end{array}$ \\
\hline \multicolumn{4}{|l|}{ Independent } \\
\hline \multirow[t]{7}{*}{$\begin{array}{l}\text { Block 1: Student } \\
\text { background }\end{array}$} & Gender & Nominal & $\begin{array}{l}0=\text { Female } \\
1=\text { Male }\end{array}$ \\
\hline & Race & Nominal & $\begin{array}{l}\text { - African } \\
\text { - American } \\
\text { - Latinx } \\
\text { - White }\end{array}$ \\
\hline & Special education status & Nominal & $0=$ No, $1=$ Yes \\
\hline & $\begin{array}{l}\text { National School Lunch } \\
\text { Program eligibility }\end{array}$ & Nominal & $0=$ No, $1=$ Yes \\
\hline & ACT PLAN Mathematics & Interval & Total score $1-32$ \\
\hline & ACT PLAN English & Interval & Total score $1-32$ \\
\hline & ACT PLAN Reading & Interval & Total score $1-32$ \\
\hline Block 2: School & School composition & Nominal & $\begin{array}{l}0=\text { Non-Title } I, \\
1=\text { Title I }\end{array}$ \\
\hline $\begin{array}{l}\text { Block 3: } \\
\text { Neighborhood }\end{array}$ & $\begin{array}{l}\text { Neighborhood } \\
\text { socioeconomic } \\
\text { designation }\end{array}$ & Nominal & $\begin{array}{ll}\text { - } & \text { Category } 1 \\
\text { - } & \text { Category } 2 \\
\text { - } & \text { Category } 3\end{array}$ \\
\hline \multicolumn{4}{|l|}{ Dependent } \\
\hline Mathematics & ACT Mathematics & Interval & Total score $1-36$ \\
\hline \multirow[t]{2}{*}{ English Language Arts } & ACT English & Interval & Total score $1-36$ \\
\hline & ACT Reading & Interval & Total score $1-36$ \\
\hline
\end{tabular}

\section{Research Design}

A correlational research design was used to examine the predictive utility of student, neighborhood, and school factors in direct relation to students' college readiness in the content domains of English Language Arts and mathematics. The correlational design was appropriate for this study as the purpose was to examine the influence of independent variables to predict the outcome variable of college readiness (Ho, 2014; 
Osborne, 2016; Petrocelli, 2003; Stevens, 2007, 2009). The correlational design provides a predictive equation for the variables, finds relationships between variables, and clarifies the influence of factors on a behavior. Moreover, the correlational design provides a basis to identify the strength of the relationships between predictor and criterion variables, allowing levels of influence to be measured. Effective use of a correlational design requires theoretical support for the inclusion and entry of variables into the model. Intraclass correlation or causal priority directs the inclusion and entry of factors into the model, and failure to provide proper theoretic support may produce inaccurate causal effects (Ho, 2014; Osborne, 2016; Petrocelli, 2003; Stevens, 2007, 2009). The review of literature for this study provided the required theoretic support. Specifically, student background factors, neighborhood poverty and ethnic-minority population rate, and school poverty were related to student achievement.

A research proposal and an Institutional Review Board (IRB) application was submitted to the University of Louisville prior to accessing data and conducting the analysis. Upon approval, the JCPS Office of Data Management provided student-level data with masked identification numbers to conceal the identity of students. Student names and addresses were redacted to protect the identity and privacy of individual students. The data were analyzed, with the results and discussion provided in later chapters.

\section{Study Participants}

Data for the current study were gathered from students enrolled in the 16 comprehensive high schools in JCPS in 2015. During the 2014-15 school year, JCPS enrolled approximately 97,000 students districtwide, with 20,450 of the students being 
educated in the 16 comprehensive high schools used within this study (JCPS, 2014a). On average, the 16 schools were comprised of $42 \%$ African American students, $46.6 \%$ White students, and $11.4 \%$ classified as other ethnicities (JCPS, 2014a). The average enrollment for the 16 schools was almost 1,100 students but ranged from 504-2,066 students (JCPS, 2014a). Approximately 4,500 Grade 11 students who attended the 16 comprehensive schools completed the ACT exam in March 2015, which produced an English, Mathematics, and Reading score for each student. Final data were based on 4,494 Grade 11 students obtained with permission from JCPS, with 4,017 considered usable for this study. Specifically, of the 4,494 students, 466 were removed because they were missing ACT PLAN scores from the 2014 school year, and 13 were removed for missing residential information. An additional 197 students were removed as their reported race was not African American, Latinx, or White. Thus, sample size was finalized at 3,818 students who met all criteria of the study.

Table 14 reports the percentage of student subgroups across neighborhoods represented in this study. Gender groups were split evenly, with $50.2 \%$ of the students reported as female $(n=1,915)$ and $49.8 \%$ reported as male $(n=1,903)$. This varied only slightly when separating students by neighborhood diversity. In particular, there were three categories of neighborhoods in the JCPS student assignment plan designed by Orfield and Frankenberg (2011); neighborhoods denoted as Category 1 were 51.4\% male ( $n=508)$, Category 2 neighborhoods were 50.4\% female $(n=1,026)$, and neighborhoods denoted as Category 3 were $51.5 \%$ female $(n=408)$. Student race for the total sample was primarily White at $57.9 \%(n=2,210)$, with $34.7 \%$ reported as African American $(n=$ $1,325)$, and $7.4 \%$ reported as Latinx $(n=283)$. 
Table 14

Percentage of Student Demographics Represented by Neighborhood Diversity Index

\begin{tabular}{lrrrr}
\hline \multicolumn{1}{c}{ Student group } & $\begin{array}{c}\text { Total } \\
\text { sample }\end{array}$ & Neighborhood & Neighborhood & Neighborhood \\
& & & 2 & 3 \\
\hline Gender & 50.2 & 48.6 & 50.4 & 51.5 \\
$\quad$ Female & 49.8 & 51.4 & 49.6 & 48.5 \\
$\quad$ Male & & & & \\
Race & 34.7 & 72.4 & 25.0 & 12.5 \\
$\quad$ African American & 7.4 & 6.5 & 8.9 & 4.8 \\
$\quad$ Latinx & 57.9 & 21.1 & 66.1 & 82.7 \\
$\quad$ White & 8.7 & 12.9 & 8.2 & 4.7 \\
Special education & 58.4 & 82.9 & 59.3 & 25.5 \\
National School Lunch Program & & & & \\
rate & 48.3 & 58.9 & 53.0 & 10.6 \\
Enrollment rate at Title I school & 48.3 \\
\hline
\end{tabular}

Separating student race by the diversity index revealed a noticeable difference in the proportion of ethnic-minority populations in each neighborhood, and Table 14 reports the highest levels of ethnic-minority populations in Category 1 neighborhoods.

Specifically, Category 1 neighborhoods were found to have a 72.4\% African American population $(n=716)$, with only $21.1 \%$ reported as White $(n=209)$ and $6.5 \%$ reported as Latinx $(n=64)$. Category 2 neighborhoods were the most racially balanced with $66.1 \%$ reported as White $(n=1,345), 25 \%$ reported as African American $(n=510)$, and $8.9 \%$ as Latinx $(n=181)$. Category 3 neighborhoods were found to report the lowest percentage of ethnic-minority students as $82.7 \%$ were reported as White $(n=656), 12.5 \%$ as African American $(n=99)$, and 4.8\% reported as Latinx $(n=38)$.

Students participating in the NSLP or receiving special education services aligned with neighborhood race, as higher ethnic-minority populations reported higher rates of 
financial and educational assistance. Students participating in the NSLP were reported as $58.4 \%(n=2,229)$ for the entire sample. Students receiving special education assistance was reported at $8.7 \%(n=332)$. The NSLP participation rate in Category 1 neighborhoods was reported as $82.9 \%(n=820)$, which was much higher than the total sample average. Similarly, the special education participation rate of $12.9 \%(n=128)$ was also higher than the total sample average. At 59.3\% student participation in the NSLP $(n=1,207)$, Category 2 neighborhoods were closely aligned with the total sample. Percentage of students receiving special education assistance was reported as $8.2 \%$ ( $n=$ 167), which also aligned with the sample average. Lastly, Category 3 neighborhoods had the lowest rate of participation in the NSLP, as $25.5 \%$ of students $(n=202)$ were reported as receiving assistance. The rate of students receiving special education assistance was also lowest in Category 3 neighborhoods, with a participation rate of $4.7 \%$ of students $(n$ $=37)$.

Finally, the rate of students attending schools receiving Title I funding was higher in higher ethnic-minority and poverty neighborhoods. The percentage of students attending Title I schools for the entire sample was reported as $48.3 \%(n=1,844)$, but $68.9 \%$ of students $(n=681)$ from Category 1 neighborhoods were reported as attending Title I schools. Fifty-three percent of students $(n=1,079)$ from Category 2 neighborhoods attended Title I schools, which was also higher than the sample average. Only $10.6 \%$ of students $(n=84)$ from Category 3 neighborhoods were reported as attending Title I schools. Category 3 neighborhoods were the only neighborhoods with Title I enrollment rates below the sample average but were also $58.3 \%$ (or 33.8 percentage points) below Category 2 neighborhoods. This is noteworthy as Category 2 
neighborhoods were designed by Orfield and Frankenberg (2011) as a balance between Category 1 and 3 neighborhoods.

Consistent with the neighborhood descriptions provided by Orfield and Frankenberg (2011), these results revealed the highest levels of ethnic-minority, poverty, special education students reside in Category 1 neighborhoods and attend Title I schools at a higher rate than Category 2 or 3 neighborhoods. Approximately $26 \%(n=989)$ of the sample was from Category 1 neighborhoods, $53 \%(n=2,036)$ was from Category 2, and $21 \%(n=793)$ was from Category 3 neighborhoods.

\section{Procedures}

The data for this study were secured from the JCPS Office of Data Management after approval of the IRB with the University of Louisville. Electronic certifications for the correct use and storage of student data were completed, and a research proposal was submitted, as required by the IRB. Acceptance of the IRB indicates that research participants are protected by observing the good clinical practice guidelines established by the U.S. Food and Drug Administration and the U.S. Department of Health and Human Services (University of Louisville, n.d.). The following information was requested by submitting an electronic request directly to the JCPS Office of Data Management:

- student gender;

- student race;

- student special education status;

- student NSLP participation status;

- neighborhood socioeconomic designation per student; 
- school composition;

- ACT English, Mathematics, and Reading scores per student; and

- ACT PLAN English, Mathematics, and Reading scores per student.

The data were provided with masked student identification numbers, after names and addresses were removed to protect the identity of individual students. The data were produced from the results of the 2015 ACT exam completed by each of the students. Data were analyzed to determine the extent to which student background, neighborhood socioeconomic factors, and school composition predict English Language Arts and mathematics achievement.

IBM SPSS 22 software was used to conduct the analysis. Variables and corresponding data were entered into the software, and a correlational research design produced the final results and tables.

\section{Operationalization of Variables}

This section identifies and describes the variables used in the study and their measurement. Independent variables are described in more detail.

Student race. Student race is provided by parents or guardians upon enrolling a student in JCPS. Student race is selected from seven possible racial designations used by Kentucky and JCPS: Hispanic or Latina/o, American Indian or Alaska Native, Asian, African American, Native Hawaiian or other Pacific Islander, White, or two or more races. For the purpose of this study, student race was limited to African American, Latinx, and White students. The variable was dummy coded for use in the IBM SPSS 22 software. 
Student gender. Student gender is provided by parents or guardians upon enrolling a student in JCPS. Student gender is selected from the options of female or male. Female students were assigned a value of 0 and male a value of 1 .

Neighborhood socioeconomic status. The neighborhood socioeconomic status variable in this study was designed by Orfield and Frankenberg as part of their student assignment plan recommendation to JCPS in 2011. In cooperation with JCPS, Orfield and Frankenberg (2011) recommended a student assignment plan with a neighborhood diversity index that includes neighborhood socioeconomic status. The diversity index is comprised of parent income, parent education, and the percentage of White students for each neighborhood in Jefferson County (Orfield \& Frankenberg, 2011). Table 5 (see Chapter 1) provides the details for the three diversity index categories. Students residing in neighborhoods designated Category 1 experience the lowest levels of income, parent education, and percentage of White population (Orfield \& Frankenberg, 2011). In contrast, students in Category 3 are in neighborhoods with the highest levels of income, parent education, and percentage of White population (Orfield \& Frankenberg, 2011).

The parent education factor of the diversity index is displayed in Table 6 (see Chapter 1). The scores displayed in the table are the weighted values assigned to seven levels of education. Ranging from finished eighth grade or less (value of 1) to doctorate (value of 6), the values assigned to the levels of education increase as parental education attainment increases (Orfield \& Frankenberg, 2011). Orfield and Frankenberg (2011) recommended that JCPS use the following formula to calculate the diversity index for each neighborhood: 
Neighborhood Socioeconomic Designation $=1+.23($ Income Integer $)+$ .33 (Parent Education Integer) +.33 (Race Integer)

The weighted averages are calculated for each of Jefferson County's 540 neighborhoods, and an overall category label is assigned to differentiate each neighborhood (Orfield \& Frankenberg, 2011). Table 7 (see Chapter 1) displays the category labels and the weighted ranges for each category. By using available neighborhood data from 2009, Orfield and Frankenberg (2011) showed 30\% of the neighborhoods were rated as Category 1, 46\% were Category 2, and 24\% were Category 3. In 2012, JCPS adopted an altered version of the plan presented by Orfield and Frankenberg by implementing a race- and socioeconomic-based assignment plan, while continuing the use of magnet programs, traditional schools, and school choice. The variable was dummy coded for use in the IBM SPSS 22 software.

School composition. Title I (from the Elementary and Secondary Education Act of 1965) is the designation given to elementary and secondary schools that receive financial assistance because of the high enrollment percentage of students from lowincome families. The purpose of Title I funding is to assist schools in providing the necessary resources and support to move students toward meeting the academic standards of the school. In accordance with the JCPS (2014e) Title I Local School Guide, schools above $40 \%$ low-income students are designated Title I. Students attending a non-Title I school received a value of 0 , and students attending Title I schools received a value of 1.

Student NSLP eligibility. According to the USDA (2016), the NSLP is a meal assistance program provided by the U.S. federal government. Free or reduced-price meals are provided by schools to students whose family income is within $130-185 \%$ of 
the poverty level (USDA, 2016). Essentially, a student from a family of four would qualify for free meals at school if the family income were between $\$ 30,615$ and $\$ 43,568$ (USDA, 2016). In JCPS parents or guardians are required to submit an annual application showing their family income meets the federal guidelines. Nonparticipating students received a value of 0 , while students participating in the NSLP received a value of 1 .

Special education designation. According to the Americans With Disabilities Act of 1990, students are considered active special education participants if they are receiving educational accommodations by having access to aids and services providing an equal opportunity to participate and benefit from a public education. Regular education students received a value of 0 , and students reported as participating in special education received a value of 1 .

\section{Instrumentation}

ACT exam. The instrument chosen to measure college readiness is the ACT college-readiness assessment, as it is administered annually to all 11th-grade students in JCPS. The ACT exam is the last of a three-test series, preceded by the ACT Explore and ACT PLAN, which are expected to measure student trajectories for college readiness (ACT, 2013a, 2013b, 2014). The ACT exam was developed for 11 th- and 12th-grade students as a measure of college readiness because it measures knowledge of curriculum through the final years of a secondary education (ACT, 2014). As such, the exam is used by many colleges and universities as a measure for admittance. It includes four multiplechoice exams concentrated on English, mathematics, reading, and science curricula, and the results are provided to postsecondary institutions to determine a student's likelihood 
to attain success in entry-level, credit-bearing courses (ACT, 2014).

The composite score produced by the ACT exam ranges from 1-36. The English, Mathematics, Reading, and Science sections are scored independently and produce a raw score that is adapted to the scale score of $1-36$ (ACT, 2014). The scale scores are then averaged to produce the total exam composite score (ACT, 2014). Seven raw subscores are also produced by the English, Mathematics, and Reading sections (ACT, 2014). The subscores are adapted to scale scores ranging from 1-18 for each subsection to indicate performance on specific content. The intended mean of the composite and section scores is 18 and 9 for the subscores (ACT, 2014). Item difficulty ranges from .20 to .89 with a mean of .58 , thus allowing the exam to separate lower and higher academic achieving students (ACT, 2014). Table 15 displays the ACT test sections, the number of items and time allotted for each section, and the subsection content with the number of items (ACT, 2014).

Table 15

ACT Sections, Subsections, and Scores

\begin{tabular}{|c|c|c|c|c|}
\hline Test section & $\begin{array}{l}\text { Total } \\
\text { items }\end{array}$ & Minutes & Subsections & $\begin{array}{l}\text { Subsection } \\
\text { items }\end{array}$ \\
\hline \multirow[t]{2}{*}{ English } & 75 & 45 & Usage/Mechanics & 40 \\
\hline & & & Rhetorical Skills & 35 \\
\hline \multirow[t]{3}{*}{ Mathematics } & 60 & 60 & Pre-Algebra/Elementary Algebra & 24 \\
\hline & & & Intermediate Algebra/Coordinate Geometry & 18 \\
\hline & & & Plane Geometry/Trigonometry & 18 \\
\hline \multirow[t]{2}{*}{ Reading } & 40 & 35 & Social Studies/Science & 20 \\
\hline & & & Arts/Literature & 20 \\
\hline Science & 40 & 35 & No subtests & - \\
\hline
\end{tabular}


The psychometric properties of the ACT have been widely reported. The scores for the ACT exam are measured against nationally normalized scores to increase score reliability (ACT, 2014). The most recent norm analysis was conducted using data from 12,000 students $(2,000$ students in six samples) gathered during national test dates in 2011 and 2012. Norm analyses were also conducted in 1988 with the development of scale scores and again in 1995 when calculators were permitted for use on the mathematics section (ACT, 2014). The norm analysis provides the intended means for the composite, scale, and subscores from 12th-grade students who indicated they would be attending a postsecondary (2- or 4-year) institution (ACT, 2014).

The analysis of the 12,000 exam results produced reliability scores and a standard error of measure for the exam, each of the sections, and the subsections (ACT, 2014). ACT (2014) reported an averaged median standard error of .93 points for the composite score, between 1.50 and 2.09 for the exam sections, and between 1.16 and 1.67 for the subscores. Additionally, the results produced a $68 \%$ confidence interval when adding or subtracting 1 point to a student's composite score or 2 points to section and subscores (ACT, 2014). In essence, less than 1 point of error occurred in $68 \%$ of the composite scores (ACT, 2014). The averaged median reliability for the composite score was .96 , whereas section scores ranged from .83 in Science to .92 in English (ACT, 2014). The reliability of the subscores ranged from .74 to .88 (ACT, 2014). Table 16 displays the score reliability and the standard error of measurement for the ACT test sections and subsections (ACT, 2014). 
Table 16

ACT Score Reliability and Standard Error of Measurement (SEM) 2011-12

\begin{tabular}{|c|c|c|c|c|}
\hline \multirow[b]{2}{*}{ Test section and subsections } & \multicolumn{2}{|c|}{ Reliability range } & \multicolumn{2}{|c|}{ SEM range } \\
\hline & Low & High & Low & High \\
\hline Composite & .96 & .97 & 0.92 & 0.95 \\
\hline English & .92 & .93 & 1.66 & 1.74 \\
\hline Usage/Mechanics & .87 & .89 & 1.27 & 1.38 \\
\hline Rhetorical Skills & .86 & .88 & 1.16 & 1.20 \\
\hline Mathematics & .90 & .92 & 1.43 & 1.60 \\
\hline Pre-Algebra/Elementary Algebra & .83 & .85 & 1.35 & 1.44 \\
\hline Intermediate Algebra/Coordinate Geometry & .72 & .77 & 1.33 & 1.46 \\
\hline Plane Geometry/Trigonometry & .71 & .80 & 1.34 & 1.60 \\
\hline Reading & .86 & .90 & 1.95 & 2.21 \\
\hline Social Studies/Sciences & .77 & .82 & 1.46 & 1.67 \\
\hline Arts/Literature & .77 & .82 & 1.55 & 1.77 \\
\hline Science & .80 & .85 & 1.95 & 2.24 \\
\hline
\end{tabular}

Note. Source: ACT Technical Manual, by ACT, 2014, Iowa City, IA: Author.

Gathering evidence to support the use of test scores for specified purposes is a basic function of the validation process (American Educational Research Association, American Psychological Association, \& National Council on Measurement in Education, 2014). The validity of ACT exam scores hinges on their potential to measure college readiness, which is their specified purpose. ACT (2014) constructs score validity by examining the relationship between ACT performance scores, exam content, and collegereadiness benchmarks. The relationship between ACT performance scores and secondary coursework and grades, as well as the relationship between scores and race, gender, and noncognitive factors, are also examined.

As a valid measure of college readiness, ACT scores and postsecondary grades should be tightly aligned to ACT benchmarks (Camara, 2013; Zwick, 2007). Allen and 
Sconing (2005) examined college course grades through a hierarchical logistical regression and specified ACT scores provided a college student a .50 probability of earning a B or higher in English composition, college algebra, social science, and biology (ACT, 2014; Allen \& Sconing, 2005). Thus, the standard of B or higher was established as the letter grade of college readiness, and the following ACT scores were designated as college-ready benchmarks: English Composition, 18; College Algebra, 22; Reading, 22; and Biology, 23 (ACT, 2014; Allen, 2013; Allen \& Sconing, 2005).

Since the ACT college-readiness exam measures knowledge learned through high school, ACT sought to measure the association of high school coursework, grades, and ACT exam scores (ACT, 2014). Using the results of a 1996 survey in which students reported completed coursework and grades, ACT determined that students completed approximately 30 common English, mathematics, natural science, and social studies courses (ACT, 2014). The results of the hierarchical logistical regression analysis revealed that mathematics, chemistry, and physics courses were significant $(p<.01)$ in explaining variance in ACT scores (ACT, 2014). ACT (2014) used the findings to recommend that students complete 4 years of high school English and 3 years of mathematics, natural science, and social studies courses. The results of the analysis also revealed that grades earned in the suggested coursework explained an additional 25-38\% of variance in ACT scores (ACT, 2014). Together, high school GPA and coursework explained 30-55\% of the variance in ACT scores (ACT, 2014). Thus, higher student GPAs are associated with higher ACT scores (ACT, 2014; Noble et al., 1999a, 1999b; Noble \& McNabb, 1989). Finally, students who completed the minimal recommended core curriculum earned higher ACT scores than students who completed less than the 
core curriculum regardless of race or gender (ACT, 2014; Noble et al., 1999a).

Therefore, the strongest influence on ACT scores is high school coursework and GPA, which confirms the validity of the ACT exam (ACT, 2014; Noble et al., 1999a, 1999b; Noble \& McNabb, 1989; Noble et al., 2006; Noble \& Sawyer, 2002; Sawyer, 1989, 2013).

ACT PLAN. As part of the college-readiness testing series, the ACT PLAN was developed to measure college readiness of 10th-grade students (ACT, 2013b). Similar to the ACT college-readiness exam, the ACT PLAN provides results for English, Mathematics, Reading, and Science multiple-choice exams. Each section of the exam produces composite scores ranging from 1-32 and is related to collegereadiness benchmarks for 10th-grade students throughout the United States (ACT, 2013b). The benchmarks of college readiness for the ACT PLAN are as follows: English, 15; Mathematics, 19; Reading, 18; and Science, 20 (ACT, 2013b). As with the ACT, the ACT PLAN benchmarks project readiness for college credit-bearing courses in English composition, college algebra, social science, and biology (ACT, 2013b, 2014). The results of the ACT PLAN are provided to students and schools to allow for coursework adjustments and assistance before students are administered the ACT their 11th- or 12th-grade year (ACT, 2013b). The validity and reliability of the ACT PLAN and the ACT are consistent as both exams share the same development procedures and the benchmarks are linked to the same college courses (ACT, 2013b, 2014). All participants of this study produced ACT PLAN scores during their 10th-grade year in 2014. 


\section{Data Analysis}

Hierarchical linear multiple regression (HLMR; Ho, 2014; Osborne, 2016; Petrocelli, 2003; Stevens, 2007, 2009) was used to address the research question of the influence of student, neighborhood, and school factors on English Language Arts and mathematics achievement. An HLMR was selected as the data analytic approach because it can be used to determine contribution of student, neighborhood, and school factors to predict college readiness (Ho, 2014; Osborne, 2016; Petrocelli, 2003; Stevens, 2007, 2009). Specifically, three variable blocks were used to examine college readiness. Block 1 was comprised of student-level factors, Block 2 was comprised of school factors, and Block 3 contained neighborhood socioeconomic factors. Proper entry of the variable blocks into the HLMR model is directed by logical or theoretic foundations of the literature (Ho, 2014; Osborne, 2016; Petrocelli, 2003; Stevens, 2007, 2009); therefore, the analysis was conducted after consideration of two different orders of entry.

The first considered order of factor entry was sequential and supported by the reviewed literature. Block 1 would be entered in the model first as race, gender, special education status, and NSLP status, as student-level, foundational factors. The reviewed literature established student-level factors as the initial contributors to child development and academic performance; thus entering Block 1 first was theoretically based. Next, Block 3 would be entered in the model, as neighborhood factors were revealed by the literature as subsequent to individual and family factors for child development and academic performance. Finally, Block 2 would be entered in the model as the schoollevel factors. 
The second considered order of entry was supported by the reviewed literature but was also logically adjusted to reflect the amount of time students spend in an educational setting. Similar to the first order of entry, Block 1 would be entered in the model first, as race, gender, special education status, and NSLP status are student-level, foundational factors. Next, Block 2, comprised of school composition factors, would be entered in the model. Although the literature showed the neighborhood factors in Block 3 to be subsequent to family factors for child development, JCPS students spend at least 7 hours per school day in class and on campus. This amount of time spent in an educational setting logically supported entering Block 2 before Block 3 in the analysis. Finally, Block 3 would be entered in the model. The final determined order of entry for the analysis was based on reviewed literature and logic; thus, Block 1 was entered first, followed by Block 2 and Block 3. The formation of block variables and order of entry clarified the level of influence of the predicting factors on the criterion dependent variable (Ho, 2014; Osborne, 2016; Petrocelli, 2003; Stevens, 2007, 2009).

The results of the HLMR analysis produced a correlational value for $R^{2}$ and $R^{2}$ change (Ho, 2014; Osborne, 2016; Petrocelli, 2003; Shavelson, 1996; Stevens, 2007; Stevens, 2009). $R^{2}$ provides the amount of explained variance a specific block of factors has on the criterion dependent variable (Ho, 2014; Osborne, 2016; Petrocelli, 2003; Shavelson, 1996; Stevens, 2007, 2009). The $R^{2}$ value was provided for Blocks 1, 2 , and 3 independently. $R^{2}$ change was provided after Blocks 2 and 3 were entered in the model to reveal any additional clarification of variance of the factors on the dependent variable (Ho, 2014; Osborne, 2016; Petrocelli, 2003; Stevens, 2007, 2009). Finally, the $F$ and $F$ change test provide a basis to judge the significance $(p<.05)$ of each variable block 
entered into the regression analysis (Ho, 2014; Osborne, 2016; Petrocelli, 2003; Stevens, 2007, 2009). The unstandardized regression coefficients, reported as B, revealed the score differences of the independent variables on the dependent variables (Ho, 2014; Stevens, 2007, 2009). Corresponding $t$ statistic and $p$ values for each unstandardized coefficient determined if any reported differences in B scores were statistically significant (Ho, 2014; Shavelson, 1996; Stevens, 2007, 2009). In essence, the B scores revealed actual score differences in the ACT exam scores, and the $t$ statistic and $p$ values determined if the score differences were significant. The HLMR was conducted by entering the data into IBM SPSS 22 software. The following null hypotheses were tested in this study:

H10. There is not a significant influence of student factors on English Language Arts and mathematics achievement.

$\mathrm{H} 2_{0}$. There is not a significant influence of neighborhood factors on English Language Arts and mathematics achievement.

$\mathrm{H} 3_{0}$. There is not a significant influence of school factors on English Language Arts and mathematics achievement.

$\mathrm{H} 4_{0}$. There is not a significant influence of student, neighborhood, and school factors on English Language Arts and mathematics achievement.

\section{Outputs of HLMR}

The HLMR analysis in the IBM SPSS 22 software produced a variety of statistical data and tables to explain the relationship between student background, school poverty, and college-readiness rates. The following outputs were provided and discussed. 
Model summary. The model summary presents the $R^{2}$, adjusted $R^{2}, R^{2}$ change, the standard error or estimate, and $F$ change to clarify the explained variance and significance of the predictor variables in the model. $R^{2}$ and adjusted $R^{2}$ clarify the amount of variance of each independent variable on the dependent variables, and highly predictive variables are reported closely to 1 (Ho, 2014; Osborne, 2016; Petrocelli, 2003; Shavelson, 1996; Stevens, 2007, 2009). $R^{2}$ change is presented to clarify the change in variance on the dependent variables as each independent variable entered the model (Ho, 2014; Osborne, 2016; Petrocelli, 2003; Stevens, 2007, 2009). Next, the standard error of estimate is provided for each model as a measure of accuracy of the predictions made by the regression equation. To demonstrate accuracy, $95 \%$ of the cases should fall within 1.96 standard deviations above or below the mean (Shavelson, 1996). Finally, $F$ change is provided to measure the explanatory power and its significance as the independent variables were added to the model (Ho, 2014; Osborne, 2016; Petrocelli, 2003; Shavelson, 1996; Stevens, 2007, 2009).

Analysis of variance (ANOVA) table. The ANOVA table provides information to measure the level of significance of the prediction equation used to test the study hypotheses. The $F$ statistic value explains the distance of the results from the hypotheses. A higher $F$ statistic indicates a larger influence of the independent variables on the dependent variables. A $p$ value less than .05 verifies that the $F$ is statistically significant (Ho, 2014; Osborne, 2016; Petrocelli, 2003; Shavelson, 1996; Stevens, 2007, 2009).

Unstandardized coefficients. The unstandardized regression coefficients, B, reveal the raw score differences of the dependent variables after the independent variables are added to the model (Ho, 2014; Osborne, 2016; Petrocelli, 2003; Stevens, 
2007, 2009). The raw score differences produced in this study clarified the change in ACT scores resulting from the influence of the unstandardized coefficient.

\section{HLMR Assumptions}

Properly conducting an HLMR analysis requires certain assumptions to be met to ensure validity of the results. These are described in detail.

Multicollinearity. Defined as an intercorrelation of the predictors, multicollinearity between predictors reduces a predictor's influence on the dependent variable and limits the size of the $R^{2}$ (Ho, 2014; Osborne, 2016; Petrocelli, 2003; Shavelson, 1996; Stevens, 2007, 2009). The predictors are inserted into the model, and a variance inflation factor of less than 10 is commonly desired by researchers (Ho, 2014; Osborne, 2016; Shavelson, 1996; Stevens, 2007, 2009). A variance inflation factor value greater than 7 indicates a possible conflict of collinearity between independent factors and may result in the removal or combining of factors (Ho, 2014; Osborne, 2016; Stevens, 2007, 2009). Highly correlated variables should be combined or removed for model accuracy (Ho, 2014; Osborne, 2016; Petrocelli, 2003; Shavelson, 1996; Stevens, 2007, 2009).

Linearity. Since this was a correlational analysis, the independent and dependent variable scores should appear to have a linear distribution (Ho, 2014; Osborne, 2016; Petrocelli, 2003; Shavelson, 1996; Stevens, 2007, 2009). Nonlinearity and nonconstant variance are violations of the linearity assumption and require an adjustment to the multiple regression model (Ho, 2014; Osborne, 2016; Petrocelli, 2003; Shavelson, 1996; Stevens, 2007, 2009). The IBM SPSS 22 software allows residuals to be entered into a 
normal probability plot, and the use of the fitted line allows the residuals to be examined for linearity.

Homoscedasticity. The normal distribution of scores in the population was observed in the residuals plot provided by the IBM SPSS 22 software. Scores should appear normally distributed at the 0 line of the residuals plot (Ho, 2014; Osborne, 2016; Petrocelli, 2003; Shavelson, 1996; Stevens, 2007, 2009). The IBM SPSS 22 software allows residuals to be entered into a normal probability plot, and the use of the fitted line allows residuals to be examined for consistency along the line.

Outliers. Outlier data for the predictors and the dependent variables overly influence the $R^{2}$. Cook's distance is used to measure the influence of outlier data and the impact of the regression (Stevens, 2007, 2009). Data with a Cook's distance greater than 1 are considered large and inclusion in the study is evaluated (Stevens, 2007, 2009). The output from IBM SPSS 22 provides a standardized residual table to be used in unison with Cook's distance. Normal distribution on the residuals table should be within 2 standard deviations (Stevens, 2007, 2009).

Independence of error terms. The predicted values produced by the HLMR are required to be independent (Ho, 2014; Stevens, 2007; Stevens, 2009). Autocorrelation occurs when residuals are not independent of the others, and a Durbin-Watson test score between 1.5 and 2.5 indicates independence of error (Ho, 2014).

The $\boldsymbol{n} / \boldsymbol{k}$ ratio. The suggested minimum of 15 cases to each predictor variable (Osborne, 2016; Shavelson, 1996; Stevens, 2007, 2009) in the HLMR analysis was met, with 8 predictor variables used in each analysis containing 3,818 cases, which had an $n / k$ ratio of 477.3:1 for each analysis. A total of three regression analyses were conducted 
with ACT English, ACT Mathematics, and ACT Reading serving separately as the dependent variable in each analysis.

\section{Summary of Methodology}

The purpose of the current study was to examine the influence of student and school characteristics on students' college readiness, in order to determine the extent to which a student assignment plan based on student race and socioeconomic status is related to students' college readiness. The analysis of the study was conducted through a HLMR with three blocks of independent variables and three dependent variables. The HLMR was chosen for this study because students exist within multiple structures (Ho, 2014; Osborne, 2016; Petrocelli, 2003; Stevens, 2007, 2009). This study includes participants who are nested in families, neighborhoods, and schools. The HLMR measures the variance on college readiness influenced by the factors of each structure and clarifies changes in variance resulting from the inclusion of each structure (Ho, 2014; Osborne, 2016; Petrocelli, 2003; Stevens, 2007, 2009). The hierarchy of the model relies on the literature supporting the development of students occurring initially at the family level, followed by schools and neighborhoods (Ho, 2014; Osborne, 2016; Petrocelli, 2003; Stevens, 2007, 2009). The results of the analysis are rooted in the reviewed literature and provide clarity as to the influence of student, neighborhood, and school factors on college readiness.

The use of HLMR in this study does come with some limitations. Students nested in structures are often similar (Osborne, 2016). In this study, all students were nested within JCPS because they all resided within Jefferson County, Kentucky. The random selection of students nationwide might produce different rates of influence for the factors 
included in this study. Nesting of participants from the same county also reduced the level of independence of the factors (Osborne, 2016). Although the factors in this study were independent, each factor was nested in Jefferson County. Again, the random sampling of students from larger or several school districts might produce a change in results (Osborne, 2016). Finally, the factors included in this study are not considered all inclusive. The limitations of this analysis do not invalidate the results but recognize that generalization to other populations may not be completely aligned. Chapters 4 and 5 provide the results of the analysis and discuss their implications. 


\section{CHAPTER 4}

RESULTS

The study purpose was to examine the influence of student and school characteristics on students' college readiness. This chapter reports study findings addressing the following research question: To what extent do student, neighborhood, and school factors predict college readiness in English Language Arts and mathematics? Descriptive and inferential statistics were used to address the study research question. First, descriptive statistics are reported regarding the characteristics of the sample. Second, the results of three separate HLMR analyses are reported for the prediction of ACT English, Mathematics, and Reading scores. Collectively, the analyses explain the variance in ACT performance and determine the amount of influence the JCPS student assignment plan has on college readiness.

\section{Descriptive Statistics}

Descriptive statistics were used to understand characteristics of the students for whom data were obtained. In particular, measures of central tendency and variability were used to examine characteristics of the students and their performance by sample and neighborhood on the ACT college-readiness exams.

Table 17 reports ACT PLAN scores obtained by the students during the 2013-14 school year. The results of the total sample showed an average score of 15.3 for PLAN English, 16.0 for PLAN Mathematics, and 15.8 for PLAN Reading sections. However, a difference in the results was revealed when the scores were separated by neighborhood 
diversity index. Category 1 neighborhoods scored below the sample average by 1.6 to 2 average points for each PLAN test section, and Category 3 neighborhoods scored above the sample average by 2.2 to 2.5 average points. The reported means revealed an achievement gap between neighborhoods of almost 4 average points. PLAN scores from students in Category 2 neighborhoods were also found to be below the average Category 3 neighborhood scores, but the Category 2 scores aligned with the total sample average for each PLAN test.

Table 17

Descriptive Statistics of ACT PLAN Scores Across Neighborhoods, 2013-14

\begin{tabular}{lcccc}
\hline Test and neighborhood & $M$ & $S D$ & Min. & Max. \\
\hline ACT PLAN English & & & & \\
$\quad$ Total sample & 15.3 & 4.3 & 3 & 32 \\
$\quad$ Neighborhood 1 & 13.5 & 3.5 & 3 & 30 \\
$\quad$ Neighborhood 2 & 15.3 & 4.1 & 6 & 32 \\
$\quad$ Neighborhood 3 & 17.8 & 4.4 & 6 & 30 \\
ACT PLAN Mathematics & & & & \\
$\quad$ Total sample & 16.0 & 4.1 & 2 & 32 \\
$\quad$ Neighborhood 1 & 14.4 & 3.2 & 2 & 30 \\
$\quad$ Neighborhood 2 & 16.0 & 3.9 & 3 & 32 \\
$\quad$ Neighborhood 3 & 18.2 & 4.4 & 3 & 32 \\
ACT PLAN Reading & & & & \\
$\quad$ Total sample & 15.8 & 4.2 & 4 & 30 \\
$\quad$ Neighborhood 1 & 14.0 & 3.5 & 4 & 27 \\
Neighborhood 2 & 15.7 & 4.1 & 4 & 30 \\
$\quad$ Neighborhood 3 & 18.1 & 4.3 & 6 & 30 \\
\hline Note. Total sample $N=3,818 ;$ Neighborhood $1 n=989 ;$ Neighborhood $2 n=$ \\
2,036; Neighborhood 3 $n=793$.
\end{tabular}

Table 18 reports the descriptive statistics for the ACT scores produced during the 2014-15 school year. An examination of ACT performance for the total sample revealed 
that students averaged 17.3 for the ACT English section, 17.8 for ACT Mathematics, and 18.4 for the ACT Reading section.

Table 18

Descriptive Statistics of ACT Scores Across Neighborhoods, 2014-15

\begin{tabular}{|c|c|c|c|c|}
\hline Test and neighborhood & $M$ & $S D$ & Min. & Max. \\
\hline \multicolumn{5}{|l|}{ ACT English } \\
\hline Total sample & 17.3 & 6.1 & 0 & 36 \\
\hline Neighborhood 1 & 14.2 & 4.8 & 0 & 34 \\
\hline Neighborhood 2 & 17.1 & 5.8 & 3 & 35 \\
\hline Neighborhood 3 & 21.5 & 6.0 & 5 & 36 \\
\hline \multicolumn{5}{|l|}{ ACT Mathematics } \\
\hline Total sample & 17.8 & 4.3 & 0 & 35 \\
\hline Neighborhood 1 & 16.1 & 3.1 & 0 & 31 \\
\hline Neighborhood 2 & 17.6 & 4.0 & 0 & 35 \\
\hline Neighborhood 3 & 20.6 & 5.0 & 11 & 35 \\
\hline \multicolumn{5}{|l|}{ ACT Reading } \\
\hline Total sample & 18.4 & 5.8 & 0 & 36 \\
\hline Neighborhood 1 & 15.9 & 4.6 & 0 & 35 \\
\hline Neighborhood 2 & 18.3 & 5.6 & 4 & 36 \\
\hline Neighborhood 3 & 22.0 & 5.8 & 4 & 36 \\
\hline
\end{tabular}

The results of the ACT exam were similar to ACT PLAN performance when disaggregating the data by neighborhood category. Category 1 neighborhoods scored 1.7 to 3.5 average points below the sample average on the ACT exams, and Category 3 neighborhoods scored 2.8 to 4.2 average points above the sample average. The reported means for ACT scores revealed an achievement gap similar to PLAN scores between Category 1 and Category 3 neighborhoods. Similar to the ACT PLAN, Category 2 neighborhoods were found to produce average ACT scores below Category 3 
neighborhoods, but the scores for students in Category 2 neighborhoods aligned with the total sample average. Finally, the minimum scores for the ACT test sections were noticeably different across neighborhood categories. Category 1 neighborhoods had the lowest minimum scores, ranging from $0-3$ for each ACT exam section, whereas Category 3 neighborhoods had comparably higher minimum ACT exam section scores, ranging from $4-11$.

Correlational analyses were conducted to measure the relationships between the ACT PLAN and the dependent variables of ACT English, ACT Mathematics, and ACT Reading. Correlational relationships between .60 and .79 are considered strong, and values .80 to 1.00 are very strong (Stevens, 2007, 2009). Overall, the correlations among the scores were high with coefficients exceeding .73. Specifically, a high correlation was found between ACT PLAN English and ACT English $(r=.83)$ and between ACT PLAN Mathematics and ACT Mathematics scores $(r=.79)$. A slightly lower correlation coefficient was found between ACT PLAN Reading and ACT Reading with a high correlation of .73. The strong correlational associations of .73 and above indicated a positive, linear association between the PLAN and ACT scores. Simply, an increase in ACT PLAN scores is likely to result in a similar increase in ACT scores.

The measures of central tendency revealed an achievement gap on ACT performance between neighborhoods. The next section provides the results of the HLMR analyses on ACT scores to provide clarification of the influences of student, school, and neighborhood factors on the ACT scores. 


\section{HLMR Results}

HLMR was used to address the research question on the degree to which student, school, and neighborhood factors predict college readiness. Student variables were gender, race (African American, Latinx, White), special education participation, NSLP status, and the ACT PLAN score from the separate PLAN test section that matched the ACT dependent variable (e.g., ACT PLAN Reading was used when examining ACT

Reading). The school composition factor included whether a school was designated Title I; schools were required to have a population greater than $40 \%$ poverty to be designated as Title I (JCPS, 2014e). Neighborhoods were represented by Category 1, 2, or 3 and were comprised of parent education, family income, and neighborhood ethnic-minority rate (Orfield \& Frankenberg, 2011). The three dependent variables were scores on ACT English, Mathematics, and Reading exams.

The HLMR analysis was conducted by sequentially entering variable blocks into the model to measure their influence on the dependent variable. Specifically, Block 1 included the aforementioned student variables (gender, race, special education participation, NSLP status, and PLAN scores). Block 2 included the school variable of Title I designation. Last, Block 3 included neighborhood category (Category 1, Category 2, and Category 3).

\section{Assumptions}

Prior to conducting the regression analysis, specific model assumptions were examined. These included multicollinearity, linearity, homoscedasticity, outliers, and independence of error terms. 
Multicollinearity. According to Stevens $(2007,2009)$, moderate to high correlations between the model predictors may create problems within the regression model. Specifically, the intercorrelation among model predictors may result in a reduction in the predictive utility of independent variables on the dependent variable, which results in a reduction of the $R^{2}$ (Ho, 2014; Osborne, 2017; Petrocelli, 2003; Shavelson, 1996; Stevens, 2007, 2009). A variance inflation factor of less than 10 is desired for each factor (Ho, 2014; Osborne, 2017; Petrocelli, 2003; Shavelson, 1996; Stevens, 2007, 2009); in this study, variance inflation factor values ranged from 1.025 to 2.549. Thus, multicollinearity was minimalized and not problematic.

Linearity. The results of the HLMR analysis are based upon the linear relationship of predictors to a dependent variable (Ho, 2014; Osborne, 2017; Petrocelli, 2003; Shavelson, 1996; Stevens, 2007, 2009). To satisfy the assumption, the residuals were entered into a normal probability plot and checked for linearity to the fitted line. The diagonal residual plot was aligned with the fitted line, which satisfied the assumption of linearity.

Homoscedasticity. Homogeneity of variance, or equal variance, between the variables is observable on the residuals plot. Specifically, the scores of the population should appear normally distributed at the 0 line of the residuals plot to avoid homoscedasticity. The residuals appear normally distributed and clustered tightly the analyses, with a minor curve to the residuals in the mathematics scatterplot. Thus, it can be stated that assumption of homoscedasticity was met.

Outliers. Outlier data for the predicting factors and dependent variables overly influence the $R^{2}$ (Stevens, 2007, 2009). Cook's distance is used to measure the influence 
of outliers on the $R^{2}$, and although Stevens $(2007,2009)$ suggested a maximum of 2 standard deviations for Cook's distance, the value for each residual should fall below 1 . Upon examination of the Cook's distance results, the maximum values were .007 ( $S D=$ $.000)$ for ACT English, $.014(S D=.001)$ for ACT Mathematics, and $.009(S D=.000)$ for the ACT Reading analyses. All cases remained in the study since the values were below 1.

Independence of error terms. The predicted values produced by the model are required to be independent to avoid an error caused by auto-correlation (Ho, 2014; Stevens, 2007, 2009). A Durbin-Watson score between 1.5 and 2.5 is required to satisfy the independence of error assumption, but a score closer to 2.0 is desired (Ho, 2014; Stevens, 2007, 2009). The ACT English analysis (1.977), the ACT Mathematics analysis (2.068), and the ACT Reading analysis (1.991) produced Durbin-Watson scores between the required 1.5 and 2.5 limits. The Durbin-Watson test confirmed each analysis avoided auto-correlation.

\section{ACT English Results}

Table 19 reports the results of the HLMR analysis of student, school, and neighborhood factors on ACT English scores. As shown, variable Block 1 comprised of student variables was found to be statistically significant $F(6,3,811)=1,563.307, p<$ .001 , and accounted for $71.1 \%$ of the variance in ACT English scores. Subsequently, the addition of variable Block 2 explained an additional $0.9 \%$ (cumulative $72 \%$ ) of the variance of ACT English scores and was statically significant, $F(7,3,810)=1,397.855, p$ $<.001$. Finally, the entry of Block 3 was found to be statistically significant, $F(9,3,808)$ 
$=1,108.067, p<.001$, and explained an additional $0.4 \%$ (cumulative $72.4 \%$ ) of the variance in ACT English scores.

Table 19

Hierarchical Linear Multiple Regression Predicting ACT English Scores

\begin{tabular}{|c|c|c|c|c|c|c|}
\hline \multirow[b]{2}{*}{ Variable } & \multirow[b]{2}{*}{$R^{2}$} & \multirow[b]{2}{*}{ Adj. $R^{2}$} & \multirow[b]{2}{*}{$\Delta R^{2}$} & \multirow[b]{2}{*}{$\Delta F$} & \multicolumn{2}{|c|}{ Estimates } \\
\hline & & & & & $B$ & $S E$ \\
\hline Model 1 & $.711 *$ & $.711^{*}$ & & & & \\
\hline (Constant) & & & & & $1.414^{*}$ & .272 \\
\hline Gender & & & & & $-0.401 *$ & .108 \\
\hline Race: African American & & & & & $-0.993 *$ & .127 \\
\hline Race: Latinx & & & & & -0.111 & .214 \\
\hline Special education & & & & & $-1.374^{*}$ & .196 \\
\hline NSLP & & & & & $-0.734 *$ & .121 \\
\hline PLAN English & & & & & $1.105^{*}$ & .014 \\
\hline Model 2 & $.720 *$ & $.719 *$ & $.009 *$ & $117.763^{*}$ & & \\
\hline (Constant) & & & & & $2.412 *$ & .283 \\
\hline Gender & & & & & $-0.374^{*}$ & .106 \\
\hline Race: African American & & & & & $-0.984 *$ & .125 \\
\hline Race: Latinx & & & & & -0.024 & .211 \\
\hline Special education & & & & & $-1.406^{*}$ & .193 \\
\hline NSLP & & & & & $-0.505^{*}$ & .121 \\
\hline PLAN English & & & & & $1.069 *$ & .014 \\
\hline School composition & & & & & $-1.227 *$ & .113 \\
\hline Model 3 & $.724 *$ & $.723 *$ & $.004 *$ & $27.010 *$ & & \\
\hline (Constant) & & & & & $3.133 *$ & .299 \\
\hline Gender & & & & & $-0.365^{*}$ & .106 \\
\hline Race: African American & & & & & $-0.799 *$ & .135 \\
\hline Race: Latinx & & & & & 0.025 & .209 \\
\hline Special education & & & & & $-1.388^{*}$ & .191 \\
\hline NSLP & & & & & $-0.324 *$ & .122 \\
\hline PLAN English & & & & & $1.058^{*}$ & .014 \\
\hline School composition & & & & & $-0.964 *$ & .118 \\
\hline Neighborhood 1 & & & & & $-1.252 *$ & .190 \\
\hline Neighborhood 2 & & & & & $-1.016^{*}$ & .148 \\
\hline
\end{tabular}

Note. NSLP = National School Lunch Program.

$* p<.05$. 
As shown in Table 19, there were several significant model predictors after the inclusion of the final variable block. Specifically, in terms of demographics, the coefficients for student gender, African American referent race subgroup, special education, NSLP status, and ACT PLAN English scores contributed significantly to the regression model. The coefficients revealed a negative influence for males $(-0.365)$ compared to females, African American students (-0.799) compared to White students, special education students (-1.388) compared to regular education students, and for students participating in the NSLP (-0.324) compared to students not eligible for the NSLP. The negative coefficients indicated that female, White, regular education, and non-NSLP students scored higher than their male, White, regular education, and NSLP participant student counterparts.

The PLAN English scores, however, were found to have a positive influence on ACT English scores (1.058). For every 1-point increase in PLAN English scores, the ACT English scores increased by 1.058 points. The coefficients for school composition and neighborhood were also reported as significant to the ACT English model. The Title I school coefficient was found to have a negative influence on ACT English scores (0.964) compared to students who attended non-Title I schools, which indicated high scores for students in non-Title I schools.

Category 1 (-1.252) and Category 2 neighborhoods (-1.016) also had a negative influence compared to Category 3 neighborhoods. Thus, students in Category 2 neighborhoods scored higher than those in Category 1 neighborhoods, but students in Category 3 neighborhoods outperformed students in Category 1 and 2 neighborhoods. The overall model accounted for $72.4 \%$ of the variance of ACT English scores. 


\section{ACT Mathematics Results}

Table 20 reports the results of the HLMR analysis of student, school, and neighborhood factors on ACT Mathematics scores. As reported in Table 20, variable Block 1 comprised of student variables was found to be statistically significant, $F(6$, $3,811)=1,084.222, p<.001$, and accounted for $63.1 \%$ of the variance in ACT Mathematics scores. In succession, the addition of variable Block 2 explained an additional $0.9 \%$ (cumulative $64 \%$ ) of the variance of ACT Mathematics scores and was statically significant, $F(7,3,810)=969.066, p<.001$. Lastly, the entry of Block 3 was found to be statistically significant, $F(9,3,808)=763.775, p<.001$, and explained an additional $0.4 \%$ (cumulative $64.4 \%$ ) of the variance in ACT Mathematics scores.

Table 20 also reports the significant model predictors after the inclusion of the final variable block. Regarding demographics, the coefficients for African American referent race subgroup, NSLP status, and ACT PLAN Mathematics scores contributed significantly to the regression model. The coefficients revealed a negative influence for African American students (-.541) compared to White students and for students participating in the NSLP (-.324) compared to non-NSLP participants. The negative coefficients indicated that White and non-NSLP students scored higher than African American and NSLP-participant students. The ACT PLAN Mathematics scores were found to have a positive influence on ACT Mathematics scores (.750). For every 1-point increase in PLAN Mathematics scores, the ACT Mathematics scores increased by 0.75 points. 
Table 20

Hierarchical Linear Multiple Regression Predicting ACT Mathematics Scores

\begin{tabular}{|c|c|c|c|c|c|c|}
\hline \multirow[b]{2}{*}{ Variable } & \multirow[b]{2}{*}{$R^{2}$} & \multirow[b]{2}{*}{ Adj. $R^{2}$} & \multirow[b]{2}{*}{$\Delta R^{2}$} & \multirow[b]{2}{*}{$\Delta F$} & \multicolumn{2}{|c|}{ Estimates } \\
\hline & & & & & $B$ & $S E$ \\
\hline Model 1 & $.631 *$ & $.630 *$ & & & & \\
\hline (Constant) & & & & & $5.956^{*}$ & .220 \\
\hline Gender & & & & & -0.119 & .086 \\
\hline Race: African American & & & & & $-0.599 *$ & .100 \\
\hline Race: Latinx & & & & & $-0.365^{*}$ & .169 \\
\hline Special education & & & & & -0.088 & .156 \\
\hline NSLP & & & & & $-0.602 *$ & .095 \\
\hline PLAN Mathematics & & & & & $0.782 *$ & .012 \\
\hline Model 2 & $.640 *$ & $.640 *$ & $.010 *$ & $103.375^{*}$ & & \\
\hline (Constant) & & & & & $6.669^{*}$ & .228 \\
\hline Gender & & & & & -0.073 & .085 \\
\hline Race: African American & & & & & $-0.578 *$ & .098 \\
\hline Race: Latinx & & & & & -0.285 & .167 \\
\hline Special education & & & & & -0.073 & .085 \\
\hline NSLP & & & & & $-0.424^{*}$ & .095 \\
\hline PLAN Mathematics & & & & & $0.757 *$ & .012 \\
\hline School composition & & & & & $-0.908 *$ & .089 \\
\hline Model 3 & $.644^{*}$ & $.643^{*}$ & $.003 *$ & $16.917 *$ & & \\
\hline (Constant) & & & & & $7.145^{*}$ & .242 \\
\hline Gender & & & & & -0.065 & .084 \\
\hline Race: African American & & & & & $-0.541 *$ & .107 \\
\hline Race: Latinx & & & & & -0.264 & .166 \\
\hline Special education & & & & & -0.114 & .153 \\
\hline NSLP & & & & & $-0.324^{*}$ & .097 \\
\hline PLAN Mathematics & & & & & $0.750^{*}$ & .012 \\
\hline School composition & & & & & $-0.759 *$ & .094 \\
\hline Neighborhood 1 & & & & & $-0.606^{*}$ & .151 \\
\hline Neighborhood 2 & & & & & $-0.685^{*}$ & .118 \\
\hline
\end{tabular}

Note. NSLP $=$ National School Lunch Program.

$* p<.05$.

The coefficients for school composition and neighborhood were also reported as significant to the ACT Mathematics model. The Title I school coefficient was found to 
have a negative influence on ACT Mathematics scores (-0.759) compared to non-Title I schools, as did residing in Category $1(-0.606)$ or Category 2 neighborhoods $(-0.685)$ when compared to Category 3 neighborhoods. The negative coefficients indicated that students in non-Title I schools scored higher than students in Title I schools. Additionally, Category 2 neighborhoods scored higher than Category 1 neighborhoods, but Category 3 neighborhoods scored higher than Category 1 and 2 neighborhoods. The overall model accounted for $64.4 \%$ of the variance of ACT Mathematics scores.

\section{ACT Reading Results}

Table 21 reports the results of the HLMR analysis of student, school, and neighborhood factors on ACT Reading scores. As shown, variable Block 1 comprised of student variables was found to be statistically significant, $F(6,3,811)=816.087, p<$ .001 , and accounted for $56.2 \%$ of the variance in ACT Reading scores. Subsequently, the addition of variable Block 2 explained an additional 1\% (cumulative 57.2\%) of the variance of ACT Reading scores and was statically significant, $F(7,3,810)=728.469, p$ $<.001$. Finally, the entry of Block 3 was found to be statistically significant, $F(9,3,808)$ $=571.253, p<.001$, and explained an additional $0.2 \%$ (cumulative $57.4 \%$ ) of the variance in ACT Reading scores.

As shown in Table 21, there were several significant model predictors after the inclusion of the third variable block. Specifically, the demographic coefficients for student gender, African American referent race subgroup, special education, NSLP status, and ACT PLAN Reading scores contributed significantly to the regression model. The coefficients revealed a negative influence for males $(-0.273)$ compared to female students, African American students (-1.059) compared to White students, special 
education students (-1.248) compared to regular education students, and for students participating in the NSLP (-0.596) compared to non-NSLP students. The negative coefficients indicated that female, White, regular education, and non-NSLP students scored higher than their male, White, regular education, and NSLP participant student counterparts. The PLAN Reading scores, however, were found to have a positive influence on ACT Reading scores (0.868). For every 1-point increase in PLAN Reading scores, the ACT Reading scores increased by 0.868 points.

The coefficients for school composition and neighborhood were also reported as significant to the ACT reading model. The Title I school coefficient was found to have a negative influence on ACT reading scores (-1.056) compared to non-Title I schools, as did residing in Category $1(-0.813)$ or Category 2 neighborhoods (-0.734) compared to Category 3 neighborhoods. The negative coefficients indicated that students in non-Title I schools scored higher than students in Title I schools. Different from the previous models, students in Category 1 neighborhoods scored higher than those in Category 2 neighborhoods, but students in Category 3 neighborhoods continued to score higher than students in Category 1 and 2 neighborhoods. The overall model accounted for $57.4 \%$ of the variance of ACT Reading scores. 
Table 21

Hierarchical Linear Multiple Regression Predicting ACT Reading Scores

\begin{tabular}{|c|c|c|c|c|c|c|}
\hline \multirow[b]{2}{*}{ Variable } & \multirow[b]{2}{*}{$R^{2}$} & \multirow[b]{2}{*}{ Adj. $R^{2}$} & \multirow[b]{2}{*}{$\Delta R^{2}$} & \multirow[b]{2}{*}{$\Delta F$} & \multicolumn{2}{|c|}{ Estimates } \\
\hline & & & & & $B$ & $S E$ \\
\hline Model 1 & $.562 *$ & $.562 *$ & & & & \\
\hline (Constant) & & & & & $5.405 *$ & .313 \\
\hline Gender & & & & & $-0.314^{*}$ & .125 \\
\hline Race: African American & & & & & $-1.181 *$ & .146 \\
\hline Race: Latinx & & & & & -0.458 & .247 \\
\hline Special education & & & & & $-1.241^{*}$ & .226 \\
\hline NSLP & & & & & $-0.969 *$ & .138 \\
\hline PLAN Reading & & & & & $0.908^{*}$ & .016 \\
\hline Model 2 & $.572 *$ & $.572 *$ & $.010 *$ & $89.304^{*}$ & & \\
\hline (Constant) & & & & & $6.339 *$ & .325 \\
\hline Gender & & & & & $-0.279 *$ & .124 \\
\hline Race: African American & & & & & $-1.157^{*}$ & .145 \\
\hline Race: Latinx & & & & & -0.355 & .245 \\
\hline Special education & & & & & $-1.258 *$ & .224 \\
\hline NSLP & & & & & $-0.720 *$ & .139 \\
\hline PLAN Reading & & & & & $0.875^{*}$ & .016 \\
\hline School composition & & & & & $-1.236^{*}$ & .131 \\
\hline Model 3 & $.574 *$ & $.573 *$ & $.002 *$ & $9.551 *$ & & \\
\hline (Constant) & & & & & $6.865^{*}$ & .347 \\
\hline Gender & & & & & $-0.273^{*}$ & .123 \\
\hline Race: African American & & & & & $-1.059 *$ & .157 \\
\hline Race: Latinx & & & & & -0.324 & .244 \\
\hline Special education & & & & & $-1.248 *$ & .223 \\
\hline NSLP & & & & & $-0.596^{*}$ & .142 \\
\hline PLAN Reading & & & & & $0.868 *$ & .016 \\
\hline School composition & & & & & $-1.056^{*}$ & .137 \\
\hline Neighborhood 1 & & & & & $-0.813^{*}$ & .222 \\
\hline Neighborhood 2 & & & & & $-0.734^{*}$ & .173 \\
\hline
\end{tabular}

Note. NSLP $=$ National School Lunch Program.

$* p<.05$. 


\section{Summary of Results}

The model summary for each analysis determined that student backgrounds, neighborhood diversity, and school composition have a significant influence on ACT performance and explained high levels of variance in ACT English scores $\left(R^{2}=.724\right)$, ACT Mathematics scores $\left(R^{2}=.644\right)$, and ACT Reading scores $\left(R^{2}=.574\right)$. The analyses of ACT scores identified common significant coefficients for each of the models. African American students were found to have a disadvantage in each model compared to White students, participation in NSLP negatively influenced student performance compared to non-NSLP students, and PLAN scores positively predicted ACT performance. School composition negatively influenced ACT performance (Title I compared to non-Title I schools), and Category 1 and Category 2 neighborhoods negatively influenced ACT scores compared to Category 3 neighborhoods. Gender and participation in special education also negatively influenced ACT for males and special education students, but those coefficients were only significant to ACT English and Reading scores.

Finally, the study addressed the following null hypotheses:

$\mathrm{H} 10$. There is not a significant influence of student factors on English Language Arts and mathematics achievement.

$\mathrm{H} 2_{0}$. There is not a significant influence of neighborhood factors on English Language Arts and mathematics achievement.

$\mathrm{H} 3_{0}$. There is not a significant influence of school factors on English Language Arts and mathematics achievement. 
$\mathrm{H} 4_{0}$. There is not a significant combined influence of student, neighborhood, and school factors on English Language Arts and mathematics achievement.

The results revealed variable Block 1, Block 2, and Block 3 as significant predictors of ACT English, Mathematics, and Reading performance. Thus, the null hypotheses were rejected. Implications of these results are reviewed in the discussion chapter. 


\section{CHAPTER 5}

\section{DISCUSSION}

The purpose of this study was to examine the influence of student background and school factors on 11th-grade students' college readiness. The measurement of college readiness serves to indicate if students have a high probability of academic success at the college level (Camara, 2013; Conley, 2007). Achieving college readiness provides a basis to judge the extent to which students may adapt to a technologically progressing and academically sophisticated society beyond their secondary education (Camara, 2013; Conley, 2007). Student background and school composition factors examined for their relationship to college readiness were a direct result of JCPS implementing a race- and socioeconomic-based student assignment plan. Through the guidance of Orfield and Frankenberg (2011), JCPS implemented the student assignment plan as a result of Meredith v. Jefferson County Board of Education (2006), which determined that racebased student assignment violated the 14th Amendment. Although the reviewed literature primarily addressed the influence of student background and school factors on student achievement, this study furthers the discussion with the inclusion of student background and school factors found in the JCPS race- and socioeconomic-based student assignment plan to determine their influence on college readiness. The following sections discuss the results for the separate variable blocks used in this study (student background, school composition, neighborhood category) as they relate to the literature and their influence on achieving the English Language Arts (ACT English, ACT 
Reading) and mathematics (ACT Mathematics) college-readiness benchmark scores. Implications of the findings on policy and practice are also provided.

\section{Discussion of Factors}

The student background variable block, comprised of gender, race, special education status, NLSP status, and PLAN scores, was the first block entered into each analyses. The results revealed that student background factors were responsible for over $56 \%$ of the explained variance in each analysis.

The first background factor examined was student gender. The previously reported literature for the influence of gender on ACT scores revealed a minimal difference, as males narrowly outperformed females on the ACT Mathematics and Reading sections, whereas females narrowly outperformed males in English (ACT, 2014; Mau \& Lynn, 2001). The results from the HLMR analyses of ACT English and Reading scores in this study were inconsistent with the literature. Specifically, female students scored above males in English, which was expected, but females also scored higher than males in Reading. The ACT Reading analysis revealed a negative influence for male students, which was inconsistent with the findings of ACT (2014) and Mau and Lynn (2001). The results of the ACT Reading analysis, however, were consistent with national ACT results reported in Table 12, in which female students outperformed males in ACT Reading. The amount of influence revealed by the analyses was consistent with the literature, as the final English and Reading models revealed a 0.3-point deduction for male students. Lastly, gender did not significantly contribute to ACT Mathematics performance. The findings of no gender differences on ACT Mathematics scores was inconsistent with the literature. 
The differences of student race between African Americans and White students was significant across the English Language Arts and mathematics analyses models. While the gender coefficient resulted in a score reduction of approximately one-third of a point across all models, the race coefficient revealed a much larger score difference, where the performance of African American students was significantly less than the performance of White students. The reviewed literature on the effects of student race reported a minimal negative influence for African American and Latinx students when socioeconomic status and PLAN scores were included in analyses (ACT, 2014; Noble et al., 1999b; Noble et al., 2006). Specifically, the inclusion of socioeconomic status and PLAN testing were expected to reduce the influence of race and gender to explain only $1-3 \%$ of variance in ACT scores (ACT, 2014; Noble et al., 1999b; Noble et al., 2006). The analyses of ACT English, Reading, and Mathematics confirmed a negative influence for African American students when socioeconomic status and PLAN scores were also considered. Consistent with the literature, the difference between African American and White students' ACT scores was approximately 1 point or less for each test section. The impact of race on Latinx student scores was also consistent with the literature in that the influence, although lesser than African American students, was negative for student performance. However, the Latinx students' coefficient was only significant in variable Block 1 of the mathematics model, and was made nonsignificant once school and neighborhood factors were considered.

The next factor included in the student background variable block was student socioeconomic status. Although family income comprises part of the neighborhood category factor developed by Orfield and Frankenberg (2011), the socioeconomic status 
of students was independently considered in variable Block 1. Represented by participation in NSLP, student poverty was significant across the English Language Arts and mathematics models. Previously reviewed literature revealed that socioeconomic status was moderately correlated to student achievement (Brooks-Gunn et al., 1993; Davis-Kean, 2005; Duncan, 1994; Israel et al., 2001). Additionally, Coleman et al. (1966) and Konstantopoulos and Borman (2011) revealed that student race and socioeconomic status had a negative influence on achievement. ACT (2014) also reported a negative influence from student socioeconomic status, but the influence was minimized when other factors such as GPA and ACT PLAN results were considered. The analyses of ACT English, Reading, and Mathematics scores confirmed that student socioeconomic status was a negative influence and reduced ACT scores by approximately $2 \%$ for students who participated in NSLP. When NSLP participation and race are considered together, an African American student receiving NSLP assistance may experience a 2-point reduction in ACT scores, which is approximately $5 \%$ of an ACT score. However, the influence was reduced when school and neighborhood factors were included

When focusing more on academic performance predictors, the reviewed literature reported that the strongest indicator for ACT performance was student GPA and high school coursework completed. Specifically, higher levels of coursework and the completion of multiple mathematics and science courses corresponded with high ACT scores (ACT, 2014; Noble et al., 1999a, 1999b; Noble \& McNabb, 1989; Noble et al., 2006; Noble \& Sawyer, 2002; Sawyer, 1989, 2013). Even though student coursework was not considered as part of this study, student participation in special education was 
included as a representation for the type of education and coursework a student experienced. The special education coefficient was nonsignificant for the ACT Mathematics analysis, but it was significant and served as the largest negative influence on scores for the ACT English and Reading analyses. Even after school and neighborhood factors were entered into the models, the negative influence of the special education coefficient resulted in an approximate -1.3-point or 3.5\% impact on ACT English and Reading scores.

Finally, confirmed specifically by ACT (2013b; 2014), the inclusion of ACT PLAN scores in the analyses of ACT English, Reading, and Mathematics scores significantly explained the variance in ACT scores. Although the influence of the PLAN scores was reduced as variable Blocks 2 and 3 were introduced to the models, their positive influence of predicting ACT performance range was the largest of all coefficients. The relationship between the PLAN and ACT was expected, as both exams appeared in the ACT college-readiness testing series. The PLAN results accurately measure the trajectory of students achieving college readiness (ACT, 2013b, 2014) and minimize the influence of student background factors when measuring college readiness (ACT, 2014).

The student background factors included in this study explained over half of variance in each analysis. Aside from ACT PLAN results, the African American race group and NSLP participation were the only predictors that were significant across the English Language Arts and mathematics models. The results indicated that African American students who participated in NSLP experienced a reduction in ACT scores by almost 2 points in ACT English, Reading, and Mathematics. Performance on ACT 
English and Reading was further reduced by over 1 point when participation in special education was considered. Finally, student gender was a negative influence for male students, but the impact was only 0.3 points. Students who were negatively influenced by the background factors may see a reduction of almost 1.2 points, 3.5 points, and 3.7 points in ACT Mathematics, English, and Reading, respectively. Although the actual point reduction to ACT scores may seem small, they comprise 3.5\%, 9.7\%, and $10.3 \%$ of performance on ACT Mathematics, English, and Reading, respectively. Since students take their backgrounds with them to school, the next section discusses the influence of school composition on ACT performance.

Even though the student background factors explained the largest amount of variance on ACT performance, the school composition and neighborhood category factors were found to reduce the influence of backgrounds on ACT scores. Since students spend a minimum of 7 hours per day at school, the school composition variable was entered second into the analysis models and was included in this study to determine the influence of school poverty on college readiness.

The JCPS student assignment plan apportions students from the three categories of neighborhoods into the 16 comprehensive high schools, which results in the schools having a unique student body and poverty level. Category 1 and 2 neighborhoods enrolled students in Title I schools at a rate that was higher than the sample average and 40-60\% higher than Category 3 neighborhoods. Hence, Title I schools were comprised of the highest levels of poverty and ethnic-minority populations. Denoted as Title I or non-Title I, school composition was significant across the analyses of ACT scores. Although the student background factors combined to explain the most amount of 
variance in ACT scores, school composition explained a difference of approximately 1 point for each ACT test section. Specifically, students who attended Title I schools experienced a 1-point reduction to their ACT English, Mathematics, and Reading scores. Furthermore, the influence of school composition was only slightly reduced when neighborhood categories were entered into the model.

The influence of the school composition factor in this study was consistent with the previously reviewed literature. Although the seminal work of Coleman et al. (1966) created questions as to the effectiveness of schools to overcome the influence of backgrounds and neighborhoods, the analyses in this study revealed that the school composition factor was nearly as or more influential than any student background factor. So, although student backgrounds (gender, race, special education status, NSLP status, and PLAN scores) explained over half of the variance in ACT scores, the school composition factor significantly contributed to the final model. Thus, the results are consistent with the literature in that variance in mathematics and reading achievement is explained with between-school measures, and students who attended higher socioeconomic schools outperformed their peers who attended lower socioeconomic schools (Borman et al., 2004; Hanushek et al., 2003; Ikpa, 1994; Konstantopoulos, 2005; Konstantopoulos \& Borman, 2011; Mickelson et al., 2013; Rumberger \& Palardy, 2005; Schwartz, 2010; Sirin, 2005).

After spending a minimum of 7 hours per day in school, students return to their homes and neighborhoods, where additional factors have been found to influence achievement. Although the literature showed the neighborhood factors in variable Block 3 to be subsequent to family factors for child development, the amount of time JCPS 
students spend per school day in class and on campus logically supported entering variable Block 3 lastly into the analyses (Ho, 2014; Osborne, 2016; Petrocelli, 2003; Stevens, 2007, 2009). Hence, neighborhood categories were the last factors entered into the models.

The JCPS student assignment plan developed by Orfield and Frankenberg (2011) created neighborhood categories that were a result of weighting parent education, family income, and the percentage of neighborhood ethnic-minority population. The neighborhood categories were included in the JCPS student assignment plan as a socioeconomic component designed to desegregate schools by using more than the sole factor of student race to diversify student populations (Orfield \& Frankenberg, 2011). The use of neighborhood categories factors was grounded in the holdings of the Meredith and Parents Involved in Community Schools cases, and the reviewed literature provided conclusions that determined parent education, family income, and neighborhood composition as influential factors on student achievement. Specifically, the influence of parental income and education explained approximately $25 \%$ of the variance in academic achievement for White students, and approximately 14\% for African American students (Duncan, 1994). Furthermore, the presence of affluent neighbors promoted the importance of educational attainment and influenced positive school performance, as affluent neighbors expanded the impact of family socioeconomic status and parent education levels (Brooks-Gunn et al., 1993; Datcher, 1982; Dornbusch et al., 1991; Duncan, 1994; Garner \& Raudenbush, 1991). Finally, students from high-ethnicminority and high-poverty neighborhoods produced lower rates of college readiness compared to low-ethnic-minority and low-poverty neighborhoods (Fruchter et al., 2012). 
Applying the literature to the demographics of the neighborhood categories revealed a gap in parental education, income, and neighborhood minority rates that resulted in lower college readiness scores. The JCPS student assignment plan utilized three categories of neighborhoods including: Category 1, Category 2, and Category 3 (see Table 5). Category 1 neighborhoods were comprised of the lowest levels of income and parent education and the highest rates of ethnic-minority populations. Category 2 neighborhoods were designed to have moderate income, parental education levels, and ethnic-minority rates that were between Category 1 and Category 3 neighborhoods. Finally, Category 3 neighborhoods possessed the highest levels of income and parent education, with the lowest rates of ethnic-minority populations (Orfield \& Frankenberg, 2011).

The inclusion of neighborhood categories in the HLMR analyses of ACT English, Mathematics, and Reading produced results similar to the reviewed literature. The sample of students used in this study was spread across the three neighborhood categories, and the examination of the demographic distribution (see Table 14) revealed that the Category 1 neighborhoods were $72 \%$ African American. The rate of students participating in special education and NSLP was also the highest in Category 1 neighborhoods. Students residing in Category 1 neighborhoods experienced the largest negative influence on ACT scores. Category 2 neighborhoods aligned with the sample average in student special education and NSLP participation, but their African American population was almost 50\% less than Category 1 neighborhoods. However, despite the difference in population rates, African American, special education, NSLP participant, and male students still experienced a negative influence from their backgrounds, but the 
negative influence of Category 2 neighborhood factors did not reduce ACT scores as much as Category 1 neighborhoods.

The influence of Category 1 and 2 neighborhoods was compared to Category 3 neighborhoods, which housed the lowest levels of African American, special education, and NSLP participant students. The ACT scores disaggregated by neighborhood (see

Table 18) aligned with the literature, as Category 3 neighborhoods produced the highest average of ACT English, Mathematics, and Reading scores. Thus, students whose backgrounds or school enrollment negatively influenced ACT performance did not experience a further reduction when residing in Category 3 neighborhoods.

\section{Summary}

The results of the analyses conducted in this study revealed that student, school, and neighborhood factors were influential to student performance on the ACT English, Mathematics, and Reading exams. Student race, participation in NSLP, ACT PLAN performance, school composition, and neighborhood category were found to be the largest and most consistent factors for predicting college readiness. Additionally, student gender and special education factors were significant, but only for the ACT English and Reading analyses. The addition of the school and neighborhood factors to each model explained only a small amount of variance; however, the factors accounted for approximately 1.5 to 2 points in ACT performance. Thus, the results of the study provide implications to student assignment, student support, and professional development policies and practices. 


\section{Implications}

This dissertation is relevant to the current JCPS student assignment plan and to the efforts to improve student college-readiness rates. By implementing a race- and socioeconomic-based student assignment plan, JCPS has made progressive strides toward integrating school populations that move beyond race and consider student, family, and neighborhood factors. However, school choice practices have impacted the racial and socioeconomic composition of student bodies and resulted in schools with vastly different levels of ethnic-minority and poverty populations (Table 10). JCPS (2014e) reported that school populations comprised of above $40 \%$ low-income students were designated as Title I, and 10 of the 16 comprehensive high schools in this study acquired the Title I designation. These Title I schools enrolled students from low-income and lowparental education neighborhoods at rate almost 50\% higher than high-income and highparental education neighborhoods. Moreover, students who attended JCPS Title I schools were shown to experience a negative influence on their ACT scores.

According to Schwartz (2010), school poverty levels between 35\% and $85 \%$ similarly influenced student performance in mathematics and reading, and school poverty levels below $20 \%$ were the most beneficial to high-poverty students. Poverty rates below $35 \%$ reduced learning barriers such as misbehavior that were associated with higher poverty levels (Schwartz, 2010). Thus, when implementing a race- and socioeconomicbased student assignment plan that promotes diversity and achievement, JCPS may benefit from establishing a policy requiring schools not to exceed a $35 \%$ poverty threshold. The use of a poverty threshold may require limitations to school choice practices currently employed by JCPS. Furthermore, an examination of the screening and 
enrollment policies for the non-Title 1 magnet and traditional school programs may be necessary in implementing a poverty threshold in the comprehensive high schools. Although JCPS cannot control the student background factors brought to school by students from the 540 district neighborhoods, the effective use of their race- and socioeconomic-based student assignment plan, as well as a change in the district's school choice practices, may limit these effects and prevent schools from being susceptible to negative influences associated with high-poverty student populations.

Beyond examining student assignment and school choice practices, JCPS may benefit from exploring and evaluating student support efforts in schools with higher rates of poverty. Attending high-socioeconomic schools has been shown as beneficial for impoverished students because of the increased access to teachers with more advanced degrees and higher learning expectations, rigorous coursework and homework requirements, and the feeling of safety at school (Rumberger \& Palardy, 2005). However, even though high-socioeconomic schools employ more effective teachers and have more effective instructional practices (Borman et al., 2004; Clotfelter et al., 2006; Orfield \& Lee, 2005; Rumberger \& Palardy, 2005; Sass et al., 2012), impoverished or ethnic-minority students assigned to the schools may experience anxiety and feelings of environmental rejection (Angrist \& Lang, 2004; Crosnoe, 2009). Thus, academic advantages may only be temporary as the students struggle to meet the academic demands in unfamiliar environments (Angrist \& Lang, 2004; Crosnoe, 2009). In an effort to provide effective student support, an examination of teacher assignment and professional development practices may be necessary to ensure schools are properly staffed and with teachers trained on supporting high-poverty students. 
The Jefferson County Board of Education (JCBE) and the Jefferson County Teachers Association (JCTA) currently have a collective bargaining agreement on teacher assignment and transfer procedures, however, the agreement grants transfer priority to more experienced teachers (JCBE, 2013). Although prior research results are varied concerning the influence of collective bargaining agreement provisions on student achievement in high-poverty and high-minority schools (Cohen-Vogel, Feng, \& OsborneLampkin, 2013; Cohen-Vogel \& Osborne-Lampkin, 2007; Goldhaber, Lavery, \& Theobald, 2016), agreements with strong seniority teacher assignment provisions have been found to aid teacher transfers away from schools containing high-poverty, highminority, or discipline-problem student populations (Cohen-Vogel \& Osborne-Lampkin, 2007; Goldhaber et al., 2016). Changes to the JCPS teacher transfer policies and procedures may be required to prevent experienced teachers from leaving high-poverty and high-minority schools. Requiring teachers to serve a specified number of years at the same school before gaining eligibility to transfer may be considered, but research on the effects of transfer limits may be necessary before implementing a change to the JCBEJCTA agreement.

The current collective bargaining agreement also requires JCPS teachers to earn 24 hours of professional development credit per school year (JCBE, 2013). As part of the agreement, teachers are allowed to voluntarily attend training sessions and may receive stipend if they are requested to attend by district or school administration (JCBE, 2013). However, teachers are not required to attend professional development relevant to their specific school improvement efforts or their students. Thus, teachers may fulfill their professional development requirement without receiving training on supporting the needs 
of high-poverty students. An examination and adjustment of the professional development requirements in the collective bargaining agreement may be necessary to ensure that teachers are receiving relevant training in providing effective support to students whose background factors negatively influence their college readiness performance.

Finally, JCPS should continue the practice of assessing the trajectory of student college readiness prior to administering the ACT to 11th-grade students. The ACT PLAN results were previously reported by ACT (2013b, 2014) as being a significant predictor of ACT performance, hence the inclusion of PLAN results in this study. The results of this study on the influence of student background and school factors coupled with individual student college readiness scores should be shared with schools to aid in assessing college-readiness concerns for students. Although JCPS has traditionally provided ACT EXPLORE and PLAN results to high schools, an understanding of the influence of student background and school composition factors may be beneficial in developing individualized student support plans focused on improving college readiness (Angrist \& Lang, 2004; Crosnoe, 2009). While Coleman et al. (1966) concluded that student backgrounds destabilize the effects of schools, the more recent research of Rumberger and Palardy (2005) and Konstantopoulos and Borman (2011) concluded that schools can counter the influence of backgrounds by using instructional resources, personnel support, and higher expectations for student achievement. Therefore, the early identification of student performance deficits may allow teachers to develop a plan to reinforce English, mathematics, or reading comprehension strategies, thus counterbalancing the influence of background factors. To assist in this effort, district and 
school leaders should ensure that teachers have the resources necessary to effectively support students who require academic or emotional interventions.

\section{Limitations and Future Research}

Several limitations existed within this study that limit the generalizability of the results. First, this study focused on a singular metropolitan school district. Relating the results to other school districts with different student, neighborhood, and school demographics may produce varying results on their influence on college readiness. Furthermore, other factors such as the effectiveness of ACT preparation programs used by districts and schools were not included. The literature review discussed the presence of academic resources in low-poverty and low-ethnic-minority schools, yet the examination of specific academic programs was not included. A future examination of the effectiveness of college preparatory resources may produce further understanding into overcoming any negative influences of student, neighborhood, or school factors.

Next, this study included data only from 11th-grade students enrolled in the 16 comprehensive JCPS high schools. Students enrolled in magnet or traditional programs were excluded. The student selection processes used by magnet and traditional programs results in student populations that are not reflective of the 16 comprehensive schools, as not all students qualify for enrollment. Students who do not meet the standards for enrollment are not considered. Instead, this study focused on the comprehensive schools for which performance in middle school is not required for enrollment. A future study on the influence of magnet and traditional programs on college readiness may provide significant insight regarding the effectiveness of those programs on college readiness. 
Finally, student factors beyond those included in this study may provide further insight and clarification into the influences of achieving college readiness. Specifically, student-level data regarding single- versus two-parent households, active military assignment for one or both parents, and parent employment status may clarify the influence of family income that reaches beyond the parental education and income levels used in the neighborhood variable block. Moreover, even though neighborhood categories were utilized, specific neighborhoods within the same category may have varying levels of influence on college readiness between neighborhoods. Category 1 neighborhoods located in urban versus suburban areas may provide further insight into the influence of specific neighborhood. Finally, the use of individual school data rather than Title I and non-Title I may provide additional clarification to the between-school relationship to college readiness. Specifically, including teacher years of experience, teacher transfer rates, degrees or certifications obtained by teachers may further clarify the influence of schools on achieving college-readiness rates. This inclusion of more specific student- and school-level data, and the use of hierarchical linear modeling may provide a deeper insight into specific influences on student college readiness. Despite the limitations present in this study, the findings have utility in understanding the influence of student, neighborhood, and school factors on college readiness.

\section{Conclusion}

The United States has seen a devastating decline in high school graduates meeting the college-readiness benchmarks (ACT, 2004), and preparing students to adapt to a technologically progressing and academically sophisticated society beyond their secondary education requires them to be college or career ready upon completion of the 
12th grade (Camara, 2013; Conley, 2007). This study was a continued attempt to understand the influence of student, neighborhood, and school factors on college readiness as these factors were brought together in the JCPS student assignment plan.

The current JCPS student assignment plan was implemented to proportionally assign students from a variety of backgrounds to schools across JCPS in a manner that sustained the desegregation efforts begun in 1975. After 25 years of desegregation efforts, a court order allowed JCPS to transition to an assignment plan that allowed school choice with racial quotas. Yet, the Meredith v. Jefferson County Board of Education (2006) case resulted in the adoption of a race- and socioeconomic-based student assignment plan that also allowed students to exercise school choice (JCPS, 2012a). Students seeking educational opportunities related to increased college readiness have been shown to use school choice options to transfer to non-Title I schools where students perform higher in mathematics and reading (Lauen, 2007; Phillips et al., 2012; Tefera et al., 2011). Additionally, magnet and traditional programs have influenced school composition as students enroll in schools other than their assigned schools. The blend of school choice along with magnet and traditional programs resulted in the de facto development of racially and socioeconomically segregated schools (see Table 10), which have been shown as disadvantageous to poorer and ethnic-minority students (Diem, 2012; Diem \& Frankenberg, 2013; Frankenberg, 2013; Frankenberg et al., 2003; Lauen, 2007; Orfield, 2001; Orfield et al., 2012; Orfield et al., 2014; Phillips et al., 2012; Tefera et al., 2011).

The seminal work of Coleman et al. (1966) brought to light some disparities in student achievement as a result of family composition and poverty that appeared to be 
unmanageable for schools. However, Konstantopoulos and Borman (2011) demonstrated with the same data that schools have an influence on achievement. This study sought to further understand how the factors in a race- and socioeconomic-based student assignment plan influenced student achievement as it related to college readiness. The development of student assignment plans are the result of political movements, federal and local legislation, and court opinions (Borman et al., 2004). Empirical evidence in this and previous studies supports the conclusion that the influence of students' backgrounds and school composition are key factors in student assignment plans used to develop schools that are racially and socioeconomically diverse, while also promoting student achievement (Borman et al., 2004; Diem \& Frankenberg, 2013; Frankenberg, 2013; Frankenberg et al., 2003; Kahlenberg, 2006, 2012; Orfield \& Frankenberg, 2011; Orfield et al., 2008; Potter et al., 2016; Reardon et al., 2006; Tefera et al., 2011).

The results of this study align with the reviewed literature regarding the influence of student, neighborhood, and school factors. Student factors (race, special education participation, and NSLP status) scores were shown to heavily influence student performance on the ACT exam. Specifically, African American and NSLP participant students were negatively influenced on their ACT performance. Special education and male students also experienced reductions in ACT performance, but only in English and Reading. Although student factors were shown to heavily influence student achievement, school and neighborhood factors were significant in explaining the variance in the ACT college-readiness exam. Students enrolled in Title I schools or residing in Category 1 or Category 2 neighborhoods were also negatively influenced on their ACT performance. The combined influence of student background, school, and neighborhood factors could 
result in an approximate 2-point reduction in ACT Mathematics scores, and a 5-point reduction in ACT English and ACT Reading score. Although the actual point reduction to ACT scores may seem small, they comprise $6 \%$ and $14 \%$ of performance on ACT Mathematics and ACT English Language Arts, respectively.

The results of the analyses and reviewed literature support the implementation of a race- and socioeconomic-based student assignment plan by JCPS. While factors in student backgrounds and neighborhood categories may negatively influence students, non-Title I schools were shown to provide educational services without additional negative influence on ACT performance compared to Title I schools. Thus, proportionally diverse schools have the proper foundation for achieving college readiness.

The next steps from this study should address the limitations found within the results of the study. The inclusion of more individualized student- and school-level data, and the use of hierarchical linear modeling may provide a deeper insight into specific influences on student college readiness. After gaining additional insight, college preparatory resources and programs should be evaluated to determine their effectiveness of overcoming the influence of student background and school factors. The analysis of resources should be conducted at the school level to provide a within- and betweenschool measurement of effectiveness. Finally, an examination on the influence of magnet and traditional programs on college readiness may provide significant insight regarding the effectiveness of those programs on college readiness. 


\section{REFERENCES}

ACT. (2004). Crisis at the core: preparing all students for college and work. Iowa City, IA: Author. Retrieved from http://www.act.org

ACT. (2009). How much growth towards college readiness is reasonable to expect in high school? Iowa City, IA: Author. Retrieved from http://www.act.org

ACT. (2013a). EXPLORE technical manual. Iowa City, IA: Author. Retrieved from http://www.act.org

ACT. (2013b). PLAN technical manual. Iowa City, IA: Author. Retrieved from http://www.act.org

ACT. (2014). ACT technical manual. Iowa City, IA: Author. Retrieved from http://www .act.org

Ainsworth, J. W. (2002). Why does it take a village? The mediation of neighborhood effects on educational achievement. Social Forces, 81, 117-152.

Allen, J. (2013). Updating the ACT college readiness benchmarks. Retrieved from ACT: http://www.act.org

Allen, J., \& Sconing, J. (2005). Using ACT assessment scores to set benchmarks for college readiness. Retrieved from ACT: http://www.act.org

American Educational Research Association, American Psychological Association, \& National Council on Measurement in Education. (2014). Standards for educational and psychological testing. Washington, DC: American Educational Research Association.

American Recovery and Reinvestment Act of 2009, Pub. L. No. 111-5, § 14005-6, Title XIV, Stat. 115 (2009).

Americans With Disabilities Act of 1990, Pub. L. No. 101-336, § 2 (1990).

Angrist, J. D., \& Lang, K. (2004). Does school integration generate peer effects? Evidence from Boston's METCO program. American Economic Review, 94, 1613-1634.

Attewell, P., Lavin, D., Domina, T., \& Levey, T. (2006). New evidence on college remediation. Journal of Higher Education, 77, 886-924. 
Balfanz, R., \& Legters, N. (2004). Locating the dropout crisis. Which high schools produce the nation's dropouts? Where are they located? Who attends them? (Report 70). Baltimore, MD: Center for Research on the Education of Students Placed at Risk. Retrieved from http://www.csos.jhu.edu/crespar/

Bankston, C., \& Caldas, S. J. (1996). Majority African American schools and social injustice: The influence of de facto segregation on academic achievement. Social Forces, 75, 535-555.

Bettinger, E., \& Long, B. T. (2004). Shape up or ship out: The effects of remediation on students at four-year colleges (NBER Working Paper No. 10369). Retrieved from the National Bureau of Economic Research: http://www.nber.org/papers/w10369

Borman, K. M., Eitle, T. M., Michael, D., Eitle, D. J., Lee, R., Johnson, L., . . Shircliffe, B. (2004). Accountability in a postdesegregation era: The continuing significance of racial segregation in Florida's schools. American Educational Research Journal, 41, 605-631.

Brooks-Gunn, J., Duncan, G. J., Klebanov, P. K., \& Sealand, N. (1993). Do neighborhoods influence child and adolescent development? American Journal of Sociology, 99, 353-395.

Brown v. Board of Education of Topeka, 347 U.S. 483, 74 S. Ct. 686, 98 L. Ed. 873 (1954).

Caldas, S. J., \& Bankston, C. (1997). Effect of school population socioeconomic status on individual academic achievement. Journal of Educational Research, 90, 269-277.

Caldas, S. J., \& Bankston, C. (1998). The inequality of separation: Racial composition of schools and academic achievement. Educational Administration Quarterly, 34, 533-557.

Camara, W. (2013). Defining and measuring college and career readiness: A validation framework. Educational Measurement: Issues and Practice, 32(4), 16-27.

Catsambis, S., \& Beveridge, A. A. (2001). Does neighborhood matter? Family, neighborhood, and school influences on eighth-grade mathematics achievement. Sociological Focus, 34, 435-457.

Charles, C. Z. (2003). The dynamics of racial residential segregation. Annual Review of Sociology, 29, 167-207.

Clotfelter, C., Ladd, H. F., Vigdor, J., \& Wheeler, J. (2007). High-poverty schools and the distribution of teachers and principals. North Carolina Law Review, 85, 13451379 . 
Cohen-Vogel, L., Feng, L., \& Osborne-Lampkin, L. (2013). Seniority provisions in college bargaining agreements and the teacher quality gap. Educational Evaluation and Policy Analysis, 35, 324-343.

Cohen-Vogel, L., \& Osborne-Lampkin, L. (2007). Allocating quality: Collective bargaining agreements and administrative discretion over teacher assignment. Educational Administration Quarterly, 43, 433-461.

Coleman, J. S., Campbell, E., Hobson, C., McPartland, J., Mood, A., Weinfield, F., \& York, R. (1966). Equality of educational opportunity. Washington, DC: National Center for Education Statistics.

Conley, D. T. (2007). Redefining college readiness. Retrieved from the Educational Policy Improvement Center: https://www.epiconline.org/

Conley, D. T. (2008). Rethinking college readiness. New Directions for Higher Education, 2008(144), 3-13.

Conley, D. T. (2012). A complete definition of college and career readiness. Retrieved from the Educational Policy Improvement Center: https://www.epiconline.org/

Crosnoe, R. (2009). Low-income students and the socioeconomic composition of public high schools. American Sociological Review, 74, 709-730.

Datcher, L. (1982). Effects of community and family background on achievement. The Review of Economics and Statistics, 64, 32-41.

Davis-Kean, P. E. (2005). The influence of parent education and family income on child achievement: The indirect role of parental expectations and the home environment. Journal of Family Psychology, 19(2), 294-304.

Diem, S. (2012). The relationship between policy design, context, and implementation in integration plans. Education Policy Analysis Archives, 20, 1-36.

Diem, S., \& Frankenberg, E. (2013). The politics of diversity: Integration in an era of political and legal uncertainty. Teachers College Record, 115(11), 1-30.

Dornbusch, S. M., Ritter, P. L., \& Steinberg, L. (1991). Community influences on the relation of family statuses to adolescent school performance: Differences between African Americans and non-Hispanic Whites. American Journal of Education, 99, $543-567$.

Duncan, G. J. (1994). Families and neighbors as sources of disadvantage in the schooling decisions of White and Black adolescents. American Journal of Education, 103, 20-53.

Elementary and Secondary Education Act of 1965, 20 U.S.C. 6301 (1965). 
Frankenberg, E. (2013). The role of residential segregation in contemporary school segregation. Education and Urban Society, 45, 548-570.

Frankenberg, E., Lee, C., \& Orfield, G. (2003). A multicultural society with segregated schools: Are we losing the dream? Retrieved from the Civil Rights Project: http://civilrightsproject.ucla.edu/

Fruchter, N., Hester, M., Mokhtar, C., \& Shahn, Z. (2012). Is demography still destiny? Neighborhood demographics and public high school students' readiness for college in New York City. A research and policy brief. Providence, RI: Annenberg Institute for School Reform at Brown University.

Gardner, D. P. (1983). A nation at risk: The imperative for educational reform. Washington, DC: The National Commission on Excellence in Education.

Garner, C. L., \& Raudenbush, S. W. (1991). Neighborhood effects on educational attainment: A multilevel analysis. Sociology of Education, 64, 251-262.

Goldhaber, D., Lavery, L., \& Theobald, R. (2016). Inconvenient truth? Do collective bargaining agreements help explain the mobility of teachers within school districts? Journal of Policy Analysis and Management, 35, 848-880.

Greene, J. P., \& Forster, G. (2003). Public high school graduation and college readiness rates in the United States. New York, NY: Manhattan Institute. Retrieved from https://www.manhattan-institute.org/

Grutter v. Bollinger, 539 U.S. 306, 123 S. Ct. 2325, 156 L. Ed. 2 d 304 (2003).

Hampton v. Jefferson County Board of Education, 102 F. Supp. 2d 358 (W.D. Ky. 2000).

Hanushek, E. A., Kain, J. F., Markman, J. M., \& Rivkin, S. G. (2003). Does peer ability affect student achievement? Journal of Applied Econometrics, 18, 527-544.

Hedges, L. V., \& Nowell, A. (1999). Changes in the Black-White gap in achievement test scores. Sociology of Education, 72, 111-135.

Ho, R. (2014). Handbook of univariate and multivariate data analysis with IBM SPSS (2nd ed.). Boca Raton, FL: Taylor and Francis Group.

Ikpa, V. W. (1994). The effects of changes in school characteristics resulting from the elimination of the policy of mandated busing for integration upon the academic achievement of African-American students. Educational Research Quarterly, 17, 19-29.

Israel, G. D., Beaulieu, L. J., \& Hartless, G. (2001). The influence of family and community social capital on educational achievement. Rural Sociology, 66(1), 4368 . 
Jefferson County Board of Education. (2013). JCBE-JCTA agreement 2013-2018. Retrieved from https://www.jefferson.kyschools.us/sites/default/files/forms /jcta_0.pdf

Jefferson County Public Schools. (2012a). Data books: 2012 college/career readiness $(C C R)$. Retrieved from http://www.jcpsky.net

Jefferson County Public Schools. (2012b). Student assignment. Retrieved from http://www.jcpsky.net

Jefferson County Public Schools. (2013). Data books: 2013 college/career readiness (CCR). Retrieved from http://www.jcpsky.net

Jefferson County Public Schools. (2014a). Data books: Current enrollment by race and gender 2014-2015. Retrieved from http://www.jcpsky.net

Jefferson County Public Schools. (2014b). Data books: Percent meeting ACT benchmarks by school 2014-2015. Retrieved from http://www.jcpsky.net

Jefferson County Public Schools. (2014c). Data books: 2014 college/career readiness $(C C R)$. Retrieved from http://www.jcpsky.net

Jefferson County Public Schools. (2014d). Data books: 2014 free reduced. Retrieved from http://www.jcpsky.net

Jefferson County Public Schools. (2014e). Title I local school guide 2014-2015 \& 20152016. Retrieved from http://jcps.jefferson.k12.ky.us/title1/

Jefferson County Public Schools. (2015a). Data books: 2015 college/career readiness (CCR). Retrieved from http://www.jcpsky.net

Jefferson County Public Schools. (2015b). The nation's report card: reading and math 2015 Trial Urban District Assessment (TUDA) Grades 4 and 8. Retrieved from http://www.jcpsky.net/

Kahlenberg, R. D. (2001). Socioeconomic school integration. Poverty and Race Research Action Council, 10(5), 1-4. Retrieved from http://www.prrac.org

Kahlenberg, R. D. (2006). A new way on school integration. Retrieved from the Century Foundation: http://www.tcf.org

Kahlenberg, R. D. (2012). The future of school integration: Socioeconomic diversity as an education reform strategy. New York, NY: The Century Foundation.

Kentucky Department of Education. (2016). Kentucky school report card [Data set]. Retrieved from http://applications.education.ky.gov/src/Default.aspx 
Konstantopoulos, S. (2005). Trends of school effects on student achievement: Evidence from NLS:72, HSB:82, and NELS:92. Teachers College Record, 108, 2550-2581.

Konstantopoulos, S., \& Borman, G. D. (2011). Family background and school effects on student achievement: A multilevel analysis of the Coleman data. Teachers College Record, 113, 97-132.

Lauen, L. L. (2007). Contextual explanations of school choice. Sociology of Education, $80,179-209$.

Leventhal, T., \& Brooks-Gunn, J. (2004). A randomized study of neighborhood effects on low-income children's educational outcomes. Developmental Psychology, 40, $488-507$.

Mattern, K., Burrus, J., Camara, W., O’Connor, R., Hanson, M. A., Gambrell, J., . . . Bobek, B. (2014). Broadening the definition of college and career readiness: A holistic approach. ACT Research Report Series, 2014(5). Iowa City, IA: ACT. Retrieved from http://www.act.orgMau, W. C., \& Lynn, R. (2001). Gender differences on the Scholastic Aptitude Test, the American College Test and college grades. Educational Psychology, 21, 133-136.

Mayer, S. E. (2002). How economic segregation affects children's educational attainment. Social Forces, 81, 153-176.

McDermott, K. A., Frankenberg, E., \& Diem, S. (2014). The "post-racial" politics of race: Changing student assignment policy in three school districts. Educational Policy, 29, 504-554. doi:10.1177/0895904813510775

McLoyd, V. C. (1998). Socioeconomic disadvantage and child development. American Psychologist, 53, 185-204.

Meredith v. Jefferson County Board of Education, 548 U.S. 938 (2006).

Merisotis, J. P., \& Phipps, R. A. (2000). Remedial education in colleges and universities: What's really going on? The Review of Higher Education, 24, 67-85.

Mickelson, R. A., Bottia, M. C., \& Lambert, R. (2013). Effects of school racial composition on K-12 mathematics outcomes: A metaregression analysis. Review of Educational Research, 83, 121-158.

National Center for Children in Poverty. (2006). The racial cap in parent education. Retrieved from http://www.nccp.org/publications/pdf/text_660.pdf

National Center for Education Statistics. (2010). ACT high school profile report, 19952010. Retrieved from https://nces.ed.gov/programs/digest/d10/tables/dt10_155 .asp 
National Center for Education Statistics. (2015a). The nation's report card: 2015 mathematics state snapshot report: Kentucky, Grade 8, public schools. Retrieved from http://nces.ed.gov/nationsreportcard/subject/publications/stt2015/pdf /2016009KY8.pdf

National Center for Education Statistics. (2015b). The nation's report card: 2015 reading state snapshot report: Kentucky, Grade 8, public schools. Retrieved from http://nces.ed.gov/nationsreportcard/subject/publications/stt2015/pdf /2016008KY8.pdf

National Center for Education Statistics. (2015c). School composition and the BlackWhite achievement gap (NCES 2015-018). Retrieved from http://nces.ed.gov /nationsreportcard/subject/studies/pdf/school_composition_and_the_bw _achievement_gap_2015.pdf

Neild, R. C., \& Balfanz, R. (2006). An extreme degree of difficulty: The educational demographics of urban neighborhood high schools. Journal of Education for Students Placed at Risk, 11, 123-141.

No Child Left Behind Act of 2001, Pub. L. No. 107-110, § 1114, Stat. 1425 (2002).

Noble, J., Davenport, M., Schiel, J., \& Pommerich, M. (1999a). High school academic and noncognitive variables related to the ACT scores of racial/ethnic and gender groups. ACT Research Report Series, 99(6). Retrieved from ACT: http://www.act.org

Noble, J., Davenport, M., Schiel, J., \& Pommerich, M. (1999b). Relationships between the noncognitive characteristics, high school course work and grades, and test scores of ACT-tested students. ACT Research Report Series, 99(4). Retrieved from ACT: http://www.act.org

Noble, J., \& McNabb, T. (1989). Differential coursework and grades in high school: Implications for performance on the ACT assessment. ACT Research Report Series, 89(5). Retrieved from ACT: http://www.act.org

Noble, J., Roberts, W., \& Sawyer, R. (2006). Student achievement, behavior, perceptions, and other factors affecting ACT scores. ACT Research Report Series, 2006(1). Retrieved from ACT: http://www.act.org

Noble, J., \& Sawyer, R. (2002). Predicting different levels of academic success in college using high school GPA and ACT composite score. ACT Research Report Series, 2002(4). Retrieved from ACT: http://www.act.org

Orfield, G. (2001). Schools more separate: Consequences of a decade of resegregation. Retrieved from the Civil Rights Project: http://civilrightsproject.ucla.edu/ 
Orfield, G., \& Frankenberg, E. (2011). Diversity and educational gains: A plan for a changing county and its schools. Retrieved from the Civil Rights Project: http://civilrightsproject.ucla.edu/

Orfield, G., Frankenberg, E., \& Garces, L. M. (2008). Statement of American social scientists of research on school desegregation to the U.S. Supreme Court in Parents v. Seattle School District and Meredith v. Jefferson County. The Urban Review, 40(1), 96-136.

Orfield, G., Kucsera, J., \& Siegel-Hawley, G. (2012). E pluribus . . separation: Deepening double segregation for more students. Retrieved from the Civil Rights Project: http://civilrightsproject.ucla.edu/

Orfield, G., \& Lee, C. (2005). Why segregation matters: Poverty and educational inequality. Retrieved from the Civil Rights Project: http://civilrightsproject.ucla .edu/

Orfield, G., Siegel-Hawley, G., \& Kucsera, J. (2014). Sorting out deepening confusion on segregation trends. Retrieved from the Civil Rights Project: http://civilrightsproject.ucla.edu/

Osborne, J. W. (2016). Regression and linear modeling: Best practices in modern methods. Thousand Oaks, CA: Sage.

Owens, A. (2010). Neighborhoods and schools as competing and reinforcing contexts for educational attainment. Sociology of Education, 83, 287-311.

Parents Involved in Community Schools v. Seattle School District No. 1, 551 U.S., 127 S. Ct. 2738, 168 L. Ed. 2d 508 (2007).

Petrocelli, J. V. (2003). Hierarchical multiple regression in counseling research: Common problems and possible remedies. Measurement and Evaluation in Counseling and Development, 36(1), 9-22.

Phillips, K. J., Hausman, C., \& Larsen, E. S. (2012). Students who choose and the schools they leave: Examining participation in intradistrict transfers. The Sociological Quarterly, 53, 264-294.

Plessy v. Ferguson, 163 U.S. 537, 16 S. Ct. 1138, 41 L. Ed. 256 (1896).

Potter, H., Quick, K., \& Davies, E. (2016). A new wave of school integration: Districts and charters pursuing socioeconomic diversity. Retrieved from the Century Foundation: http://www.tcf.org

Reardon, S. F., Yun, J. T., \& Kurlaender, M. (2006). Implications of income-based school assignment policies for racial school segregation. Educational Evaluation and Policy Analysis, 28, 49-75. 
Roderick, M., Nagaoka, J., \& Coca, V. (2009). College readiness for all: The challenge for urban high schools. The Future of Children, 19(1), 185-210.

Rumberger, R., \& Palardy, G. (2005). Does segregation still matter? The impact of student composition on academic achievement in high school. Teachers College Record, 107, 1999-2045.

Sanbonmatsu, L., Kling, J. R., Duncan, G. J., \& Brooks-Gunn, J. (2006). Neighborhoods and academic achievement results from the Moving to Opportunity experiment. Journal of Human Resources, 41, 649-691.

Sass, T. R., Hannaway, J., Xu, Z., Figlio, D. N., \& Feng, L. (2012). Value added of teachers in high-poverty schools and lower poverty schools. Journal of Urban Economics, 72, 104-122.

Sawyer, R. (1989). Validating the use of ACT assessment scores and high school grades for remedial course placement in college. ACT Research Report Series, 89(4). Retrieved from ACT: http://www.act.org

Sawyer, R. (2013). Beyond correlations: Usefulness of high school GPA and test scores in making college admissions decisions. Applied Measurement in Education, 26(2), 89-112.

Schiel, J., Pommerich, M., \& Noble, J. P. (1996). Factors associated with longitudinal educational achievement, as measured by PLAN and ACT assessment scores. Retrieved from ACT: http://www.act.org

Schwartz, H. (2010). Housing policy is school policy: Economically integrative housing promotes academic success in Montgomery County, Maryland. Retrieved from the Century Foundation: http://www.tcf.org

Shavelson, R. (1996). Statistical reasoning for the behavioral sciences (3rd ed.). Needham Heights, MA: Allyn \& Bacon.

Sirin, S. R. (2005). Socioeconomic status and academic achievement: A meta-analytic review of research. Review of Educational Research, 75, 417-453.

Squires, G. D., \& Kubrin, C. E. (2006). Privileged places: Race, residence, and the structure of opportunity. Boulder, CO: Lynne Rienner.

Stevens, J. P. (2007). Intermediate statistics: A modern approach (3rd ed.). New York, NY: Taylor and Francis Group.

Stevens, J. P. (2009). Applied multivariate statistics for the social sciences (5th ed.). New York, NY: Taylor and Francis Group. 
Tefera, A., Frankenberg, E., Siegel-Hawley, G., \& Chirichigno, G. (2011). Integrating suburban schools: How to benefit from growing diversity and avoid segregation. Retrieved from the Civil Rights Project: http://civilrightsproject.ucla.edu/

U.S. Department of Agriculture (2016). Food and nutrition service: National School Lunch Program. Retrieved from http://www.fns.usda.gov/nslp/national-school -lunch-program-nslp

University of Louisville. (n.d.). About the IRB. Retrieved May 31, 2016, from http://louisville.edu/research/humansubjects/about-the-irb

Zwick, R. (2007). College admission testing. Arlington, VA: National Association for College Admission Counseling. Retrieved from http://education.ucsb.edu 


\section{CURRICULUM VITA}

NAME:

ADDRESS:

DOB:

EDUCATION:

EXPERIENCE \& TRAINING:
Gregory Paul Herberger

3300 Audubon Ridge Drive

Louisville, KY 40213

Louisville, Kentucky - October 6, 1980

B.A., Political Science

Bellarmine University

1999-2003

MAT, Middle and Secondary Education University of Louisville 2004-2006

Ed.S., Educational Administration P-12

University of Louisville

2009-2011

Secondary Social Studies Teacher

Jefferson County Public Schools

2006-2011

The Civics Institute

Kentucky Teacher Network for Civic Education and Engagement 2008 High School Pilot Design

University of Louisville Aspiring Leadership Program 2009-2010

Principals for Tomorrow Aspiring Leadership Program Jefferson County Public Schools 2010-2011

Smaller Learning Communities Resource Teacher Jefferson County Public Schools

2011 
Secondary Assistant Principal

Jefferson County Public Schools

2011-Present

Jefferson County Association of School Administrators

Executive Board Member

2016-Present 